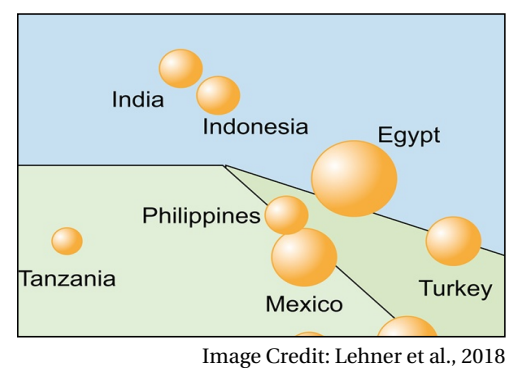

\title{
Frugal Innovation
}

Welcome to the April issue of the Technology

Innovation Management Review. We welcome your comments on the articles in this issue as well as suggestions for future article topics and issue themes.

Editorial: Frugal Innovation

Chris McPhee, Deepak S. Gupta, and Mokter Hossain

Frugal or Fair? The Unfulfilled Promises of Frugal Innovation Mario Pansera

Approach for a Pattern-Based Development of Frugal Innovations Anne-Christin Lehner, Christian Koldewey, and Jürgen Gausemeier

Patterns of Frugal Innovation in Healthcare Hareem Arshad, Marija Radić, and Dubravko Radić

Overcoming Barriers to Frugal Innovation: Emerging Opportunities for Finnish SMEs in Brazilian Markets Mirva Hyypiä and Rakhshanda Khan

Science Is Indispensable to Frugal Innovations Balkrishna C. Rao

Author Guidelines 


\section{Publisher}

The Technology Innovation Management Review is a monthly publication of the Talent First Network.

\section{ISSN}

1927-0321

\section{Editor-in-Chief}

Chris McPhee

\section{Advisory Board}

Tony Bailetti, Carleton University, Canada

Peter Carbone, Ottawa, Canada

Parm Gill, Gill Group, Canada

Leslie Hawthorn, Red Hat, United States

Michael Weiss, Carleton University, Canada

\section{Review Board}

Tony Bailetti, Carleton University, Canada

Peter Carbone, Ottawa, Canada

Parm Gill, Gill Group, Canada

G R Gangadharan, IBM, India

Seppo Leminen, Laurea University of Applied Sciences

and Aalto University, Finland

Colin Mason, University of Glasgow, United Kingdom

Steven Muegge, Carleton University, Canada

Jennifer Percival, University of Massachusetts, United States

Risto Rajala, Aalto University, Finland

Sandra Schillo, University of Ottawa, Canada

Marina Solesvik, Nord University, Norway

Stoyan Tanev, Carleton University, Canada

Michael Weiss, Carleton University, Canada

Mika Westerlund, Carleton University, Canada

Blair Winsor, Memorial University, Canada

(C) $2007-2018$

Talent First Network

www.timreview.ca

\section{Overview}

The Technology Innovation Management Review (TIM Review) provides insights about the issues and emerging trends relevant to launching and growing technology businesses. The TIM Review focuses on the theories, strategies, and tools that help small and large technology companies succeed.

Our readers are looking for practical ideas they can apply within their own organizations. The TIM Review brings together diverse viewpoints - from academics, entrepreneurs, companies of all sizes, the public sector, the community sector, and others - to bridge the gap between theory and practice. In particular, we focus on the topics of technology and global entrepreneurship in small and large companies.

We welcome input from readers into upcoming themes. Please visit timreview.ca to suggest themes and nominate authors and guest editors.

\section{Contribute}

Contribute to the TIM Review in the following ways:

- Read and comment on articles.

- Review the upcoming themes and tell us what topics you would like to see covered.

- Write an article for a future issue; see the author guidelines and editorial process for details.

- Recommend colleagues as authors or guest editors.

- Give feedback on the website or any other aspect of this publication.

- Sponsor or advertise in the TIM Review.

- Tell a friend or colleague about the TIM Review.

Please contact the Editor if you have any questions or comments: timreview.ca/contact

\section{About TIM}

The TIM Review has international contributors and readers, and it is published in association with the Technology Innovation Management program (TIM; timprogram.ca), an international graduate program at Carleton University in Ottawa, Canada. 


\section{Editorial: Frugal Innovation Chris McPhee, Editor-in-Chief Deepak S. Gupta, Guest Editor Mokter Hossain, Associate Guest Editor}

\section{From the Editor-in-Chief}

Welcome to the April 2018 issue of the Technology Innovation Management Review. This month's editorial theme is Frugal Innovation, and it is my pleasure to introduce Guest Editor Deepak S. Gupta, Executive Director of Applied Research, Innovation and Entrepreneurship Services (ARIES) at Centennial College in Toronto, Canada, and Associate Guest Editor Mokter Hossain, Assistant Professor in the Center for Industrial Production at Aalborg University, Denmark.

For future issues, we are accepting general submissions of articles on technology entrepreneurship, innovation management, and other topics relevant to launching and growing technology companies and solving practical problems in emerging domains. Please contact us (timreview.ca/contact) with potential article topics and submissions, and proposals for future special issues.

\section{Chris McPhee \\ Editor-in-Chief}

\section{From the Guest Editors}

Frugal innovation embodies human ingenuity in its rawest, unrefined form. It is a recognition that every human being is capable of innovation, no matter their education, experience, wealth, or access to networks.

Millions of people around the world continue to live in poverty without access to basic resources. Frugal innovation leads to home-grown solutions using local resources to address fundamental needs. It leads to transformational change, enabling people to achieve things they have never done before. Multinational, small firms, and individuals are developing frugal innovation. The quality and number of frugal innovation developed in emerging countries are increasingly significantly.

The frugal innovation concept overlaps with a number of concepts, such as reverse innovation, disruptive innovation, "Jugaad" in Hindi, grassroots innovation, catalytic innovation, and Gandhian innovation. Frugal innovation represents innovation at its democratized finest. It is driven by the direst necessity and often empowers not just millions but also billions of humans. Examples of frugal innovation include the lunch box delivery system developed by Mumbai's "dabbawala" or corporate frugal innovation, such as GE's Ultrasound machine and Tata's Nano - the cheapest car in the world.

Frugal innovations result in the ultimate "minimum viable products". The existing literature indicates that frugal innovations are more sustainable than alternatives (Levänen et al., 2016), diffuse from emerging countries to rich countries (Hossain et al., 2016), and need different business models (Winterhalter et al., 2017).

However, despite substantial recent interest in the topic among practitioners and scholars alike, frugal innovation is in a state of infancy from a theoretical perspective and lacks systematic approaches in practice. In this special issue, the authors offer differing perspectives on the topic while sharing a common call for 


\section{Editorial: Frugal Innovation}

Chris McPhee, Deepak S. Gupta, and Mokter Hossain

reflection on our current approaches - especially in light of frugal innovation's potential for greater inclusivity and sustainability - and the development of new, systematic approaches that rely on scientific principles and pattern identification.

In the first article, Mario Pansera from the University of Bristol in the United Kingdom calls on us to critically reflect on the existing body of literature on frugal innovation, which he argues has not yet delivered on its promise for two reasons. First, the literature's emphasis on the role of scarcity neglects the fact that "scarcity can be socially constructed to deny certain social sectors the access to resources essential for their flourishing". Second, the frugal innovation literature rarely even mentions the underlying causes of the problems it seeks to address, particularly poverty, which is a matter of social justice. He calls for a new wave of frugal innovation literature and practice that engages with the complex politics of poverty and resource allocation.

In the second article, Anne-Christin Lehner, Christian Koldewey, and Jürgen Gausemeier describe their pattern-based approach to developing frugal innovations, which is based on their work at the Heinz Nixdorf Institute of the University of Paderborn, Germany. Their approach is based on a simple assumption: given that different contexts share similar challenges in the development of frugal innovations, we can expect to find similarities in the resulting solutions. The search for solution patterns lies at the heart of their systematic approach, which they describe and validate in this article based on the example of a telemedicine assistant system.

Next, Hareem Arshad, Marija Radić, and Dubravko Radić from Leipzig University in Germany identify patterns among 50 frugal innovations in the healthcare sector. They classified various characteristics of each innovation, such as the country of origin, first launch market, type of innovator, type of innovation, type of care, and geographic diffusion. By examining the identified patterns and discussing the relationships between these variables, they provide a future outlook for the study and practice of frugal innovation in the healthcare sector.
Then, Mirva Hyypiä and Rakhshanda Khan from Lappeenranta University of Technology, Finland, focus on the development processes for frugal innovations in small and medium-sized enterprises (SMEs). They present a case study of three Finnish SMEs developing mobile learning services for Brazilian markets as part of a development project that leverages action research. Their findings highlight the barriers such companies face in developing frugal innovations for emerging markets, and they suggest how SMEs can overcome these barriers through a broader emphasis on frugality - not only in their products and services, but also in their development processes.

Finally, Balkrishna C. Rao from the Indian Institute of Technology Madras applies the "factor of safety" concept to the field of frugal innovation as a means of improving both grassroots and advanced frugal products by grounding their development processes in systematically applied scientific principles. He argues that many frugal innovations suffer from limited lifespans due to premature failure and offers a "factor of frugality" design approach to help overcome such limitations and yield the desired benefits of frugal innovations to business and society.

We hope that this special issue will contribute to a maturation of the study and practice of frugal innovation, including the eventual development of conceptual frameworks for broader adoption to advance towards a more sustainable and inclusive future.

Deepak S. Gupta, Guest Editor Mokter Hossain, Associate Guest Editor 


\section{Editorial: Frugal Innovation}

Chris McPhee, Deepak S. Gupta, and Mokter Hossain

\section{About the Editors}

Chris McPhee is Editor-in-Chief of the Technology Innovation Management Review. Chris holds an MASc degree in Technology Innovation Management from Carleton University in Ottawa, Canada, and $\mathrm{BScH}$ and MSc degrees in Biology from Queen's University in Kingston, Canada. He has nearly 20 years of management, design, and content-development experience in Canada and Scotland, primarily in the science, health, and education sectors. As an advisor and editor, he helps entrepreneurs, executives, and researchers develop and express their ideas.

Deepak S. Gupta is the Executive Director for Applied Research, Innovation, and Entrepreneurship Services at Centennial College in Toronto, Canada. Previously, Dr. Gupta has worked at NAIT, Pella Corporation, and at the University of South Florida. He has cofounded two companies, and advised several others. Dr. Gupta has a Bachelor of Technology (Honors) degree from the Indian Institute of Technology, Kharagpur, India. His masters' and doctoral degrees in Chemical Engineering are from Washington University in St. Louis. He has co-authored 31 publications, including papers, technical reports, conference proceedings, and a book chapter. His research contributions range from composites processing to smart sensors to new control algorithms. Dr. Gupta is a professional engineer, and a member of Institute of Electrical and Electronics Engineers (senior member status), Sigma Xi, Indian Institute of Chemical Engineers, and Tau Beta Pi.

Mokter Hossain is an Assistant Professor at the Center for Industrial Production, Aalborg University, Denmark, and he a Visiting Scholar at the Institute of Strategy and Venturing in the Department of Industrial Engineering and Management at Aalto University in Finland. He was a post-doctoral researcher at Imperial College London and at Aalto University after graduating with a Doctor of Science degree in Technology and Knowledge Management in 2016 from Aalto University. His research interests include innovation, strategy, and entrepreneurship. He has published over 35 journal articles, book chapters, and conference papers on a range of research topics, including open innovation, crowdsourcing, crowdfunding, frugal innovation, reverse innovation, grassroots innovation, and business model innovation.

\section{References}

Hossain, M., Simula, H., \& Halme, M. 2016. Can Frugal Go Global? Diffusion Patterns of Frugal Innovations. Technology in Society, 46: 132-139.

https://doi.org/10.1016/j.techsoc.2016.04.005

Levänen, J., Hossain, M., Lyytinen, T., Hyvärinen, A., Numminen, S., \& Halme, M. 2016. Implications of Frugal Innovations on Sustainable Development: Evaluating Water and Energy Innovations. Sustainability, 8(1): 1-17.

https://doi.org/10.3390/su8010004

Winterhalter, S., Zeschky, M. B., Neumann, L., \& Gassmann, O. 2017. Business Models for Frugal Innovation in Emerging Markets: The Case of the Medical Device and Laboratory Equipment Industry. Technovation, 66-67: 3-13.

https://doi.org/10.1016/j.technovation.2017.07.002

Citation: McPhee, C., Gupta, D. S., \& Hossain, M. 2018.

Editorial: Frugal Innovation. Technology Innovation

Management Review, 8(4): 3-5.

http://doi.org/10.22215/timreview/1147

Keywords: frugal innovation, sustainability, internationalization, inclusion, sustainability, emerging markets, grassroots, patterns, healthcare, SMEs, development processes 


\title{
Frugal or Fair? The Unfulfilled Promises of Frugal Innovation Mario Pansera
}

\author{
"People need new tools to work with rather than new") \\ tools that work for them.
}

Ivan Illich (1926-2002)

In Tools for Conviviality (1973)

\begin{abstract}
Frugal innovation has become a popular buzzword among management and business scholars. However, despite its popularity, I argue that the frugal innovation literature, in its present form, is problematic for at least two reasons. First, the frugal innovation literature assumes that scarcity is a normal condition of the "Global South". In this article, I show that this assumption neglects the fact that scarcity can be socially constructed to deny certain social sectors the access to resources essential for their flourishing. Second, despite all the good intentions underpinning the idea of "alleviating poverty", frugal innovation studies rarely challenge, or even discuss, the causes of destitution and social exclusion. Innovation, as well as technology, is overwhelmingly framed in an agnostic and neutral way that sidelines the socio-economic complexity of the exclusion mechanisms that cause poverty and underdevelopment. By ignoring this, the frugal innovation literature risks limiting the understanding of the problems it seeks to solve and, most importantly, it risks limiting its impact. Most frugal innovation literature, in other words, seems to elude the fact that, rather than being a mere lack of resources or technology, poverty is a matter of social justice. In order to be empowering, technology has to be value-based, normative framed, socially controlled, and democratically debated. In this article, I propose that we should use these principles to develop a new wave of frugal innovation literature and practice.
\end{abstract}

\section{Introduction}

Frugal innovation has become a popular buzzword in the last two decades (Pisoni et al., 2018; Tiwari et al., 2017). The notion went under the radar of an increasing variety of academics and practitioners that span from organizations studies and management scholars to non-governmental organizations and multinational corporations (Hossain, 2016). The basic idea is that innovation can and does emerge even where and when financial, material, and human resources are scarce (Pansera, 2013). This concept is extremely relevant for those interested in improving the living conditions of the poor of the world, who confront every day with resource constraints. If innovation is possible everywhere, at least in its frugal, low-technology and low-cost forms, why would we not use it to alleviate poverty?
The concept itself is not new. The idea of developing "good-enough" solutions for the poor dates back (at least) to the appropriate technology movement initiated by E. F. Schumacher in the 1970s (Kaplinsky, 2011; Schumacher, 1973) and, in a quite different formulation, in the work of Ivan Illich (1973). What it is new is the kind of authors and audience that now debate the topic, including business, innovation, and organizational scholars (Pansera \& Owen, 2017). This new trend has very much monopolized the debate around two basic assumptions:

1. Poverty is caused by resource scarcity; thus, frugal innovation might help solve poverty.

2. Frugal innovation offers a "triple bottom line" approach able to create social impact, environmental benefits, and business opportunities. 


\section{Frugal or Fair? The Unfulfilled Promises of Frugal Innovation}

\section{Mario Pansera}

In this article, I will argue that those assumptions are problematic - and thus so is most of the frugal innovation literature in its present form - for two main reasons. First, despite all the good intentions behind the idea of alleviating poverty, frugal innovation rarely challenges, or even discusses, the causes of poverty and social exclusion. Resource scarcity in the "Global South" (Box 1) is a complex phenomenon that is not necessarily linked to the lack of material or financial resources. On the contrary, natural and human resources are in many cases abundant but their access is often limited or totally denied to certain social groups. Second, the frugal innovation literature seems to ignore the insights and evidence coming from other fields, such as science and technology studies, responsible research and innovation, and post-development studies. The central argument of these contributions is that technological innovation is neither necessary nor sufficient to reverse the causes of poverty and exclusion. In certain circumstances, innovation, even if frugal, can reinforce unequal power relationships by favouring those who already enjoy privileged positions in the community (Pansera \& Owen, 2018). In order to be empowering, technology has to be value-based, rooted in solid normative framings and socially controlled (Stirling, 2008).

This article is structured as follows. In the next section, I discuss the notion of scarcity as a social construct and its implications for the idea of frugal innovation. In the third section, I describe the apolitical rhetoric that characterizes, I argue, most of the literature on frugal innovation. Finally, I conclude by inviting academics and practitioners to re-introduce political questions in the study of innovation for development.

\section{The Idea of Scarcity and Its Limits}

Necessity is the mother of invention. This popular phrase suggests that the necessity to address compelling needs sharpens ingenuity and encourages innovative thinking. Recent literature focused on business and management has approached the topic by introducing such concepts as frugal innovation but also resourceconstrained innovation, bricolage, or jugaad (Horn \& Brem, 2013). The main argument here is that scarcity of (material, financial, human, or organizational) resources can stimulate the search for innovative solutions that are cost-effective, more efficient (e.g., reduce the use of water, energy, material, labour), often more socially acceptable, and even greener. For these reasons, proponents of frugal innovation suggest that frugality can have great implications for the global com-

\section{Box 1. The Global South}

The term "Global South" indicates what used to be called the "Third World" (i.e., Africa, Latin America, and the developing countries in Asia), "developing countries", "less developed countries", or "less developed regions". More than an economic classification, the term Global South refers to a specific geo-political order, an arrangement of power relationships that dominate the relations between the former dominant colonial empires and the dominated colonies. As Dados and Connell (2012) eloquently say, the term refers to these countries' "interconnected histories of colonialism, neoimperialism, and differential economic and social change through which large inequalities in living standards, life expectancy, and access to resources are maintained".

petitiveness of the middle-low income countries (Zeschky et al., 2011; Zeschky et al., 2014) and represents an alternative pathway for their sustainable development (Rosca et al., 2017).

The idea of frugal innovation is also central in the socalled "bottom of the pyramid" literature (Kolk et al., 2013). The notion of the bottom of the pyramid was famously introduced by Prahalad in 2005 in his book The Fortune at the Bottom of the Pyramid: Eradicating Poverty through Profits (Prahalad, 2010). The main argument posited by Prahalad's work is that the poor are unserved consumers who represent an immense unexploited market. Those at the bottom of the pyramid, he argues, are currently excluded from mass consumption because of their very limited purchasing power. By appropriately targeting the poor, the private sector would have access to new and unsaturated markets and the poor, in turn, would gain access to consumer goods that are currently inaccessible because they are too expensive, raising their standards of living. In a nutshell: doing more with less and for more people (Prahalad, 2010, 2012; Prahalad \& Mashelkar, 2010). Central to the bottom-of-the-pyramid concept is the idea that poverty can be addressed by increasing consumption of material goods. The strategy, then, is to produce affordable - frugal - products and services with the objective of raising the consumption rate of the poor. According to these scholars, those institutions that are best placed to implement such a strategy are multinational corporations (Kanter, 2008; Rosenbloom 


\section{Frugal or Fair? The Unfulfilled Promises of Frugal Innovation}

\section{Mario Pansera}

\& Althaus, 2007). The underlying philosophy of the bottom-of-the-pyramid approach is that the quest for profit can simultaneously generate economic growth and deliver social value (that in this case equals material consumption): making money by doing good (Agnihotri, 2013; Bardy et al., 2012; Chakravarti, 2006; Faulconbridge, 2013; Seelos \& Mair, 2007).

Although frugal innovation and its companion buzzwords (e.g., jugaad, resource-constrained innovation, bottom-of-the-pyramid innovation) remain essentially flexible notions, their definitions and meanings are continuously contested and reframed (see also Soni \& Krishnan, 2014 and Arora \& Romijn, 2011), they share the fundamental assumption that poverty is caused by a lack of resources. However, instead of discussing how to escape scarcity, most frugal innovation literature is merely focused on the study of those capabilities that are presumably needed to innovate in resource-scarce contexts. For instance, Srinivas and Sutz (2008) argue that, in the academic literature, there has been a misguided quest for uniformity of the conditions in which innovation occurs (i.e., abundance of resources, efficient institutions, developed markets, etc.). This has in turn sidelined the study of those capabilities needed to innovate in conditions of scarcity, conditions that characterize large sections of the so-called developing world. In this view, scarcity is a given variable, an inescapable condition that characterizes the Global South. There are good reasons to think that this assumption is groundless.

First, let me distinguish between what Mehta (2005) calls "lived/experienced" scarcity (i.e., shortages of food, water, fodder, etc. that local people experience cyclically due to biophysical conditions) and "constructed" scarcity (i.e., shortages artificially manufactured through socio-political processes to suit the interests of powerful players). There is no doubt that certain regions of the globe present serious limits of critical resources such as water, arable land, or livestock. In these situations, human societies react by developing a huge variety of strategies to cope with cyclical scarcity. The work of Elinor Ostrom demonstrates that human societies are able to create complex systems for the management of common resource pools that are based on collaboration, solidarity, and equality (Ostrom, 1990, 2010). In those contexts, scarcity as such is not perceived as a constraint because the wants of the community are shaped on the availability of resources, that, in turn, are allocated through social processes that favour (at least in principle) equal allocation to guarantee the resilience of the system. The same mechanisms doc- umented by Ostrom are also very well known by anthropologists that have provided overwhelming evidence that in non-market societies people satisfy their wants through a different logic that includes reciprocity, redistribution, and exchange (Polanyi, 2001; Sahlins, 1992). This does not mean that pre-industrial societies are fairer or inherently egalitarian. It is important not to romanticize traditional societies that, in many cases, have been proven to be extremely oppressive and unjust. The important lesson that comes from the "ethnography of the commons" is that collaborative behaviour can be a crucial advantage under conditions of resource scarcity.

Constructed scarcity, on the other hand, is not directly linked to an absolute lack of resources or biophysical limits, but it is socially constructed. Yapa (1996), for instance, shows that, in many contexts, scarcity is not experienced by society at large, but instead by specific social sectors and is a "socially specific condition". Scarcity, in this view, is the result of exclusion and unequal gender, social, and power relations that legitimize asymmetric access to and control over finite resources (Mehta, 2010). Land dispossession, privatization of commons, and even colossal state-driven development projects such as dams, mines, and power plants all can contribute to constructed scarcity that eventually leads to a mass of new prolitarianized urban poor (Baka, 2013; Escobar, 2012). This explains why rich regions in the Indian Subcontinent, Africa, Asia or the Americas are still characterized by huge pockets of poverty despite their enormous natural resources stocks and their ancient and complex agricultural know-how and indigenous knowledge. This also explains why relative poverty in the Global North is increasing whereas access to social welfare and public goods are decreasing despite unprecedented levels of wealth accumulation. The assumption of scarcity ubiquity that underpins most of the frugal innovation literature neglects the politics of resource allocation and the ways scarcity is politicized, especially to suit the interests of powerful groups. By focusing on the skills that are needed to innovate in resource-constrained contexts, the frugal innovation literature has refused to seriously engage with the social and political factors that force certain groups to innovate under conditions of scarcity.

\section{The Apolitical Rhetoric of Frugality}

Above, I argued that the frugal innovation literature is generally based on incorrect assumptions about the ubiquity and the origin of scarcity. This situation arose, 


\section{Frugal or Fair? The Unfulfilled Promises of Frugal Innovation}

\section{Mario Pansera}

in my view, because the frugal innovation literature emerged in a pro-business intellectual environment that unconsciously - but in some cases even overtly frames innovation, science, and technology in an apolitical way. My recent studies on the discourses of innovation in the Indian Subcontinent suggest that this is also true in the case of similar notions that usually surround frugal innovation such as bottom-of-the-pyramid innovation, inclusive innovation, or inclusive growth (Pansera \& Owen, 2017, 2018). I found that narratives of frugality and inclusive innovation usually promulgates a depoliticized rhetoric of inclusion and participation that neglects the existence of unequal global and local power relations and norms that are known to shape the processes of socio-technical change and innovation, while unreflexively perpetuating capitalist hegemony at a global scale. Arora and Romijn (2011) describe this process as follows:

“...the Bottom of the Pyramid literature is rap-
idly inching toward a new corpus of apolitical
management studies for managing the (adverse)
incorporation of the poor into world markets and
further neoliberalization of extremely indigent
areas of the planet. Such an apolitical understand-
ing of complex social dynamics, by masking extant
privilege and its consolidation will only serve to re-
produce existing inequalities at the local level and
further entrench the dominance of national and
global capitalist formations."

We might replace "bottom of the pyramid literature" with frugal innovation literature" and the main message of the quotation still would be valid. In the frugal innovation literature, innovation, as well as technology, is overwhelmingly framed in an agnostic and neutral way that sidelines the socio-economic complexity of the exclusion mechanisms that underpin poverty and underdevelopment. There is an extended literature that shows how technology can be socially constructed to exclude or favour certain social groups (Leach et al., 2010). By ignoring this, the frugal innovation literature risks limiting the understanding of the problem it seeks to solve and, most importantly, it risks limiting its impact. Most frugal innovation literature, in other words, seems to elude the fact that rather than being a mere lack of resources or technology, poverty is a matter of social justice (Smith et al., 2014).

In my view, a new wave of frugal innovation studies might enormously benefit from disciplines that emphasize the role of society, power dynamics, and culture in the emergence of innovation. I refer here to science and technology studies (Winner, 1980), development and post-development studies (Escobar, 2012), and those authors that attempt to re-politicize the links between poverty, inequality, and innovation (Ferguson, 1990; Swyngedouw, 2015). In particular, I argue that authors interested in frugal innovation could benefit from the insights coming from the grassroots innovation literature. According to Smith, Fressoli, and Thomas (2014) grassroots innovation discourse rests on three key dimensions. First, like frugal innovation, it is locally-specific yet widely-applicable: grassroots ingenuity stimulates innovation that can be applied locally as project-based solutions and, potentially, in a number of other contexts that share common features such as material and human resource scarcity (lived/experienced or constructed). Second, grassroots innovation movements encourage the emergence of socio-technical practices within different value systems than, for example, those associated with profit-driven innovation within a market economy paradigm. Third, it stimulates a debate about social reform, transformation, and structural change in light of extant economic and political structures. Smith and colleagues (2012) have documented the activities of several formal and informal networks of grassroots innovators in the Global South. Smith, Fressoli, and Thomas (2014) identify at least three major grassroots groups: the people's science movement and the Honey Bee Network (www.sristi.org/hbnew/) in India and the technologies for social inclusion movement in Latin America. These movements share the idea that innovation, science, and technology are a part of a participatory process of development where citizens themselves assume a central role. Rather than passive recipients of technology transfer, citizens are knowledgeable and actively involved in both upstream technology choice and design, and downstream deliberations around technology delivery and regulation (Leach et al., 2008). These movements deliberately chose to run a slower race opposed to the fast and frenetic competition race preached by capitalist globalization. In the words of Leach, Sumner, and Waldman (2008):

\footnotetext{
"[The slower race] emphasises pathways to poverty reduction which, while recognising the importance of science and technology, are specific to local contexts; recognise that technological fixes are not enough and that social, cultural and institutional dimensions are key; create hybrids between local and external knowledge for appropriate solutions, and go the extra mile to make already-existing technologies more readily available to those who are poor and marginalised. In
} 


\section{Frugal or Fair? The Unfulfilled Promises of Frugal Innovation}

\section{Mario Pansera}

this view, science and technology are a part of a participatory process of development where citizens themselves take centre stage. Rather than passive beneficiaries of trickle-down development or technology transfer, citizens are knowledgeable, active and centrally involved in both upstream technology choice and design, and downstream deliberations around technology delivery and regulation-perhaps challenging external perspectives. This, so the policy argument goes, makes for technologies more appropriate to the challenges of poverty reduction and social justice."

\section{Implications for Academics and Practitioners}

There are increasingly countervailing voices that call for a more complex understanding of the relation between poverty, technology, power, and resource allocation. The arguments those voices bring to the debate about frugal innovation have important implications for academics and practitioners. As regards management academics, I argue that it is crucial for them to reconsider critically the way they have promoted frugal innovation. As I showed elsewhere (Pansera \& Owen, 2018), some management scholars have been too often complicit with the interests of multinational corporations and uncritically aligned with the neoliberal ideology that promotes the idea that poor need material goods rather than justice, equal opportunities, or democracy. Most of them uncritically embraced the idea that frugal technology can be simply transferred to the poor without any significant implication for their lifestyle, their traditional networks of subsistence, their cultural bonds and moral values, and their social relations. They also promulgated the idea that the "inclusion" of the poor into the volatile global market would benefit both the companies and the socially excluded. Despite two decades of research, the evidence of this mutual benefit remains elusive.

The unfulfilled promises of frugal innovation suggest that management scholars need to redirect their effort towards other goals. A possible direction, as illustrated by the examples in the previous section, is to (re)politicize the study of poverty, possibly in collaboration with colleagues from other disciplines such as anthropology, sociology, geography, science and technology studies, innovation studies, or development studies. This essentially means to focus on the politics of innovation that is always context, value, and cultural based (Stirling, 2008).

Rather than being neutrally described, frugal innovation examples should be critically analysed by making ques- tions such as: Who wins? Who loses? By what mechanisms of power? What futures, new relations, and new arrangements do frugal innovation enable/disable? What are the alternatives? As Flyvbjerg (2001) has shown, endless research topics can spring from these questions. Here I suggest a few such topics that, in my opinion, remain under-researched:

- It is fundamental to understand under which conditions frugal innovation is able reshape power or social arrangements. We know that technology does not simply have the "innocence of the tools" but it does embed values, modes of being, and power arrangements (Pansera \& Owen, 2017; Winner, 1980). What kind of frugal technology in a given context is able (or can contribute) to the reshaping of the social mechanisms that underpin poverty and exclusion?

- Given that innovation always originates from learning processes and knowledge creation, it is crucial to understand what socio-technical arrangements facilitate the inclusion of forms of knowledge (e.g., indigenous or community knowledge) that are often considered "less legitimate" (or even subordinate) by scientific institutions but that can feed a flow of frugal, contextbased, and appropriate innovations (Winter \& Boudreau, 2018).

- Innovation can create or increase inequality (Cozzens \& Kaplinsky, 2009; Schillo \& Robinson, 2017); therefore, it is important to understand how frugal innovation can enable more equal forms of participation in the economic life of a village, region, or nation.

- Finally, it would be interesting to explore how frugal innovation can contribute to the creation of post-capitalist economies (Parker et al., 2014) and the flourishing of non-monetized forms of economy (e.g., gift economies, social innovation, solidarity economies) vis-à-vis the expansion of market capitalism (Zanoni et al., 2017).

A more nuanced way of framing scarcity and frugality could also benefit the work of practitioners and businesses that are sincerely interested in addressing the problem of poverty in the Global South but also the rising inequality in the North. My suggestion is to explore different ways of creating value that are more inclusive, more transformative, and more democratic. This implies the inclusion and recognition of different forms of knowledge, as mentioned above, but it also requires a serious engagement to create equal relationships based on mutual recognition with a variety of 


\section{Frugal or Fair? The Unfulfilled Promises of Frugal Innovation}

\section{Mario Pansera}

stakeholders. A particular emphasis, in my opinion, should be given to those organizational models that use subordinate knowledge to develop technological solutions (especially in their "frugal" form) that challenge the power arrangements that create exclusion. Some examples are:

- Those organizations that challenge knowledge production systems based on "expert authority", such as the experiences of Kerala rural technologies (Pansera \& Owen, 2017) and the makers and open source communities (Smith et al., 2013).

- Those organizations that question hierarchy in the work places, such as social cooperatives and alternatives economies networks (Gibson-Graham, 2003; Parker et al., 2014).

- Those organizations that challenge the dynamic of top-down resource appropriation, such as community-business based on management of commons such as water, land, education, welfare, etc. (Kostakis et al., 2015; Sekulova et al., 2013).

\section{Conclusion}

In this article, I argued that, despite its increasing popularity, the frugal innovation literature is still problematic for two main reasons. First, it is mainly based on the idea that resource scarcity is just a natural condition in the Global South. I showed that this assumption is underpinned by an ideological posture that neglects the fact that scarcity can be socially constructed to deny certain social sectors the access to resources essential for their flourishing. Second, by framing underdevelopment as a technical or delivery problem, frugal innovation usually neglects that poverty is a socio-economic problem that requires a search for political solutions. The idea of innovation as a tool for addressing poverty, however, rests on highly contested ground.
The ways innovation is framed in the field of development implies a huge diversity of world views, values, motivations, interests, and political positions. Innovation is not an agnostic apolitical process but is rather, in the words of Sterling (2008), "a vector... increasingly recognized to be open to individual creativity, collective ingenuity, economic priorities, cultural values, institutional interests, stakeholder negotiation, and the exercise of power." The frugal innovation literature has barely engaged with the complex politics of resource allocation in the Global South. Furthermore, apart from scattered anecdotic evidence, frugal innovation has not delivered what it has promised. In order to better understand the role of innovation in the context of development, I argue, frugal innovation scholars have to re-politicize its study. They have to consciously and purposively engage with, and interrogate, the politics of poverty and scarcity.

\section{About the Authors}

Mario Pansera is a Research Fellow at the University of Bristol in the United Kingdom. He gained a $\mathrm{PhD}$ in Management from the University of Exeter Business School in the United Kingdom. His dissertation focused on the discourses of innovation and development with a particular interest for the Global South. He joined the University of Bristol after completing a Marie Skłodowska-Curie Post-Doctoral fellowship at the Academy of Business in Society in Brussels. His primary research interests are responsible research and innovation, sustainable and ecological transition, and the critique of the development discourse and growth. He is also particularly interested in the dynamics of innovation in emerging economies, appropriate technologies, grassroots, and social innovations. 


\section{Frugal or Fair? The Unfulfilled Promises of Frugal Innovation}

\section{Mario Pansera}

\section{References}

Agnihotri, A. 2013. Doing Good and Doing Business at the Bottom of the Pyramid. Business Horizons, 56(5): 591-599.

https://doi.org/10.1080/0965254X.2014.970215

Arora, S., \& Romijn, H. 2011. The Empty Rhetoric of Poverty Reduction at the Base of the Pyramid. Organization, 19(4): 481-505.

https://doi.org/10.1177/1350508411414294

Baka, J. 2013. The Political Construction of Wasteland: Governmentality, Land Acquisition and Social Inequality in South India. Development and Change, 44(2): 409-428.

http://doi.wiley.com/10.1111/dech.12018

Bardy, R., Drew, S., \& Kennedy, T. F. 2012. Foreign Investment and Ethics: How to Contribute to Social Responsibility by Doing Business in Less-Developed Countries. Journal of Business Ethics, 106(3): 267-282.

https://doi.org/10.1007/s10551-011-0994-7

Chakravarti, D. 2006. Voices Unheard: The Psychology of Consumption in Poverty and Development. Journal of Consumer Psychology, 16(4): 363-376.

https://doi.org/10.1207/s15327663jcp1604_8

Cozzens, S., \& Kaplinsky, R. 2009. Innovation, Poverty and Inequality: Cause, Coincidence, or Co-Evolution? In B.-A. Lundvall (Ed.), Handbook of Innovation System and Developing Countries: 57-82. Cheltenham, UK: Edward Elgar.

Dados, N., \& Connell, R. 2012. The Global South. Contexts, 11(1): $12-13$.

https://doi.org/10.1177/1536504212436479

Escobar, A. 2012. Encountering Development: The Making and Unmaking of the Third World (2nd ed.). Princeton, NJ: Princeton University Press.

Faulconbridge, J. R. 2013. Situated Bottom of the Pyramid Markets and the Multinational Corporation. Marketing Theory, 13(3): 393-396. https://doi.org/10.1177/1470593113489192

Ferguson, J. 1990. The Anti-Politics Machine: "Development," Depoliticization, and Bureaucratic Power in Lesotho. Cambridge, UK: Cambridge University Press.

Flyvbjerg, B. 2001. Making Social Science Matter. Cambridge, UK: Cambridge University Press.

Gibson-Graham, J. K. 2003. Enabling Ethical Economies: Cooperativism and Class. Critical Sociology, 29(2): 123-161. https://doi.org/10.1163/156916303769155788

Horn, C., \& Brem, A. 2013. Strategic Directions on Innovation Management - A Conceptual Framework. Management Research Review, 36(10): 939-954. https://doi.org/10.1108/MRR-06-2012-0142

Hossain, M. 2016. Grassroots Innovation: A Systematic Review of Two Decades of Research. Journal of Cleaner Production, 137: 973-981. https://doi.org/10.1016/j.jclepro.2016.07.140

Illich, I. 1973. Tools for Conviviality. New York: Harper \& Row.

Kanter, R. M. 2008. Transforming Giants. Harvard Business Review, 86(1): 43-52, 136.
Kaplinsky, R. 2011. Schumacher Meets Schumpeter: Appropriate Technology Below the Radar. Research Policy, 40(2): 193-203. https://doi.org/10.1016/j.respol.2010.10.003

Kolk, A., Rivera-Santos, M., \& Rufin, C. 2013. Reviewing a Decade of Research on the "Base/Bottom of the Pyramid" (BOP) Concept. Business \& Society, 20(10): 2-40. https://doi.org/10.1177/0007650312474928

Kostakis, V., Niaros, V., \& Giotitsas, C. 2015. Production and Governance in Hackerspaces: A Manifestation of Commons-Based Peer Production in the Physical Realm? International Journal of Cultural Studies, 18(5): 555-573. https://doi.org/10.1177/1367877913519310

Leach, M., Scoones, I., \& Stirling, A. C. 2010. Dynamic Sustainabilities: Technology, Environment, Social Justice. London, New York: Routledge/Earthscan.

Leach, M., Sumner, A., \& Waldman, L. 2008. Discourses, Dynamics and Disquiet: Multiple Knowledges in Science, Society and Development. Journal of International Development, 20(6): 727-738. https://doi.org/10.1002/jid.1492

Mehta, L. (Ed.). 2010. The Limits to Scarcity. Contesting the Politics of Allocation. London: Earthscan.

Metha, L. 2005. The Politics and Poetics of Water: Naturalising Scarcity in Western India. New Delhi: Orient Longman.

Ostrom, E. 1990. Governing the Commons: The Evolution of Institutions for Collective Action. Cambridge, UK: Cambridge University Press.

Ostrom, E. 2010. Polycentric Systems for Coping with Collective Action and Global Environmental Change. Global Environmental Change, 20(4): 550-557. https://doi.org/10.1016/j.gloenvcha.2010.07.004

Pansera, M. 2013. Frugality, Grassroots and Inclusiveness: New Challenges for Mainstream Innovation Theories. African Journal of Science, Technology, Innovation and Development, 5(6): 469-478. https://doi.org/10.1080/20421338.2013.820445

Pansera, M., \& Owen, R. 2017. Innovation for De-Growth: A Case Study of Counter-Hegemonic Practices from Kerala, India. Journal of Cleaner Production, In press.

https://doi.org/10.1016/j.jclepro.2016.06.197

Pansera, M., \& Owen, R. 2018. Framing Inclusive Innovation within the Discourse of Development: Insights from Case Studies in India. Research Policy, 47(1): 23-34.

https://doi.org/10.1016/j.respol.2017.09.007

Parker, M., Cheney, G., Fournier, V., \& Land, C. (Eds.). 2014. The Routledge Companion to Alternative Organization. Oxford: Routledge.

Pisoni, A., Michelini, L., \& Martignoni, G. 2018. Frugal Approach to Innovation: State of the Art and Future Perspectives. Journal of Cleaner Production, 171(10): 107-126. https://doi.org/10.1016/j.jclepro.2017.09.248

Polanyi, K. 2001. The Great Transformation: The Political and Economic Origins of Our Time. Boston, MA: Beacon Press.

Prahalad, C. K. 2010. The Fortune at the Bottom of the Pyramid: Eradicating Poverty through Profits (2nd ed.). Upper Saddle River, NJ: Pearson Education. 


\section{Frugal or Fair? The Unfulfilled Promises of Frugal Innovation}

\section{Mario Pansera}

Prahalad, C. K. 2012. Bottom of the Pyramid as a Source of Breakthrough Innovations. Journal of Product Innovation Management, 29(1): 6-12.

https://doi.org/10.1111/j.1540-5885.2011.00874.x

Prahalad, C. K., \& Mashelkar, R. A. 2010. Innovation's Holy Grail. Harvard Business Review, 88(7/8): 132-141.

Rosca, E., Reedy, J., \& Bendul, J. C. 2017. Does Frugal Innovation Enable Sustainable Development? A Systematic Literature Review. The European Journal of Development Research, 30(1): 136-157. https://link.springer.com/article/10.1057/s41287-017-0106-3

Rosenbloom, A., \& Althaus, R. 2007. Reducing Global Poverty: Building the Business Case. International Journal of Interdisciplinary Social Sciences, 2(1): 417-423.

Sahlins, M. 1992. The Economics of Develop-Man in the Pacific. Anthropology and Aesthetics, 21: 12-25.

https://doi.org/10.1086/RESv21n1ms20166839

Schillo, R. S., \& Robinson, R. 2017. Inclusive Innovation in Developed Countries: The Who, What, Why, and How. Technology Innovation Management Review, 7(7): 34-46.

https://timreview.ca/article/1089

Schumacher, E. F. 1973. Small is Beautiful. New York: Harper \& Row.

Seelos, C., \& Mair, J. 2007. Profitable Business Models and Market Creation in the Context of Deep Poverty: A Strategic View. Academy of Management Perspectives, 21(4): 49-63. https://doi.org/10.5465/AMP.2007.27895339

Sekulova, F., Kallis, G., Rodríguez-Labajos, B., \& Schneider, F. 2013. Degrowth: From Theory to Practice. Journal of Cleaner Production, 38: $1-6$.

https://doi.org/10.1016/j.jclepro.2012.06.022

Smith, A., Arond, E., Fressoli, M., Thomas, H., \& Abrol, D. 2012. Supporting Grassroots Innovation: Facts and Figures. SciDev.Net, May 2, 2012. Accessed April 16, 2018:

http://www.scidev.net/global/enterprise/spotlight/supportinggrassroots-innovation.html

Smith, A., Fressoli, M., \& Thomas, H. 2014. Grassroots Innovation Movements: Challenges and Contributions. Journal of Cleaner Production, 63: 114-124.

https://doi.org/10.1016/j.jclepro.2012.12.025

Smith, A., Hielscher, S., Dickel, S., Soderberg, J., \& van Oost, E. 2013. Grassroots Digital Fabrication and Makerspaces: Reconfiguring, Relocating and Recalibrating Innovation? SPRU Science and Technology Policy Research Working Paper SWPS 2013-02. Brighton, UK: University of Sussex.

http://sro.sussex.ac.uk/49317/1/2013_02_SWPS_APS_SH_GDF_wo rking_paper.pdf

Soni, P., \& T. Krishnan, R. 2014. Frugal Innovation: Aligning Theory, Practice, and Public Policy. Journal of Indian Business Research, 6(1): 29-47.

https://doi.org/10.1108/JIBR-03-2013-0025
Srinivas, S., \& Sutz, J. 2008. Developing Countries and Innovation: Searching for a New Analytical Approach. Technology in Society, 30(2): 129-140.

https://doi.org/10.1016/j.techsoc.2007.12.003

Stirling, A. 2008. "Opening Up" and “Closing Down": Power, Participation, and Pluralism in the Social Appraisal of Technology. Science, Technology \& Human Values, 33(2): 262-294. https://doi.org/10.1177/0162243907311265

Swyngedouw, E. 2015. Depoliticization (“The Political”). In G. D'Alisa, F. Demaria, \& G. Kallis (Eds.), Degrowth: A Vocabulary for a New Era: 90-93. London: Routledge.

Tiwari, R., Fischer, L., \& Kalogerakis, K. 2016. Frugal Innovation in Scholarly and Social Discourse: An Assessment of Trends and Potential Societal Implications. Working Paper. Hamburg and Leipzig, Germany: Center for Frugal Innovation, Hamburg University of Technology, Fraunhofer Center for International Management and Knowledge Economy.

https://doi.org/10.15480/882.1288

Winner, L. 1980. Do Artifacts Have Politics? Daedalus, 109(1): 121-136. http://www.jstor.org/stable/20024652

Winter, J., \& Boudreau, J. 2018. Supporting Self-Determined Indigenous Innovations: Rethinking the Digital Divide in Canada. Technology Innovation Management Review, 8(2): 38-48. https://doi.org/10.22215/timreview/1138

Yapa, L. 1996. What Causes Poverty? A Postmodern View. Annals of the Association of American Geographers, 86(4): 707-728. https://doi.org/10.1111/j.1467-8306.1996.tb01773.x

Zanoni, P., Contu, A., Healy, S., \& Mir, R. 2017. Post-Capitalistic Politics in the Making: The Imaginary and Praxis of Alternative Economies. Organization, 24(5): 575-588.

https://doi.org/10.1177/1350508417713219

Zeschky, M., Widenmayer, B., \& Gassmann, O. 2011. Frugal Innovation in Emerging Markets. Research-Technology Management, 54(4): 38-45.

https://doi.org/10.5437/08956308X5404007

Zeschky, M., Winterhalter, S., \& Gassmann, O. 2014. From Cost to Frugal and Reverse Innovation: Mapping the Field and Implications for Global Competitiveness. Research-Technology Management, 57(4): 20-27.

https://doi.org/10.5437/08956308X5704235

Citation: Pansera, M. 2018. Frugal of Fair? The Unfulfilled Promises of Frugal Innovation. Technology (cc) BY Innovation Management Review, 8(4): 6-13.

http://doi.org/10.22215/timreview/1148

Keywords: frugal innovation, inclusive innovation, social justice, scarcity 


\title{
Approach for a Pattern-Based Development of Frugal Innovations
}

\section{Anne-Christin Lehner, Christian Koldewey, and Jürgen Gausemeier}

\author{
"Creativity and insight almost always involve an") \\ experience of acute pattern recognition: the eureka \\ moment in which we perceive the interconnection \\ between disparate concepts or ideas to reveal \\ something new.
}

Jason Silva

Futurist, filmmaker, and public speaker

\begin{abstract}
Emerging markets have become increasingly interesting for companies from industrialized countries, but the requirements in these markets differ dramatically from those in the companies' traditional markets. New products and services are demanded - so-called frugal innovations. Since the challenges for the development of frugal innovations are often quite similar - for example, low income of the target customer, poor infrastructure, etc. - the hypothesis appears that the solutions will also be similar. In our earlier TIM Review article (Lehner \& Gausemeier, 2016), we showed how solution patterns for frugal innovations can be derived. The article at hand summarizes those findings and supplements an innovation process for frugal innovation using the solution patterns. The validation based on the example of telemedical assistant systems shows the benefit of the pattern-based development of frugal innovations. The article addresses managers and engineers who plan to introduce frugal innovations, as well as university-based researchers interested in the development of frugal innovations.
\end{abstract}

\section{Introduction}

In 1980 , almost $80 \%$ of global gross goods turnover was generated in industrialized countries. Since then, this share has been steadily declining; by 2013 , almost $40 \%$ of gross goods turnover had already been converted to developing and emerging countries (McKinsey Global Institute, 2015). In recent years, markets in developing and emerging countries have thus increasingly become the focus of international companies (Högl \& Weiss, 2014). However, customers in these markets are much more price-sensitive and demand products and services that are adapted to their local needs. One of the most common names for such products and services is the term frugal innovations (Basu et al., 2013; The Economist, 2010), but see Box 1 for a list of related terms. Besides the redesigning of products, the adaptation of the entire value chain and of the business model is equally important for frugal innovations (The Economist, 2010). We define frugal innovations in accordance with Eagar and colleagues (2011), Tiwari and Herstatt (2014), and Lehner (2016):

Frugal innovations are novel or significantly modified market products and services and business models adapted to the needs of the poorer populations in developing and emerging countries.

Frugal innovations usually focus on the price (Bound \& Thornton, 2012; Tiwari \& Herstatt, 2014; Zeschky et al., 2011), but also on sustainability and social aspects (Bhatti, 2012; Bound \& Thornton, 2012). An example of a sustainable frugal innovation is a water filter with a replaceable filter cartridge, developed by the University of Aalto for Ahlstrom. In Tanzania, it removes the need to boil drinking water, which usually consumes firewood or charcoal. In doing so, greenhouse gases are reduced and deforestation and adverse health effects are avoided (Hyvärinen et al., 2016). In practice, there are many other examples of frugal innovations. 


\section{Approach for a Pattern-Based Development of Frugal Innovations}

\section{Anne-Christin Lehner, Christian Koldewey, and Jürgen Gausemeier}

The target group for these products and services is, in most cases, the global middle class; they have experienced a significant increase in prosperity over the past few years. According to the World Bank, the global middle class includes people who have between $\$ 2$ and $\$ 13$ USD a day at their disposal (Ravallion, 2009). Large sections of the population are still lacking money for expensive products from the highly developed industrialized countries (Tiwari \& Herstatt, 2013; Zeschky et al., 2011). In addition, the products must also meet requirements different from industrialized countries today (Gausemeier \& Wiendahl, 2011), as they are used in a completely different environment. With such products, western companies can maintain their competitive position against upcoming competitors from emerging markets (e.g., Haier or Huawei) (Radjou et al., 2012).

However, many western companies are not exploiting the existing potential for frugal innovations. For example, in a survey of more than 60 companies, Roland Berger Strategy Consultants found out that only $29 \%$ of the companies surveyed are satisfied with frugal innovations' profits (Roland Berger Strategy Consultants, 2013). Reasons for this low level of satisfaction include time problems with the planning of product costs and the design of the value chain; a lack of market knowledge or competitive prices; and shortages of local engineering and problem-solving skills (Roland Berger Strategy Consultants, 2015). Overall, existing R\&D and innovation processes in western companies are often optimized for the development of advanced products and technologies. Most of the time, the resulting products are still based on a western product architecture and therefore are not suitable as frugal innovations (Zeschky et al., 2011). However, the innovation process of frugal innovations is hardly considered in the literature. Often, the focus is on the actual product or service (Hossain, 2016). This prevents both the conceptual and managerial understanding and exploitation of the potentials of frugal innovations (Hossain et al., 2017), therefore leaving a research gap for the development of a frugal innovation process.

The pattern-based solution of recurring problems in the course of the development of a technical system has proven itself in many domains; this applies, for example, to the operating principles of mechanical design and to the design pattern of software development. According to Alexander and co-authors (1995), a pattern encompasses "a problem that occurs repeatedly in our environment, the core of the solution to this problem, in such a way that this solution can be used millions of times without ever repeating itself". Several patterns in
Box 1. Terms related to "frugal innovation"

In addition to the term frugal innovation, the literature contains a large number of other terms dealing with innovations in the context of developing and emerging countries. These include:

- resource-constrained innovation

(Capasso et al., 2013; Ray \& Ray 2010)

- cost innovation

(Williamson, 2010)

- reverse innovation

(Govindarajan \& Trimble, 2012)

- frugal re-engineering

(Shivaraman et al., 2012)

- shanzhai

(Kao \& Lee, 2010)

- lean innovation

(Tiwari \& Herstatt, 2012)

- disruptive innovation

(Bower \& Christensen, 1995; Tiwari \& Herstatt, 2012)

- jugaad

(Radjou et al., 2012)

- grassroots innovation

(Hilmi, 2012; Seyfang \& Smith, 2007)

- inclusive innovation

(Heeks et al. 2013; Nijhof et al., 2002)

- bottom of the pyramid innovation

(Bieger \& Reinhold, 2011; Ernst et al., 2013)

- Ghandian innovation

(Prahalad \& Mashelkar 2010)

a domain can be grouped together to form so-called pattern catalogues. If the dependencies between the patterns are also considered, the implementation described, and the problem-solving process supported, it is considered a pattern system (Buschmann et al., 2000). It is therefore clear that, with the aid of patterns, solutions can be externalized, structured, and documented; complexity and input are reduced and a uni- 


\section{Approach for a Pattern-Based Development of Frugal Innovations}

\section{Anne-Christin Lehner, Christian Koldewey, and Jürgen Gausemeier}

form communication is created (Amshoff et al., 2014). In this way, expert knowledge can be transferred to non-experts (Corfman, 1998), for example, expert knowledge about problems and solutions in frugal markets can be used by engineers in industrialized countries. An indication for the benefits of a pattern-based approach for frugal innovation is provided by Tiwari \& Herstatt (2013): the analysis of three case studies shows that developers are very specifically looking for analogies in the development of frugal innovations, which are strongly focused on cost reduction and efficiency. The search is not limited to the early innovation phase, but extends over the entire innovation process.

Therefore, we believe that the transmission of the solution pattern approach to the development of frugal innovations is very promising to address the problems mentioned above. To prove this point, the three following hypotheses have to be validated (Lehner et al., 2015):

1. Product developers face similar problems while developing market services and business models for developing and newly industrializing countries (e.g., insufficient infrastructure, adverse climatic conditions, etc.).

2. If the problems are similar, the solutions will also be similar as well.

3. By abstracting the applied solutions to patterns, they can be used to develop market services and business models facing similar problems.

To validate the first and second hypotheses, we derived a frugal innovation pattern system analyzing 29 frugal innovations from different countries and industries. This is shown in the next section; a more detailed description of the pattern system can be found in our 2016 TIM Review article (Lehner \& Gausemeier, 2016). The third hypothesis is validated in the section after that. We used the design research methodology (Blessing \& Charkrabarti, 2009) to derive the innovation process model for pattern-based frugal innovation presented there. The last section summarizes the findings and gives a conclusion.

\section{Solution Patterns for Frugal Innovation}

The frugal innovation pattern system is developed in a four-step procedure (Lehner, 2016; Lehner \& Gausemeier, 2015; Lehner et al., 2015) and is based upon the design pattern theory (e.g., Alexander et al., 1995; Buschmann et al., 2000; Zimmer, 1995). The procedure is explained below:

1. First of all, a representative overview of existing frugal innovations has to be compiled, which is documented in the form of frugal innovation profiles. This is necessary because the inductive approach to finding patterns is the agreed paradigm in the pattern community. The inductive approach is based upon the observation and analysis of existing cases (Kohls \& Wedekind, 2011).

2. Given that a solution pattern addresses a recurring problem (Alexander et al., 1995), the causal problems are identified that prevented the use of a product and a business model from an industrialized country and led to the development of the frugal innovations. The identified problems can be clustered into six problem areas: environment, infrastructure, education, culture, regulation, and finance. In addition, it is possible to identify which aspects of the product and business model are affected by the problems.

3. The second component of a solution pattern is the core of the solution to the recurring problem (Alexander et al., 1995). Therefore, it is determined how the researched frugal innovations coped with the identified problems. These solutions are abstracted to extract the core idea of the solution in such a way that it is transferable to other problems. Figure 1 shows this procedure using electrocardiography (ECG) devices. The analysis of the device for industrialized countries revealed, for example, that its use in remote areas in developing and emerging countries is not possible due to the lack of resistance of the installed print heads to temperature and humidity. This problem can be assigned to the problem area environment and the impact area solution element. The problem is solved by the device for developing and emerging countries by using printers from bus stations in India. Abstraction results in the Pattern "Use of existing technologies from other industries".

4. An analysis of the pattern catalogue can be used to obtain further information, for example, how widespread a pattern is or with which patterns it frequently occurs together. Such information supports the author and user of the solution pattern: it helps in choosing the right pattern for a specific situation and closing the gap between patterns as well as understanding the relations between patterns (Buschmann 


\section{Approach for a Pattern-Based Development of Frugal Innovations}

\section{Anne-Christin Lehner, Christian Koldewey, and Jürgen Gausemeier}

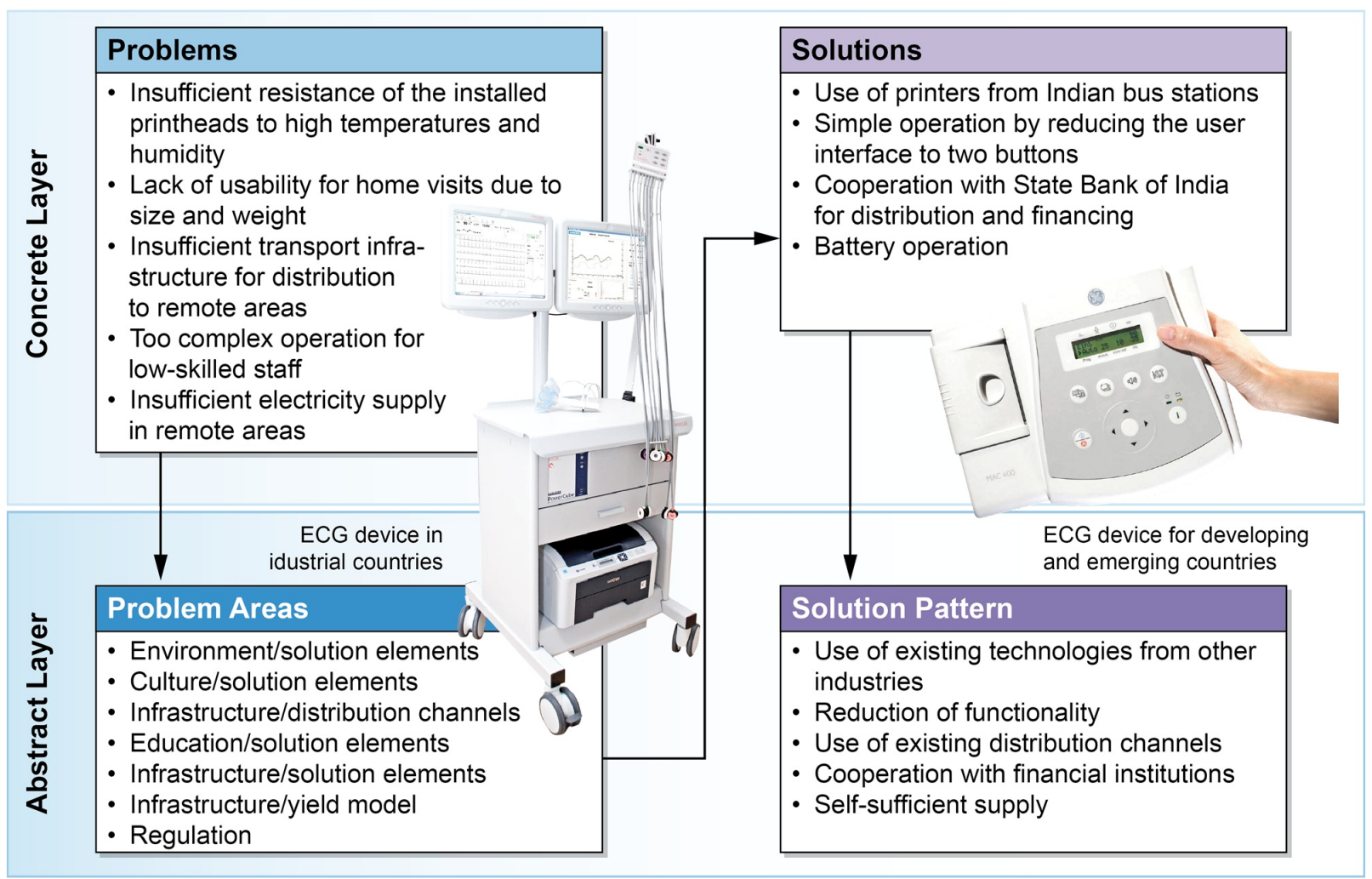

Figure 1. Procedure for the determination of patterns using the example of ECG devices (Lehner, 2016)

et al., 2000). The patterns are finally documented as pattern profiles. A profile includes a description, best practices, and classification in the pattern system. Figure 2 shows an overview of the identified solution patterns for the problem area "infrastructure".

\section{Process Model for Pattern-Based Frugal Innovation}

We, therefore, propose a four-stage process model for the development of frugal innovations in accordance with Figure 3. The starting point of the approach is a given product and business model concept, which is to be adapted for a developing or emerging market (Lehner, 2016). To derive the process model, we used the design research methodology (DRM) (Blessing \& Charkrabarti, 2009). The research was based on a research project classified as DRM type 5. A type 5 research project consists of four elements: clarification of the research objective (goals), descriptive study I (understanding), prescriptive study (solution), and de- scriptive study II (initial evaluation). The article at hand focuses on the results of the prescriptive study. The resulting approach is an innovation process model that integrates common elements of innovation such as an analysis of the environment as well as specific elements for frugal innovation. Such is the focus on the most common problem areas of frugal innovation (environment, infrastructure, education, culture, regulation, and finance) and the application of solution patterns to tackle specific problems in those problem areas.

The four elements of the proposed process model can be summarized as follows:

1. Identification of target markets: First of all, the approximately 150 developing and emerging countries potentially eligible for a frugal innovation will be successively narrowed down. The selection of promising target markets is based on the dimensions of market attractiveness and fit to the boundary conditions. 


\section{Approach for a Pattern-Based Development of Frugal Innovations} Anne-Christin Lehner, Christian Koldewey, and Jürgen Gausemeier

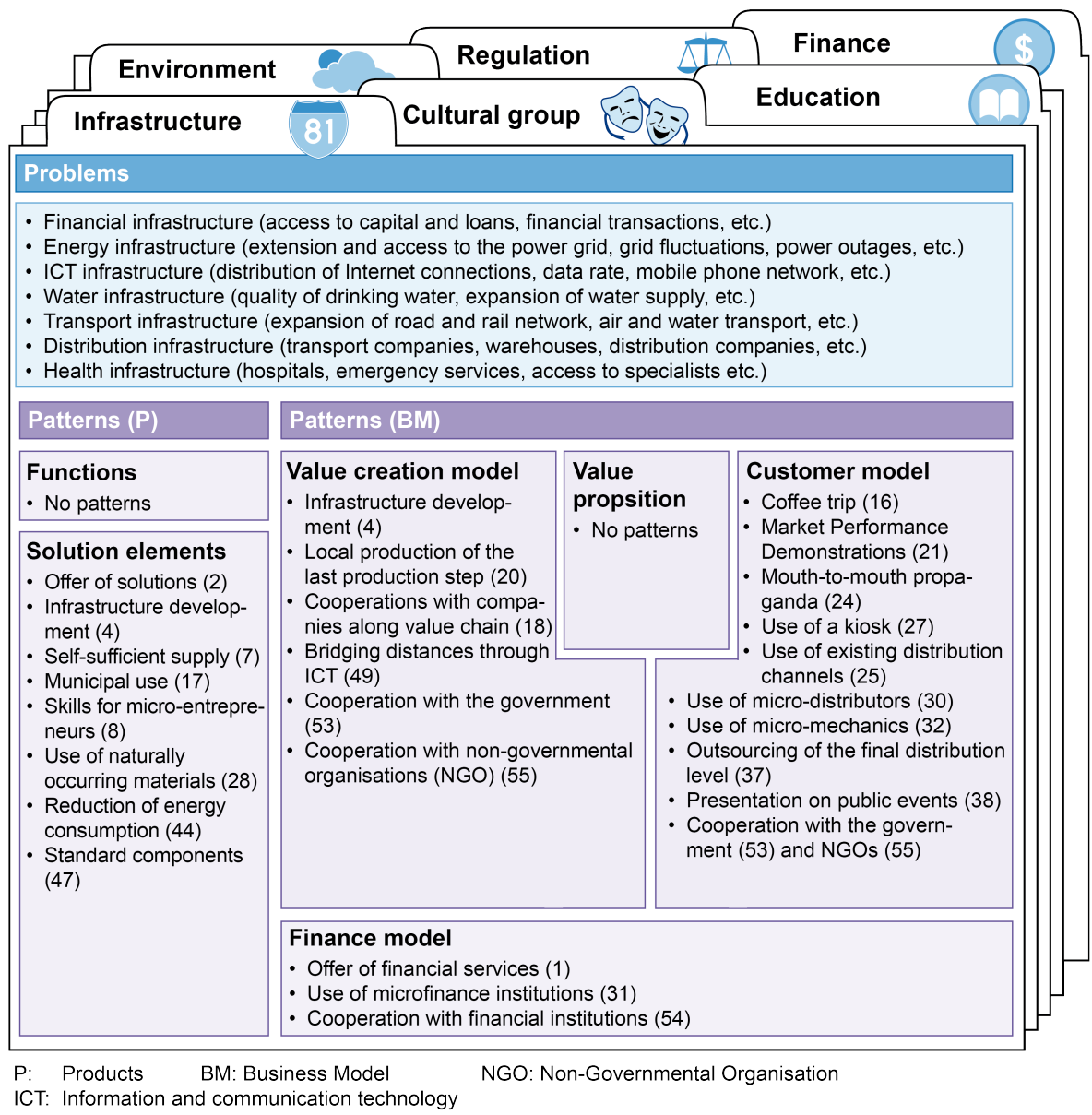

Figure 2. Overview of the identified solution patterns for the problem area "infrastructure" (Lehner, 2016)

Phases/Milestones

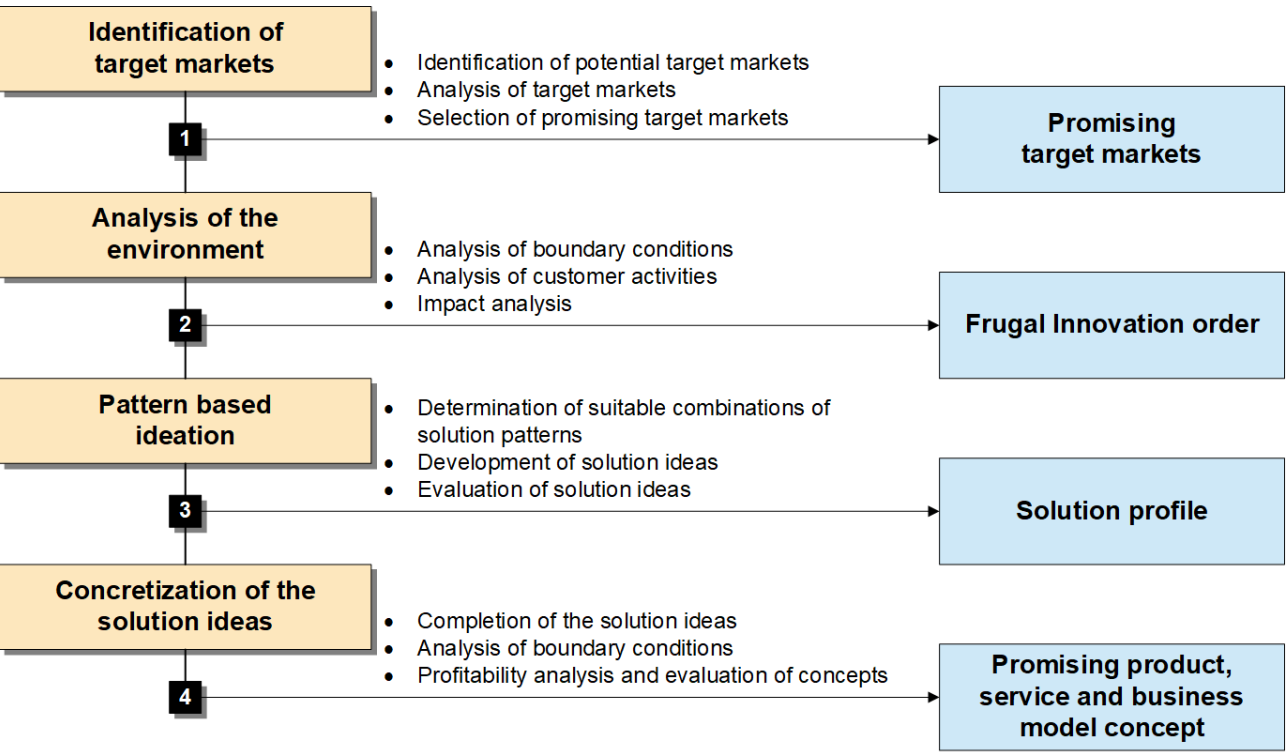

Figure 3. Process model for the pattern-based development of frugal innovations (Lehner, 2016) 


\section{Approach for a Pattern-Based Development of Frugal Innovations}

\section{Anne-Christin Lehner, Christian Koldewey, and Jürgen Gausemeier}

2. Analysis of the environment: The objective is to identify problems in the transfer of products and business models to developing or emerging countries. To this end, the boundary conditions and customer needs, as well as comparable market services, are analyzed. The findings result in a frugal innovation development order.

3. Pattern-based ideation: The objective is to find solutions for the identified problems. For this purpose, patterns are used and creativity workshops are held. The ideas are put together in a morphological environment, they are evaluated, and then the most promising ones are selected.

4. Concretization of the ideas: Finally, the ideas for market service and business model concepts are concretized, while taking account of economic considerations. The final concept is selected on the basis of the dimensions of cost-effectiveness, fit to the boundary conditions, and customer needs. On the basis of the concept, initial feasibility studies can then be carried out.

In the following section, the explained procedure is illustrated. The starting point for the system is a product and a market service for industrialized countries that are to be offered in fresh markets.

\section{Approach in Detail}

Here, we illustrate the explained procedure using the example of a telemedical assistance system for monitoring the health status of patients.

\section{Identification of target markets}

The identification of suitable target markets is carried out in several steps. According to the definition of frugal innovation, all developing and emerging countries are the starting point - it concerns about 150 countries. First of all, a restriction can be made on the basis of macroeconomic criteria. A geographical limitation (e.g., only Latin America and the Caribbean) is carried out and the number of inhabitants is evaluated. The size of the sales market is of paramount importance due to the low-profit margin attainable with frugal innovations (Universe Foundation, 2013). A further refinement of the relevant target markets makes it possible to examine macroeconomic location factors, for example, with the help of the Economic Freedom Index (The Heritage Foundation, 2015). The final selection of the target markets is based on microeconomic criteria. Three assessment dimensions are taken into account: market attractiveness, fit to the conditions, and fit to the company.

- Market attractiveness: It results from the consideration of the criteria market potential, competitive intensity, expected benefit, and future relevance.

- Fit to the boundary conditions: In doing so, six problem areas identified in the analysis of more than 30 frugal innovations are taken into account as criteria. The problem areas are environment, infrastructure, education, culture, regulation, and finance.

- Fit to the company: The starting position of the company is considered here. The criteria of local presence, market knowledge, and strategy conformity are used.

The selection of the target market for frugal innovation is then made on the basis of a bubble chart shown in Figure 4. In this example, Egypt was selected as the target market.

\section{Analysis of the environment}

The objective of this phase is the frugal innovation order. This includes a description of possible problems of the product and the business model for the introduction in the target market. The identification of the problems is based on an analysis of the current and future boundary conditions as well as customer needs in the target market. Based upon that, the environmental effects on the western product and the business model are finally determined.

- Analysis of the boundary conditions: This is carried out in two steps. First, so-called descriptive factors are determined. They characterize the differences between the source and target markets. The six problem areas of frugal innovations form the framework for the analysis. An example of a descriptive factor from the problem area of infrastructure is information and communication technology. Second, the descriptive factors are characterized by means of indicators. An indicator for the descriptive factor mentioned above is, for example, fixed broadband access per inhabitant. The characteristics of the indicators are then determined in the initial and target market. In Germany, for example, $95 \%$ of the population has a broadband connection; in Egypt only 3\% does. In addition, the future development of the indicator in the target market is assessed.

- Identification of customer needs: This is conducted in three steps. First, substitutes are identified for the 


\section{Approach for a Pattern-Based Development of Frugal Innovations}

\section{Anne-Christin Lehner, Christian Koldewey, and Jürgen Gausemeier}

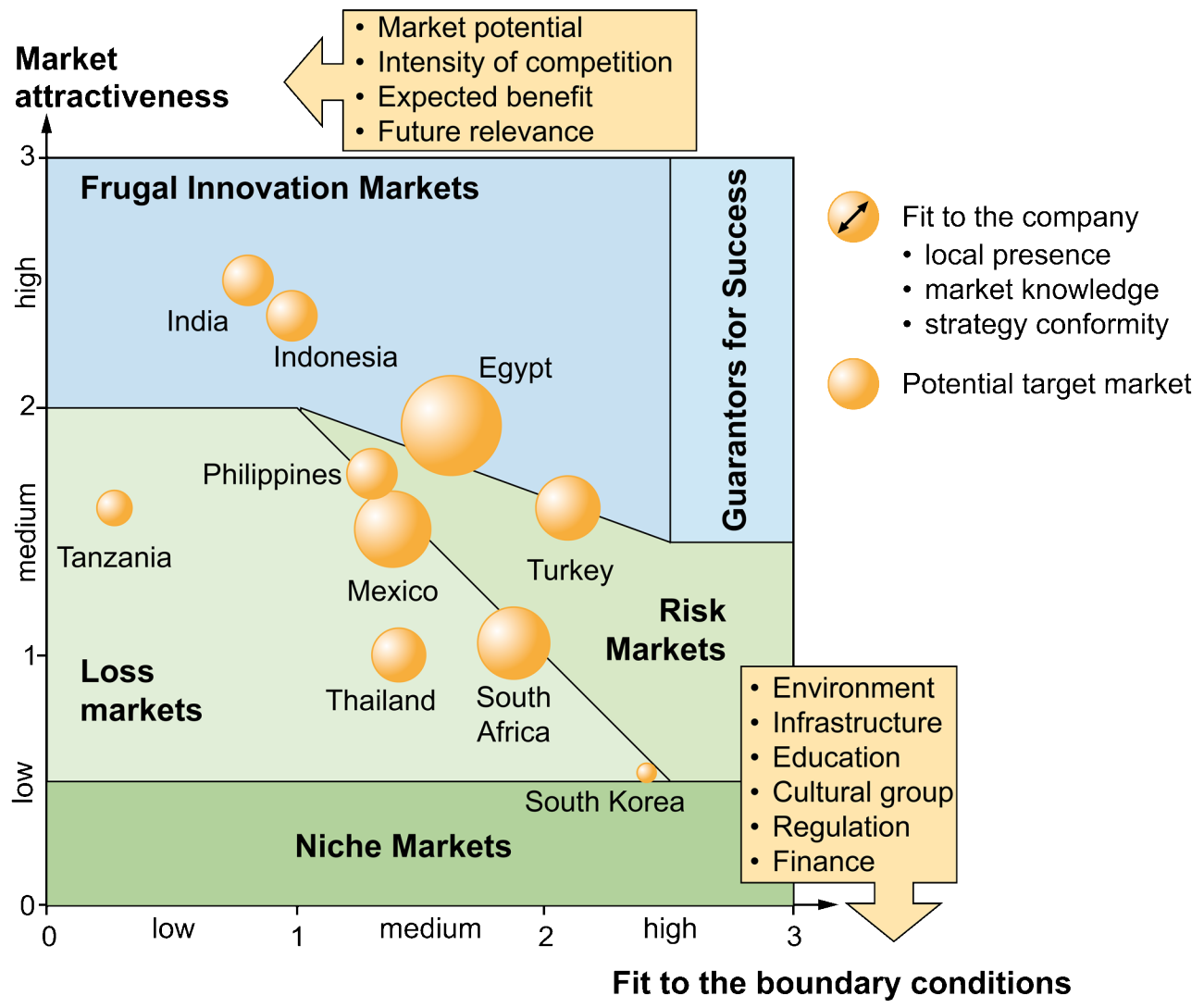

Figure 4. Bubble chart for selecting suitable target markets (Lehner, 2016)

targeted product in the target market. Second, customers are then observed when using substitutes. Customer activities are recorded in the form of a process description. Third, the documentation of the results summarizes customer needs that are addressed with the individual substitutes and evaluates their fulfillment by the substitutes. The findings are recorded in profiles.

- Determination and assessment of the effects: Two steps are carried out. First, based on the boundary conditions and local needs, the effects on the current business model and the product offered are determined. In order to assess the effects, the boundary conditions and customer needs of the product are compared with the business model (Figure 5). Depending on the application, different views must be taken into account. Figure 5 (right) shows a selection of possible views of the object of observation. The problems are derived from the views on the object of observation. For example, the analysis of the product can be carried out on the basis of its functionality, shape, or solution elements. The identified problems are then assigned to the problem areas and the areas of impact. Areas of impact characterize which elements of the product (func- tions or elements) and of the business model (e.g., customer segments) are affected by the problem. Second, the analysis of the environment thus shows the need for action for a frugal innovation. As shown in Figure 6 , the results are summarized in a frugal innovation order. It contains a description and evaluation of the current product and the current business model as well as an overview of the identified problems. The problems are summarized in the problem matrix. The matrix contains the problem areas in the rows and the elements of the business model and products in the columns. The cells indicate whether an element of the business model or product is affected by problems from a problem area. The customer needs profile also assesses how well the current concept meets customer requirements.

\section{Pattern-based brainstorming}

Ideas are developed to solve the identified problems. Given that frugal innovations often face recurring problems, such as poor infrastructure, adverse climatic conditions, or lack of education, a pattern-based approach to find solutions is recommended. For this purpose, solution patterns are used, which have been identified by the analysis of existing frugal innovations. Ideas are 


\section{Approach for a Pattern-Based Development of Frugal Innovations}

\section{Anne-Christin Lehner, Christian Koldewey, and Jürgen Gausemeier}
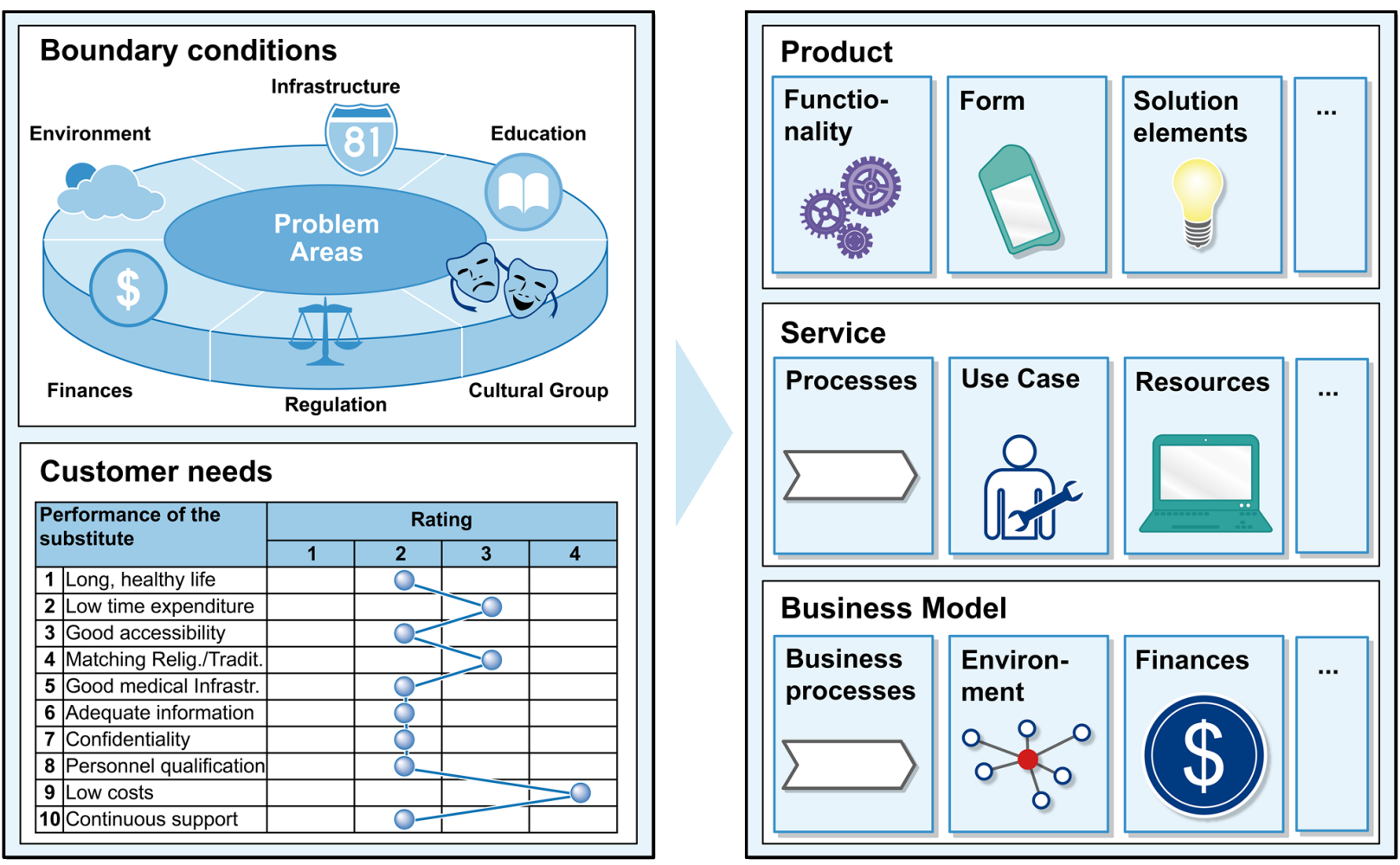

Figure 5. Comparison of boundary conditions and customer needs with the product (including services) and the business model (Lehner, 2016)

generated cyclically and successively improved with each pass through as the requirements of the target market are approached. A cycle always consists of three steps: the identification of suitable combinations of patterns, the development of ideas, and the evaluation of ideas. At the end of each cycle, a decision is made whether the cycle has to be run again, whether the idea has to be postponed, or whether the idea is passed on to concretization.

- Identification of suitable combinations of patterns: These are patterns that address at least one identified problem area. To solve all existing problems, combinations of patterns are created to cover all problem areas as far as possible. On the one hand, the compatibility of the patterns, and on the other hand, the accuracy of fit, are checked and ensured. The accuracy of fit describes how well the patterns address the problem areas of the application case. The selection of the further pattern combinations is based on the criteria of accuracy of fit, problem-solving potential, and cost-reduction potential. An algorithm then determines from the available combinations of patterns those that are particularly promising.
- Development of ideas: The following process is run for each combination of patterns: First, specific partial ideas are sought for the individual patterns. For problem areas for which there are no patterns, it is necessary to find "conventional" ideas for partial solutions. In both cases, common creativity techniques can be applied. The partial solutions can then be combined in a modified morphological box to form ideas, whereby the lines represent the partial ideas for the individual patterns. For example, the "partial ideas" for the "contact established by the Egyptian Diabetes Association" or "joint information campaigns" can be generated for the "cooperation with NGOs" pattern.

- Evaluation of the ideas: In order to transfer the ideas into the phase of concretization, they have to fulfil three criteria: conformity with the corporate strategy, fit to the boundary conditions, and fulfilment of customer requirements. If this is not the case, it is to decide whether to postpone the idea or run through the cycle again. 


\section{Approach for a Pattern-Based Development of Frugal Innovations} Anne-Christin Lehner, Christian Koldewey, and Jürgen Gausemeier

\begin{tabular}{l}
\hline $\begin{array}{l}\text { Frugal Innovation Order: } \\
\text { Development of a telemedical assistance system for Egypt }\end{array}$ \\
\hline $\begin{array}{l}\text { Market Performance and Business Model } \\
\text { The telemedical assistance system under considerati- } \\
\text { on is used for the therapy of diabetes and hypertensi- } \\
\text { on patients. Using the device, patients can record data } \\
\text { and send it to a database via smartphone. The } \\
\text { attending physician and a medical call centre have } \\
\text { access to these services. Depending on the parame- } \\
\text { ters collected, the patient receives feedback and } \\
\text { recommendations for his or her personal state of } \\
\text { health. The costs for the terminal device and the } \\
\text { service are borne by the patient. They are sold directly } \\
\text { or through pharmacies. }\end{array}$ \\
Editor: A.L.
\end{tabular}

\begin{tabular}{|l|}
\hline Overview of Identified Problems (Excerpt) \\
\hline Environment \\
\hline - EN.1 Fogged screen \\
- EN.2 Vulnerable flap \\
- EN.3 Sensor overheating \\
- EN.4 Poor handling
\end{tabular}

Education

- ED.1 Training of rural doctors

- ED.2 Expert knowledge with the sales partners

- ED.3 Illiteracy of the population

- ED.4 Lack of basic medical knowledge

\begin{tabular}{l}
\hline Regulation \\
- R.1 Authorized representative \\
- R.2 Customer service in the country \\
- R.3 Drug price maintenance
\end{tabular}

\section{Customer Needs}

- CN.1 Insufficient involvement in religion/tradition

- CN.2 Too expensive for citizens of the lower and middle class

\begin{tabular}{|c|c|c|c|c|c|c|c|c|c|c|c|c|c|c|c|c|}
\hline \multicolumn{17}{|c|}{ Evaluation of the existing market performance and business model concept } \\
\hline \multicolumn{12}{|c|}{ Problem matrix } & Customer needs profile & \multicolumn{4}{|c|}{ Rating } \\
\hline & * & *is & $\frac{*}{*}$ & 苗 & ${ }_{4}^{*}$ & $\frac{*}{0}$ & $\frac{1}{*}$ & * & ${ }^{*}$ & $\stackrel{*}{*}$ & $\begin{array}{lll}* \\
*\end{array}$ & Customer needs & 0 & 1 & 2 & 3 \\
\hline & 0 & 0 & 0 & $>$ & $\underline{1}$ & $\underline{x}$ & $\underline{x}$ & & & & & Long, healthy life & & & & 0 \\
\hline 20 & 0 & 0 & 0 & 0 & 0 & 0 & 0 & 0 & 0 & 0 & $x$ & Low time expenditure & & & & Q \\
\hline$(\overline{81})$ & 0 & $x$ & $x$ & 0 & 0 & 0 & 0 & 0 & & & & Good accessibility & & & & -0 \\
\hline (01) & 0 & $\hat{\lambda}$ & $\lambda$ & 0 & 0 & 0 & 0 & 0 & 0 & 0 & $x$ & Matching with religion/tradition & 6 & & & \\
\hline (6) & 0 & 0 & $x$ & $x$ & 0 & 0 & 0 & 0 & 0 & $x$ & $x$ & Good medical infrastructure & & & -0 & \\
\hline$\theta 2$ & 0 & 0 & $x$ & $X$ & 0 & 0 & 0 & 0 & 0 & $x$ & 0 & Adequate information on disease & & & 0 & \\
\hline & & & & & & & & & & & & Good relationship of trust & & & O. & \\
\hline$\Delta \underline{\Delta}$ & 0 & 0 & 0 & 0 & 0 & 0 & 0 & 0 & 0 & 0 & 0 & High qualification of personnel & & & & $=0$ \\
\hline (\$) & & & & & & $x$ & & & & & & \begin{tabular}{|l} 
Low costs \\
Continuous support
\end{tabular} & & & & -O \\
\hline
\end{tabular}

* Elements of the business model (from left to right): customer segments, customer relationships, channels, value proposition, key activities, key resources, key partners, revenue model, cost model

** Elements of market performance (from left to right): functions, solution elements

Figure 6. Profile of a frugal innovation order (Lehner, 2016) 


\section{Approach for a Pattern-Based Development of Frugal Innovations} Anne-Christin Lehner, Christian Koldewey, and Jürgen Gausemeier

For documentation purposes, a profile is created for each idea. After each time a cycle is run, it is updated. The profile contains a concise description of the idea, information on the patterns used, and the number of cycles to be run. It also describes how to solve the identified problems. In addition, the evaluation of the idea with regard to the fit to the boundary conditions and the fit to the customers' needs is presented. Finally, the recommended course of action is listed. Figure 7 shows the solution outline for the idea "Mobile Telemedicine Bus", which will be examined further below.

Solution Idea Profile No. 1.2.1.1 "Mobile Telemedicine Bus".

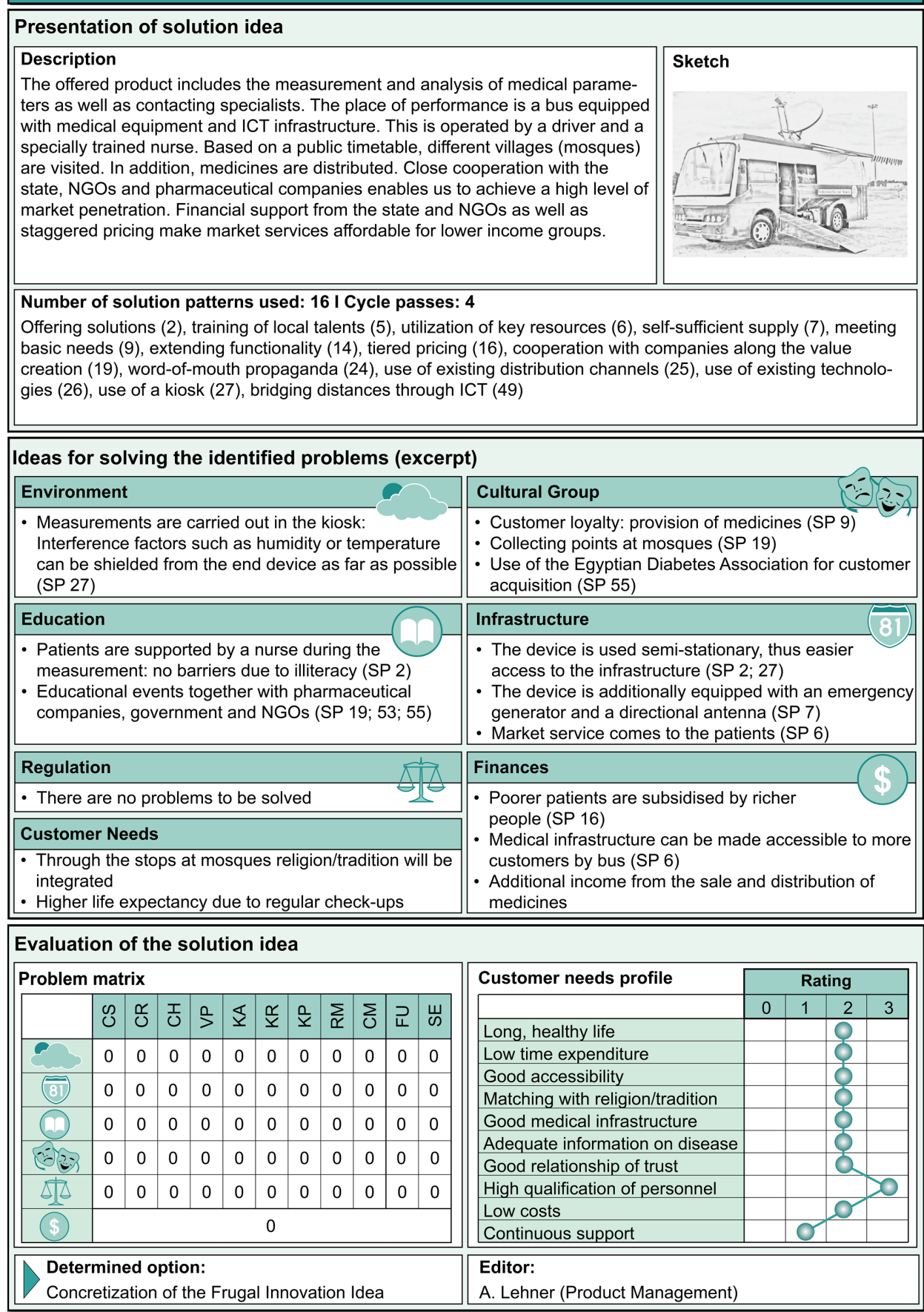

Figure 7. Solution Idea Profile for the idea "Mobile Telemedicine Bus” (Lehner, 2016) 


\section{Approach for a Pattern-Based Development of Frugal Innovations}

\section{Anne-Christin Lehner, Christian Koldewey, and Jürgen Gausemeier}

\section{Concretization of the frugal innovation ideas}

The objective of the last phase is a sustainable product concept and business model concept. To this end, the ideas for solutions handed over to this phase are completed at first. On the basis of the profile, a function and process hierarchy and a business model canvas can be filled initially. The profile for the Mobile Telemedicine Bus, for example, states that problems with the energy and information infrastructure are to be solved by an emergency power generator and a satellite antenna. This results in the functional hierarchy of the functions "Provide energy" and "Receive signals" as well as the corresponding solution elements "Emergency power generator" and "Directional antenna". Different aspects of the business model can also be derived from the idea. For customer acquisition, for example, the network of the Egypt Diabetes Foundation will be used, resulting in its classification as a key partner in the business model. As a rule, there are no comprehensive product and business model concepts available at this point, so it is necessary to refine the existing concept further. For this purpose, the usual methods of product and business model development are used.
Before the final selection of a concept, it is necessary to check whether the assumptions from the analysis of the environment have changed as a result of the concept. In addition, the analyses carried out there will be adapted and expanded. If new challenges arise, the respective solution concept must be adapted accordingly. In our example, three solution concepts achieved this maturity: the "Telemedicine Bus", a "Communal Internet Workstation with Telemedicine Interface", and a "Function-integrated Telemedicine Smartphone". The final selection of a solution concept is based on a bubble chart with the three dimensions fit to the environment, fit to the company and economic efficiency (Figure 8). These are explained below.

- Fit to the environment: It is checked whether the idea solves the identified problems (fit to the boundary conditions). In addition, it is determined whether the customer needs are met (fit to the customer needs).

- Fit to the company: An important criterion is the corporate strategy (fit to the corporate strategy). In addition, it is examined whether the idea can be realized

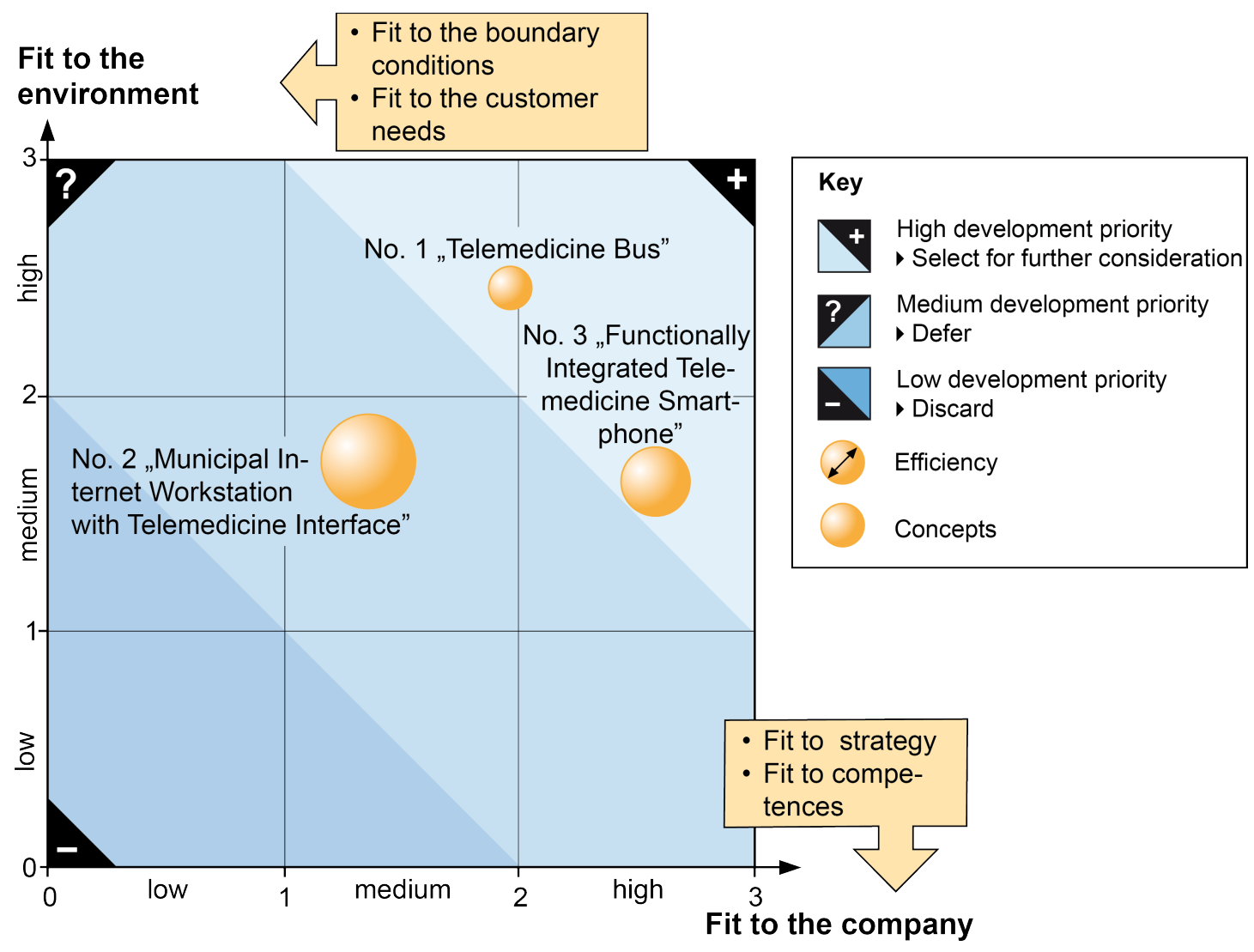

Figure 8. Bubble chart for selecting a promising frugal innovation concept (Lehner, 2016) 


\title{
Approach for a Pattern-Based Development of Frugal Innovations
}

\author{
Anne-Christin Lehner, Christian Koldewey, and Jürgen Gausemeier
}

with the company's competences (fit to the competences).

- Economic efficiency: On the basis of the information available at this time, an initial economic efficiency assessment can be carried out. Its results allow a rough evaluation of the economic efficiency.

The further development priority of a concept increases in the diagonal from bottom left to top right in the bubble chart. Accordingly, ideas should be selected for further development that lie as high as possible in the upper right-hand corner of the chart and are as economical as possible. In the present case, the company selected the concept of the "Telemedicine Bus". The next steps follow the usual procedure for developing market services.

\section{Conclusion}

Markets in developing and emerging countries are becoming increasingly important as the prosperity of the global middle-class increases. However, they demand products that are adapted to the local needs of the population. Frugal innovation offers companies from industrialized countries an excellent opportunity to participate in this development. The method presented gives them a guideline to plan frugal innovations. It is particularly suitable for more complex market services with a high adaptation effort. However, key success factors in the various stages of the value chain must be taken into account (Roland Berger Strategy Consultants, 2013):

- Market analysis: A comprehensive understanding of the customer must be established and, in particular, the willingness of customers to pay. It is just as important to determine what the customer does not want to pay for. In addition, an early analysis of competitor products is of outstanding importance.

- Development: Market-oriented research and development is leading the way in developing market services that address local customer needs. In addition, it is evident that interdisciplinary teams offer a significant advantage here.

- Purchasing and the value chain: Frugal innovations are particularly successful when local suppliers are integrated into the value chain. Flexibility with regard to the existing specifications is also advantageous.
- Marketing and sales: Innovative sales concepts are necessary to reach the targeted customer groups.

Given that the pattern approach is already used in many disciplines, its application to the frugal innovation process seemed very promising. By developing the pattern system, we validated that frugal innovation patterns exist. Furthermore, by introducing and utilizing a pattern-based frugal innovation process, we showed that the pattern approach can be used to develop frugal products and business models. But still, like Hossain and co-authors (2017), we find that there is a lack of conceptual and managerial understanding of frugal innovation. Future research should focus on the enhancement of the pattern system to strengthen the understanding of problems and solutions of frugal innovation. Furthermore, research should focus on frugal innovation strategies. This should comprise the analysis of cannibalization effects, cooperation planning, and brand strategy. For this specific approach, a software tool should be programmed to facilitate the application of the innovation process.

For the practitioners, the article at hand shows an approach to design their own innovation process integrating solution patterns as well as how to generate a frugal innovation pattern system to acquire and store knowledge about frugal innovations. This seems highly promising given that the different problems companies face developing frugal innovations share similarities. That is why we expect a pattern-based search to generate comparable solutions that are both fruitful and frugal. To apply the approach in practice, companies should form an interdisciplinary team of experts from all departments concerned. Their work should be discussed in regular consultations and joint workshops in order to avoid bias. After each phase, management should review the results and decide on the further progress of the project. This ensures that decisions are made transparently and comprehensibly and without bias.

\section{Acknowledgements}

A shorter, German-language version of this article is part of the upcoming book by J. Gausemeier and colleagues: Innovationen für die Märkte von morgen Strategische Planung von Produkten, Dienstleistungen und Geschäftsmodellen (Innovations for the Markets of the Future - Strategic Planning of Products, Services and Business Models). 


\section{Approach for a Pattern-Based Development of Frugal Innovations}

\section{Anne-Christin Lehner, Christian Koldewey, and Jürgen Gausemeier}

\section{About the Authors}

Anne-Christin Lehner (Dr.-Ing.) is employed by Hella GmbH \& Co. KGaA in the field of Operations Strategy \& Capacity Planning. She studied Industrial Engineering with a focus on Electrical Engineering at the University of Paderborn, Germany, and the University of Ottawa, Canada. Until 2016, Anne-Christin was a Research Associate of Professor Gausemeier at the Heinz Nixdorf Institute of the University of Paderborn. Her main focus was on strategic planning and innovation management.

Christian Koldewey (M.Sc.) is a Research Associate at the Heinz Nixdorf Institute of the University of Paderborn, Germany. He works in the team strategic planning and innovation management within the working group strategic product planning and systems engineering at the chair of Professor Gausemeier. His research topics are digital service innovation, business and diversification strategy as well as business model generation. Previously, he studied Mechanical Engineering with a focus on manufacturing technology at the University of Paderborn and the Bielefeld University of Applied Science in Germany.

Jürgen Gausemeier (Prof. Dr.-Ing.) is a Senior Professor at the Heinz Nixdorf Institute of the University of Paderborn, Germany, and is Chairman of the Board of the Leading Edge Cluster "Intelligente Technische Systeme Ostwestfalen-Lippe (it's OWL)", which was initiated by the Federal Ministry of Education and Research. He was speaker of the Collaborative Research Centre 614 "Self-Optimizing Concepts and Structures in Mechanical Engineering" and member of the German Council of Science and Humanities from 2009 until 2015. Jürgen is Initiator and Chairman of the Supervisory Board of the consulting company UNITY AG. Since 2003, he has been a member of "acatech - German Academy of Science and Engineering" and, since 2012, has been its Vice President. In 2014, Jürgen received the Medal of Honor from the academic society "Wissenschaftliche Gesellschaft für Produktentstehung (WiGeP)".

Citation: Lehner, A.-C., Koldewey, C., \& Gausemeier, J. 2018. Approach for a Pattern-Based Development of

Frugal Innovations. Technology Innovation

Management Review, 8(4): 14-27.

http://doi.org/10.22215/timreview/1149

Keywords: frugal innovations, emerging markets, patterns, business model, products and services

\section{References}

Alexander, C., Ishikawa, S., Silverstein, M., Jacobson, M., King, I. F., \& Angel, S. 1995. Eine Muster-Sprache: Städte Gebäude Konstruktion. Vienna: Löckler.

Amshoff, B., Dülme, C., Echterfeld, J., \& Gausemeier, J. 2014. Geschäftsmodellmuster für disruptive Technologien. Berlin: Gausemeier, J.: Vorausschau und Technologieplanung. 10. Symposium für Vorausschau und Technologieplanung, November 20-21, 2014, HNI-Verlagsschriftenreihe, Band 334, Paderborn: $165-190$.

Basu, R. R., Banerjee, P. M., \& Sweeny, E. G. 2013. Frugal Innovation: Core Competencies to Address Global Sustainability. The Journal of Management for Global Sustainability, 1(2): 63-82. http://dx.doi.org/10.13185/JM2013.01204

Bhatti, Y. 2012. What Is Frugal, What Is Innovation? - Towards a Theory of Frugal innovation. Oxford: Said Business School Working Paper Series.

Bhatti, Y., \& Ventresca, M. 2013. How Can 'Frugal Innovation' Be Conceptualized? Oxford: Said Business School Working Paper Series.

Bieger, T., \& Reinhold, S. 2011. Das wertbasierte Geschäftsmodell ein aktualisierter Strukturansatz. In T. Bieger, D. zu KnyphausenAufseß, \& C. Krys (Eds.), Innovative Geschäftsmodelle: Konzeptionelle Grundlagen, Gestaltungsfelder und unternehmerische Praxis: 11-70. Berlin: Springer.

Blessing, L. T. M., \& Chakrabarti, A. 2009. DRM, a Design Research Methodology. London: Springer-Verlag.

Bound, K., \& Thornton, I. 2012. Our Frugal Future - Lessons from India's Innovation System. London: Nesta.

Bower, J. L., \& Christensen, C. M. 1995. Disruptive Technologies Catching the Wave. Harvard Business Review, 72(1): 43-53.

Buschmann, F., Meunier, R., Rohnert, H., Sommerlad, P., \& Stal, M. 2000. Pattern-orientierte Softwarearchitektur: Ein Pattern-System. Bonn: Addison-Wesley.

Capasso, A., Dagnino, G. B., \& Tienari, J. 2013. Resource Constrained Innovation at the Bottom of the Pyramid - Towards a Theoretical Framework. Paper presented at the AIDEA Bicentenary Conference, Bologna, Italy, September 19-21, 2013.

Corfman, R. 1998. An Overview of Patterns. In L. Rising (Ed.), The Patterns Handbook: Techniques, Strategies, and Applications: 19-30. Cambridge: Cambridge University Press.

Eagar, R., van Oene, F., Boulton, C., Roos, D., \& Dekeyser, C. 2011. The Future of Innovation Management - The Next 10 Years. Prism, 1: 21-37.

The Economist. 2010. First Break All the Rules: The Charms of Frugal Innovation. The Economist, April 15, 2010. Accessed April 11, 2018: https://www.economist.com/node/15879359

Ernst, H., Prabhu, J., \& Kahle, H. N. 2013. Base of the Pyramid Innovations - Results of a Research Study. Cambridge: WHU University, Cambridge Judge Business School.

Gausemeier, J., \& Wiendahl, H.-P. 2011. Hebel zur Gestaltung von Produktentstehung, Produktion und Wertschöpfung in Deutschland - Zusammenfassung und Schlussfolgerungen. In J. Gausemeier, \& H.-P. Wiendahl (Eds.), Wertschöpfung und Beschäftigung in Deutschland: 103-108. Berlin: Springer. 


\section{Approach for a Pattern-Based Development of Frugal Innovations}

\section{Anne-Christin Lehner, Christian Koldewey, and Jürgen Gausemeier}

Govindarajan, V., \& Trimble, C. 2012. Reverse Innovation: Create Far From Home, Win Everywhere. Watertown: Harvard Business Review Press.

Heeks, R., Amalia, M., Kintu, R., \& Shah, N. 2013. Inclusive Innovation: Definition, Conceptualisation and Future Research Priorities. Working Paper No. 53. Manchester, UK: Centre for Development Informatics, University of Manchester.

The Heritage Foundation. 2015. Index of Economic Freedom. The Heritage Foundation. Accessed October 12, 2015: http://www.heritage.org/index/ranking

Hilmi, M. F. 2012. Grassroots Innovation from the Bottom of the Pyramid. Current Opinion in Creativity, Innovation and Entrepreneurship, 1(2).

http://dx.doi.org/10.11565/cuocient.vli2.5

Högl, M., \& Weiss, M. 2014. Innovationen in Schwellen- und Entwicklungsländern: Eine Diskussion wichtiger Forschungsfragen. In C. Schultz \& K. Hölzle (Eds.), Motoren der Innovation: Zukunftsperspektiven der Innovationsforschung: 81-96. Wiesbaden: Springer Gabler.

Hossain, M. 2016. Frugal Innovation: A Systematic Literature Review. Available at SSRN:

http://dx.doi.org/10.2139/ssrn.2768254

Hossain, M., Levänen, J., Lindeman, S., \& Wierenga, M. 2017. Frugal Innovation Process: Comparing between Grassroots and Elite Contexts. Paper presented at the 2017 R\&D Management Conference, Leuven, Belgium, July 1-5, 2017.

Hyvärinen, A., Keskinen, M., \& Varis, O. 2016. Potential and Pitfalls of Frugal innovation in the Water Sector: Insights from Tanzania to Global Value Chains. Sustainability, 8(9): 888. https://doi.org/10.3390/su8090888

Kao, H., \& Lee, J. 2010. The Application of Shanzhai Innovation Model in China: The Examples of Mobile Phone, Notebook Computer and Automobile. Paper presented at the Summer Conference on Opening Up Innovation - Strategy, Organization and Technology, Imperial College London Business School, June 16-18, 2010.

Kohl, C., \& Wedekind, J. 2011. Investigations of E-Learning Patterns: Context Factors, Problems, and Solutions. New York: Information Science Reference.

Lehner, A.-C. 2016. Systematik zur lösungsmusterbasierten Entwicklung von Frugal innovations. Paderborn: HNIVerlagsschriftenreihe.

Lehner, A.-C., \& Gausemeier, J. 2015. A Pattern-Based Approach to the Development of Frugal innovations. In Proceedings of the International Society for Professional Innovation Management (ISPIM) Summit, Brisbane, Australia, December 6-9, 2015.

Lehner, A.-C., \& Gausemeier, J. 2016. A Pattern-Based Approach to the Development of Frugal Innovations. Technology Innovation Management Review, 6(3): 13-21.

http://timreview.ca/article/971

Lehner, A.-C., Gausemeier, J., \& Röltgen, D. 2015. Nutzung von Lösungsmustern bei der Entwicklung von Frugal Innovations. In J. Gausemeier (Ed.), Vorausschau und Technologieplanung. 11. Symposium for Foresight and Technology Planning, 347: 11-37. Paderborn: HNI-Verlagsschriftenreihe.

McKinsey Global Institute. 2015. Playing to Win: The New Global Competition for Corporate Profits. New York: McKinsey \& Company.
Mundim, A., Sharma, M., Arora, P., \& McManus, R. 2012. EmergingMarkets Product Development and Innovation: The New Competitive Reality. Chicago, IL: Accenture.

Nijhof, A., Fischer, O., \& Looise, J. K. 2002. Inclusive Innovation: A Research Project on the Inclusion of Social Responsibility. Corporate Social Responsibility and Environmental Management, 9(2): 83-90. https://doi.org/10.1002/csr.10

Prahalad, C. K., \& Mashelkar, R. A. 2010. Innovation's Holy Grail. Harvard Business Review, 88(7/8): 132-141.

Radjou, N., Prabhu, J., \& Ahuja, S. 2012. Jugaad Innovation - Think Frugal, Be Flexible, Generate Breakthrough Growth. San Francisco: Jossey-Bass.

Ray, P., \& Ray, S. 2010. Resource-Constrained Innovation for Emerging Economies: The Case of the Indian Telecommunications Industry. IEEE Transactions on Engineering Management, 57(1): 144-156.

https://doi.org/10.1109/TEM.2009.2033044

Ravallion, M. 2009. The Developing World's Bulging (But Vulnerable) "Middle Class". Washington, DC: The World Bank Development Research Group.

Roland Berger Strategy Consultants. 2013. Frugal Products - Study Results. Munich: Roland Berger Strategy Consultants.

Roland Berger Strategy Consultants. 2015. Simply the Best - Frugal Products Are Not Just for Emerging Markets: How to Profit from Servicing New Customer Needs. Munich: Roland Berger Strategy Consultants.

Seyfang, G., \& Smith, A. 2007. Grassroots Innovations for Sustainable Development: Towards a New Research and Policy Agenda. Environmental Politics, 16(4): 584-603. https://doi.org/10.1080/09644010701419121

Shivaraman, S., Mathur, M., \& Kidambi, R. 2012. Frugal ReEngineering - Innovatively Cutting Product Costs. Chicago: A.T. Kearney.

Tiwari, R., \& Herstatt, C. 2012. Open Global Innovation Networks as Enablers of Frugal innovation: Propositions Based on Evidence from India. Working Paper No. 72. Hamburg, Germany: Hamburg University of Technology.

Tiwari, R., \& Herstatt, C. 2013. Innovieren für preisbewusste Kunden: Analogieeinsatz als Erfolgsfaktor in Schwellenländern. Working Paper No. 75. Hamburg, Germany: Hamburg University of Technology.

Tiwari, R., \& Herstatt, C. 2014. Aiming Big with Small Cars: Emergence of a Lead Market in India. Berlin: Springer.

Universe Foundation. 2013. Frugal Innovation - A Manual. Sondeborg, Denmark: Universe Foundation.

Williamson, P. J. 2010. Cost Innovation: Preparing for a 'Value-forMoney’ Revolution. Long Range Planning, 43(2-3): 343-353. https://doi.org/10.1016/j.lrp.2009.07.008

Zeschky, M., Widenmayer, B., \& Gassmann, O. 2011. Frugal innovation in Emerging Markets. Research Technology Management, 54(4): 38-45. https://doi.org/10.5437/08956308X5404007

Zimmer, W. 1995. Relationships between Design Patterns. In J. Coplien \& D. Schmidt, D. (Eds.), Pattern Languages of Program Design:345-364. Reading, MA: Addison-Wesley. 


\title{
Patterns of Frugal Innovation in Healthcare Hareem Arshad, Marija Radić, and Dubravko Radić
}

\author{
"Any intelligent fool can make things bigger," \\ more complex, and more violent. It takes a touch \\ of genius - and a lot of courage to move in the \\ opposite direction.
}

\author{
E. F. Schumacher (1911-1977) \\ Economist and author \\ In Small Is Beautiful (1973)
}

\begin{abstract}
Frugal innovations have the potential to offer simple and cost-effective solutions to the healthcare challenges of the world. However, despite the potential for frugal innovations in healthcare, this context has been rarely studied. The objective of this article is to shed some light on patterns of frugal innovations in healthcare and thereby contribute to the literature. With this aim, we conducted a comprehensive literature review and searched for innovations that were labelled as frugal and were related to healthcare. This led us to a sample of 50 frugal innovations in the healthcare sector. For each of the 50 selected examples, we examined various characteristics of the innovation, such as the country of origin, first launch market, type of innovator, type of innovation, type of care, and geographic diffusion. Our findings show that most of the frugal innovations originated in the United States, followed by India. The most frequent first launch market was India. In terms of types of innovators, academia seemed to be the strongest driver. Most frugal innovations are product innovations in the fields of neonatology and general practice. In this article, we expand on these findings and examine the relationships between individual variables to reveal further insights. Finally, we offer conclusions, an outlook for frugal innovation in the healthcare sector, and future research questions.
\end{abstract}

\section{Introduction}

The philosophy behind the development of frugal innovation has been described as "instead of adding more bells and whistles, they strip their products down to their bare essentials" (The Economist, 2010). Various researchers have since tried to define frugal innovation and differentiate the term from similar terms such as low-cost innovation, good-enough innovation, jugaad innovation, frugal engineering, constraintbased innovation, Gandhian innovation, or reverse innovation (e.g., Bhatti and Ventresca, 2013; Brem \& Wolfram, 2014; Ostraszewska \& Tylec, 2015; Zeschky et al., 2014). Weyrauch and Herstatt (2016) have analyzed various definitions and recommend that an innovation should be considered as frugal if it meets the following relevant criteria: a substantial reduction of cost, the concentration on core functionalities, and optimized performance levels.
Frugal innovations have been adopted in a wide range of industries including automotive, energy, information and communication technology, and healthcare. One of the most prominent products is certainly the TATA Nano, introduced in 2009 as the world's cheapest family car created for the needs of Indian and Chinese families at a remarkable cost of only \$2000 USD (Prahalad, 2012). Other examples of frugal innovation in other sectors include the Mitticool refrigerator, a natural refrigerator made entirely from clay, and GE Healthcare's high-efficiency Lullaby baby warmer for neonatal care. In each case, the frugal innovations in these examples were developed for the needs of emerging economies.

Researchers in the field of frugal innovation have predominantly explored the differences and similarities of frugal innovation with respect to other types of innovation (Brem \& Wolfram, 2014; Landrum, 2007; Weyrauch \& Herstatt, 2016; Zeschky et al., 2014). Others have con- 


\title{
Patterns of Frugal Innovation in Healthcare
}

\author{
Hareem Arshad, Marija Radić, and Dubravko Radić
}

ducted case studies that discuss the relationship between frugal innovation and sustainability (Kahle et al., 2013; Pansera \& Sarkar, 2016; Rosca et al., 2016; Tiwari et al., 2016) or the importance of frugal innovation for the competitiveness of multinational corporations (Agarwal \& Brem, 2012; Anderson \& Markides, 2007; Tiwari \& Herstatt, 2012). Only a limited number of studies have focused on the potential of frugal innovation to improve global health and primarily conduct case studies on singular frugal innovations (e.g., Ramdorai \& Herstatt, 2015).

Access to healthcare and wellbeing is a human right. Despite the progress that has been made worldwide in recent years to improve healthcare access and wellbeing, inequalities in healthcare still continue to exist (UN, 2015). For example, fifty percent of women in developing regions do not have access to adequate healthcare services; every year six million children die before reaching the age of five, and epidemics such as HIV/AIDS "thrive where fear and discrimination limit people's ability to receive the services they need to live healthy and productive lives" (UN, 2015). So, despite some global progress, health is still a major issue worldwide. Indeed, the United Nations has proclaimed that "ensuring healthy lives and promoting the wellbeing for all at all ages is essential to sustainable development" and has made this issue the third of its " 17 goals to transform our world" (UN, 2015).

In our view, frugal innovations have the potential to contribute to the achievement of this goal. Thus, the aim of this article is to shed more light on possible patterns of frugal innovation in healthcare by taking a closer look at 50 examples of frugal innovation in this sector. The article is structured as follows. In the next section, we provide the theoretical background. We then describe the methodology and findings of our empirical study. Finally, we close with a conclusion on the outlook for frugal innovation in healthcare, discuss potential limitations of our study, and provide recommendations for further research.

\section{Theoretical Background}

Frugal innovations have the potential to contribute to achieving sustainable development goals. Several studies highlighting the link between frugal innovation and sustainability often outline prominent healthcare examples such as Aravind Eye Care Systems or Narayana Hrudayalaya (e.g., Allen et al., 2016; Basu et al., 2013; Hossain, 2016; Kahle et al., 2013; Oppong, 2015; Rosca et al., 2016; Sarangi et al., 2014; Tiwari \& Herstatt, 2012).
Kahle and colleagues (2013) provide support for the notion that the creation of more inclusive markets through frugal innovation contributes to socioeconomic development, which in turn strengthens democratization and state building. The authors also point out that multinational corporations can have a positive impact on democratization by offering for-profit products and services to serve bottom-of-the-pyramid (BOP) markets.

The bottom of the pyramid is an untapped market of more than four billion people worldwide living their lives on less than two US dollars per day (Prahalad, 2004). The management thinker Prahalad and his colleagues initiated the BOP market approach more than two decades after E.F. Schumacher's movement of "appropriate technologies" as a development approach based on technology to address socioeconomic challenges in developing countries (Schumacher, 1973). They argued for market-based solutions for poverty by including billions of people in the formal economy (Prahalad \& Lieberthal, 1998). Addressing these markets would require "radical innovations in technology and business models" (Prahalad \& Hart, 2002; Ramdorai \& Herstatt, 2015; Prahalad \& Lieberthal, 1998). They presented several frugal low-cost innovations from emerging markets that provide essential functionality and fit to the local needs (Prahalad, 2004; Prahalad \& Hammond, 2002). This exposure to the concept created immense interest in academia and industry.

Despite the importance of frugal innovations in improving global health, the literature on frugal innovation in healthcare is rather scarce and consists mostly of case studies (Hossain, 2016). As mentioned above, prominent cases of frugal innovation in healthcare are the Aravind Eye Care System (Clyde, 2005) and Narayana Hrudayalaya (Khanna et al., 2005). The Aravind Eye Care System is a network of ophthalmology hospitals that treats most of its patients for free or at a subsidized rate and still is economically viable due to its ability to decrease cost dramatically through innovation. A similar example - also from India - is Narayana Hrudayalaya, which provides quality cardiological services to the poor. While both approaches have a process and product innovation at their core, there are also multiple examples of product innovations from multinational corporations. GE Healthcare has been very active in developing healthcare products for the BOP market, including the Lullaby and Embrace low-cost infant warmers or the MAC electrocardiogram series priced at only a fraction of the products sold in industrialized countries (Ramdorai \& Herstatt, 2015). 


\title{
Patterns of Frugal Innovation in Healthcare
}

\author{
Hareem Arshad, Marija Radić, and Dubravko Radić
}

With this study, we try to shed more light on patterns of frugal innovations in healthcare by studying a variety of frugal innovations with respect to their innovation characteristics. This effort brings out the features of these innovations and further highlights the potential of frugal innovation to improve global health.

\section{Empirical Analysis}

To identify examples of frugal innovation in healthcare, a comprehensive literature review using five databases (Cochrane, EBSCO, Google Scholar, Scopus, and Web of Science) and following the PRISMA approach was conducted between August 2016 and March 2017 (PRISMA, 2018). We used the two search strings "frugal innovations in healthcare" and "frugal innovation AND healthcare." The English search terms bear a risk of creating, first, a bias towards frugal innovations from industrialized countries and, second, a bias towards frugal innovations from multinational corporations and academia compared to grassroots entrepreneurs from emerging or developing countries. Despite these limitations, our study should still shed light on the current scarcity of literature on frugal innovations in healthcare. We only included cases that fulfill the criteria of frugality as defined in the introduction above. If sufficient information about an innovation and its frugality could not be found, it was discarded. In total, 45 examples were discarded based on the above-mentioned criteria and 50 frugal innovations were selected for the study. For these 50 innovations, we retrieved information on different innovation characteristics. We explored the country of origin, first launch market, type of innovator, type of innovation, medical specialty, WHO healthcare and essential health services coverage categories, and geographic diffusion measured as the number of countries the innovation is distributed to. Information on each variable was gathered through an Internet search for the innovation or on the innovator's website, publications, or news articles describing the innovation. We then analyzed the variables across the 50 cases as well as the relationships between variables using contingency tables. Due to the small sample size, we report descriptive results only.

Entrepreneur's country of origin and first launch market The country of origin is usually associated with the country where a product is produced or made. In order to differentiate the country of origin - specifically with respect to multinational companies - we differentiate between the entrepreneur's country of origin and the first launch market. The entrepreneur's country of origin is thus defined as the country where the entrepren- eur is from or was originally founded (e.g., in the case of GE the United States). We also segment the results into continents and according to the International Monetary Fund's classification into either advanced or emerging and developing economies (IMF, 2017).

For 21 out of 50 frugal healthcare innovations, the entrepreneur's country of origin was the United States, whereas India and the Netherlands represented 7 and 5 out of 50 innovations (Figure 1). Looking at continents, exactly half of the frugal innovations' entrepreneurs were from North America, followed by Europe with 12 out of 50 innovations. Three quarters of frugal healthcare innovation entrepreneurs in our sample (38 out of 50 ) thus have their origin in the industrialized countries of the world.

We define the first launch market as the country where the product or service was first launched. Similarly, we segment first launch markets by continent and country classification. As shown in Figure 2, the most popular launch market for healthcare innovations is India, where about a quarter (12 of 50) of the healthcare innovations were first launched. The United States was second with nine launches. As expected, the majority of products were first launched in emerging and developing economies, most of them in Africa (18) and in Asia (15).

\section{Type of innovator and type of innovation}

We differentiated the types of innovators into five different categories: grassroots entrepreneurs, small and medium-sized enterprises (SMEs), multinational companies (MNCs), research/academia, and non-governmental organizations (NGOs). We chose these categories on the one hand to account for the types of innovators that are mentioned in the frugal innovation literature. On the other hand, we chose them to account for the drastically changed innovation process of the 21st century that can be resumed in a shift from a "managed economy" to an "entrepreneurial economy" where small and new firms gain in importance (Audretsch \& Thurik, 2004; OECD, 2010; Thurik, 2009). Figure 3 shows that research is the most active innovator type with over $40 \%$ of innovations, followed by MNCs and grassroots entrepreneurs with around 25\% of innovations respectively. The three groups account for over $90 \%$ of all frugal healthcare innovations. NGOs and SMEs play a secondary role in our sample.

To determine the types of innovation, we use the classification from the OECD's Oslo Manual for innovation, which distinguishes between four types of innovations: 


\section{Patterns of Frugal Innovation in Healthcare}

Hareem Arshad, Marija Radić, and Dubravko Radić

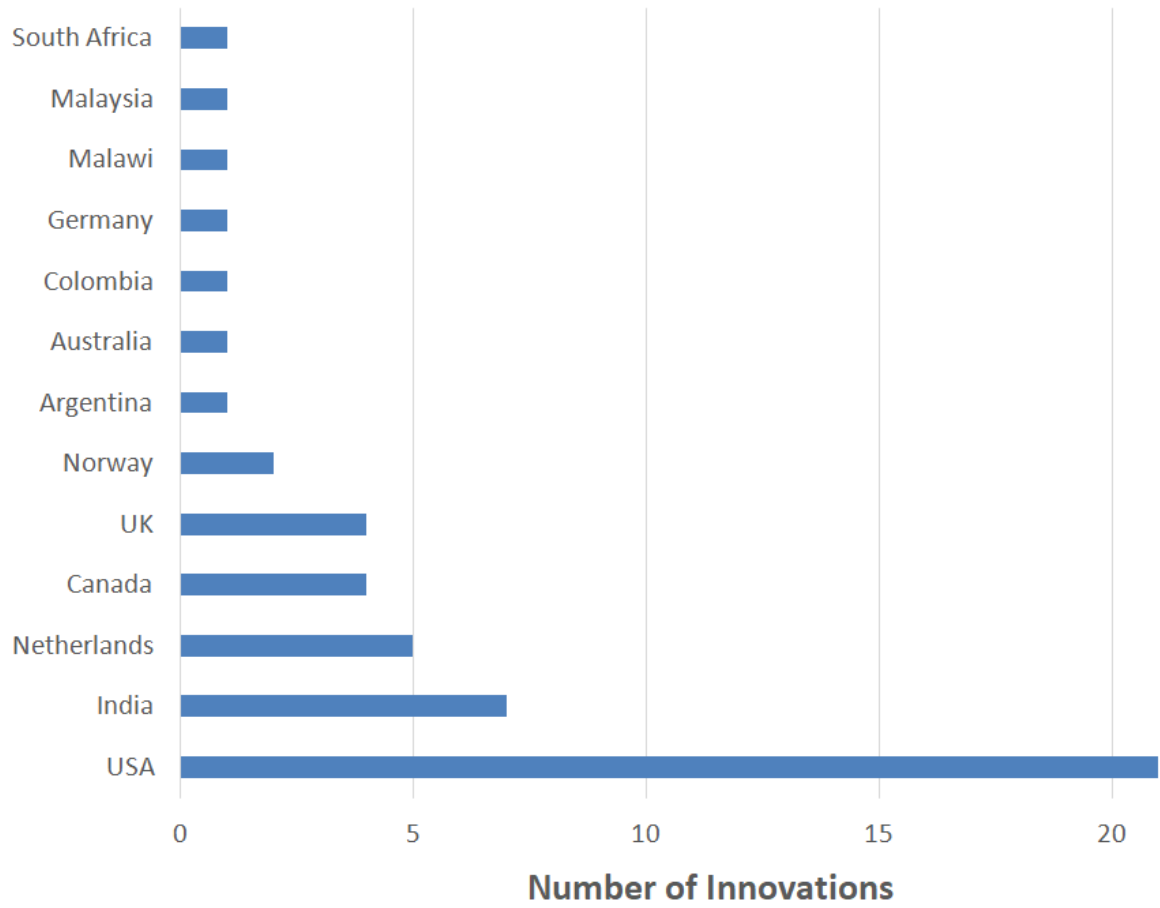

Figure 1. Number of innovations by innovators' countries of origin

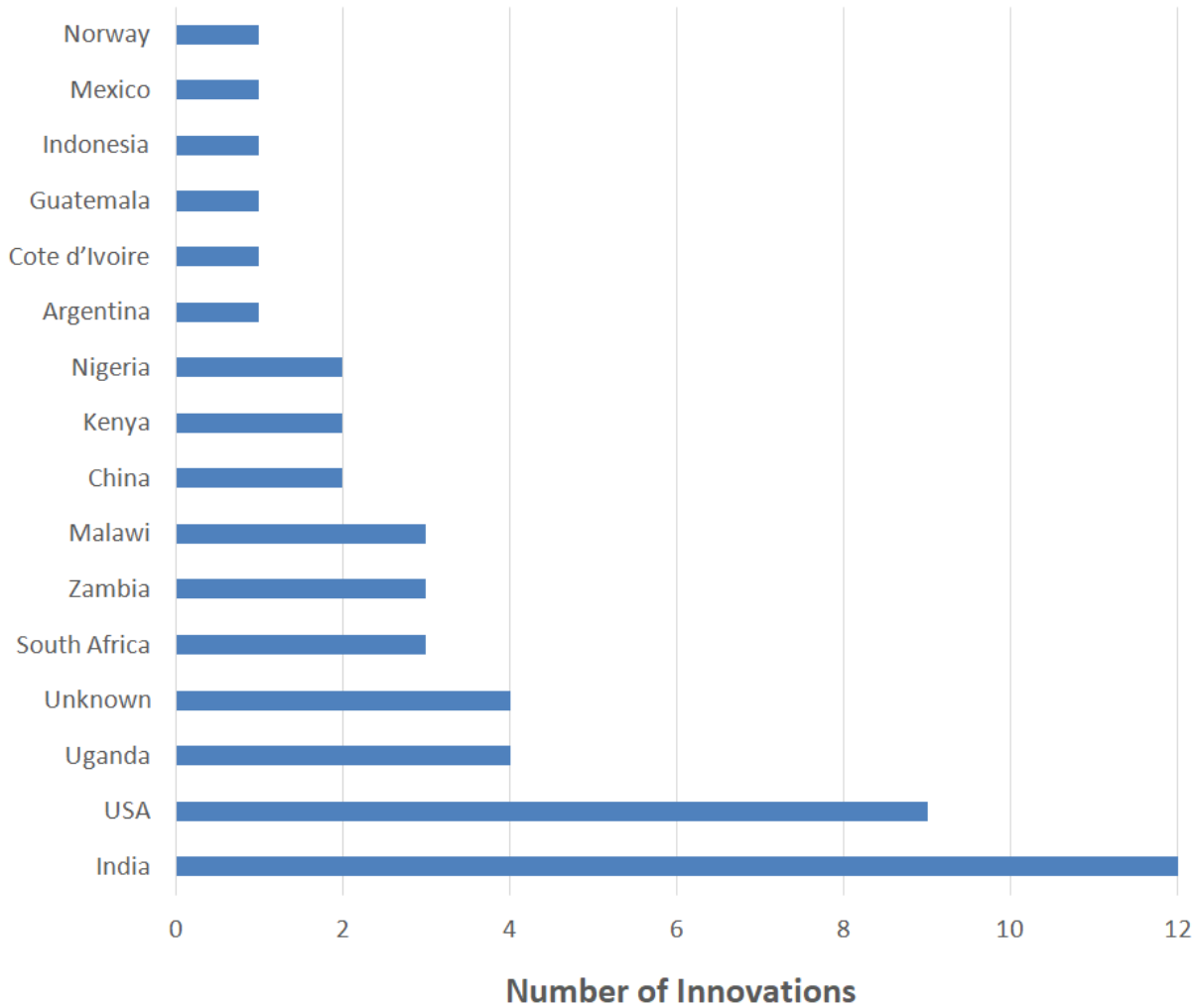

Figure 2. Number of innovations by first launch market 


\section{Patterns of Frugal Innovation in Healthcare}

\section{Hareem Arshad, Marija Radić, and Dubravko Radić}

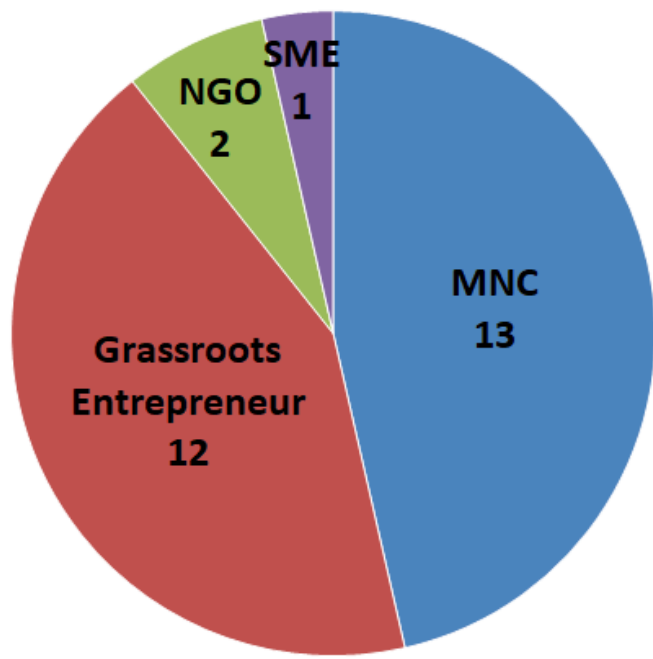

Figure 3. Number of innovations by type of innovator

product, process, marketing, and organizational (OECD, 2005). Figure 4 shows that $76 \%$ of the innovations are product innovations. Nine frugal innovations $(18 \%)$ are process innovations, and three are both product and process innovations (e.g., Kit Yamoyo).We found no marketing and organizational innovations, which is not surprising due to the fact that these tend not to be commercialized.

\section{Medical specialty and WHO healthcare categories}

We also looked into the medical specialty of the frugal innovation (European Parliament and Council, 2005). Overall, the frugal innovations target a wide range of specialties: allergy and immunology, anesthesiology, audiology, cardiology, endocrinology, gastroenterology, general practice, gynecology, medical oncology, neonatology, ophthalmology, orthopedics, otolaryngology, pediatric pulmonology, and radiology (Figure 5). The two most frequent specialties are neonatology and general practice with 11 innovations each, which in part might be driven by funding opportunities from large granting agencies and non-profit organizations. Innovations for general practice include the water purifier Tata Swach, a frugal thermometer (from Leiden University, TU Delft, and Erasmus University), and a portable ventilator (small size, ease of use, and low cost) from Philips. Many innovations are also in the field of orthopedics, including prosthetics such as the Jaipur foot, a rubber-based artificial limb, and Cyborg Beast, a 3Dprinted hand prosthetic.

The WHO tracks progress towards universal health coverage around the world. Universal health coverage

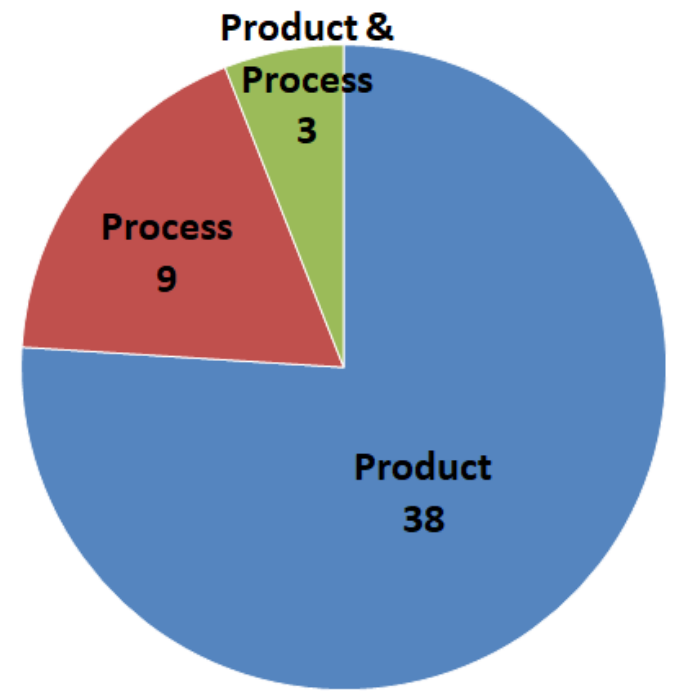

Figure 4. Innovations by type of innovation

means that "all people and communities can use the promotive, preventative, curative, rehabilitative and palliative health services they need" without exposing them to financial hardship (WHO, 2017). We use this classification of health services to analyze which parts of the health continuum are addressed by our sample of frugal innovations (Figure 6). Half of the innovations, and thus the majority, are of preventative character (e.g., Tata Swach). Another third of the frugal innovations are curative (e.g., Kit Yamoyo). Three are rehabilitative (e.g., the Jaipur foot). Six innovations are classified as enablers. A number of frugal innovations, such as bicycle ambulances, allow better access but are not adequately reflected by the categorization, which is why we added a new category and classified them as enablers.

\section{Geographic diffusion}

Finally, we tried to assess the success of the innovations in our sample by looking at sales numbers or revenues or number of reached persons. Unfortunately, for most innovations these numbers were not available. We thus chose the geographic diffusion as a proxy. Based on the underlying data, we defined the following spans: i) if the innovation is available in one country only, its geographic diffusion is defined as national ii) multinational diffusion describes an innovation that is available in two to five countries; and, finally, iii) worldwide if it is used or commercialized in more than five countries. Over $40 \%$ of innovations have a national focus only (e.g., Kit Yamoyo in Zambia). Almost as many innovations are available in at least five countries, including Embrace, Foldscope, and the Jaipur foot. Eleven innovations have a multinational geographic diffusion. 


\section{Patterns of Frugal Innovation in Healthcare}

Hareem Arshad, Marija Radić, and Dubravko Radić

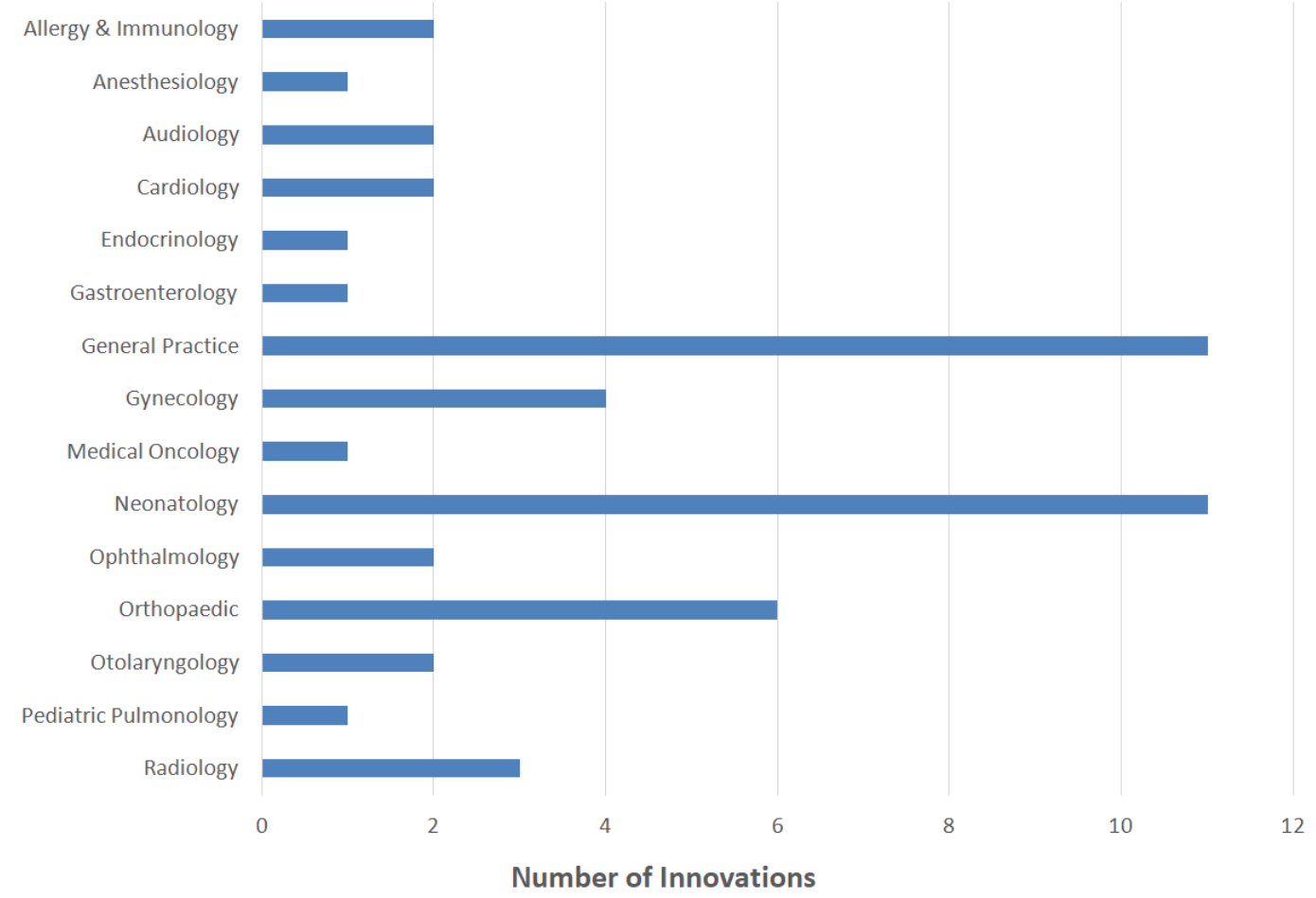

Figure 5. Number of innovations by medical specialty

Type of innovator, entrepreneur's country of origin, and first launch market

Research innovators in our sample are largely from the United States and Canada (15 and 3 out of 22 innovations respectively). About a third of the group of grassroots entrepreneurs are from India. Europe accounts for almost half of all MNC innovations (6 out of 13 innovations), dominated by the two large European healthcare firms Philips and Siemens. Overall, we find that almost $85 \%$ of innovations from MNCs and research are from advanced economies (32 out of 38 innovations) while grassroots entrepreneurs are predominantly from developing countries (7 out of 12 innovations). Research, MNCs, and grassroots entrepreneurs chose developing economies as their first launch market.

\section{Type of innovator and innovation characteristics}

Eleven out of 13 MNC innovations in our sample are product innovations; $70 \%$ have a preventative focus and $30 \%$ a curative focus. Examples are the Tata Swach water purifier or GE Healthcare's ECG device. From a medical specialty perspective, the innovations mostly fall into the categories of neonatology and general practice, which were the most frequent categories in the total sample.

Research also focuses heavily on developing products (20 out of 22 innovations are product innovations). Com-

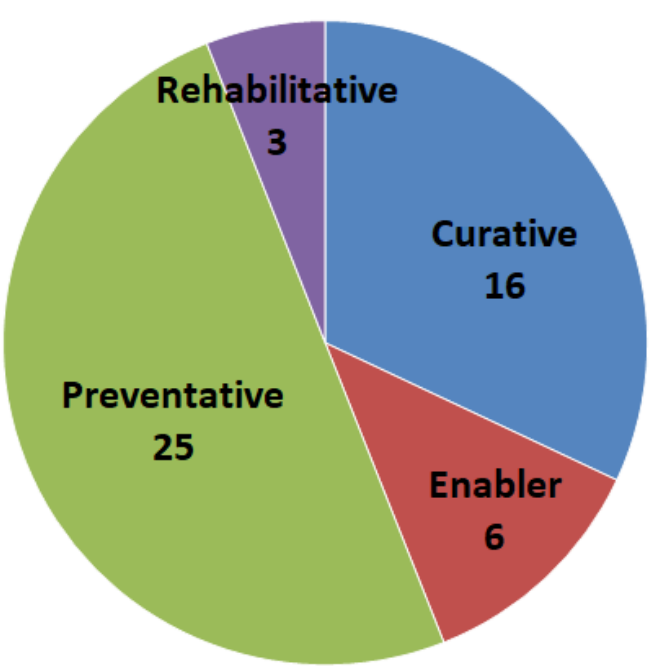

Figure 6. Innovations segmented by WHO healthcare categories

pared to MNCs, research focuses on preventative and curative innovations. More than $77 \%$ of the 22 research innovations fall into these two categories. In terms of medical specialties, the research innovations can be roughly equally attributed to neonatology, general practice, and orthopedics. Research innovations include the Embrace infant warmer and the Cyborg Beast prosthetic. 


\title{
Patterns of Frugal Innovation in Healthcare
}

\author{
Hareem Arshad, Marija Radić, and Dubravko Radić
}

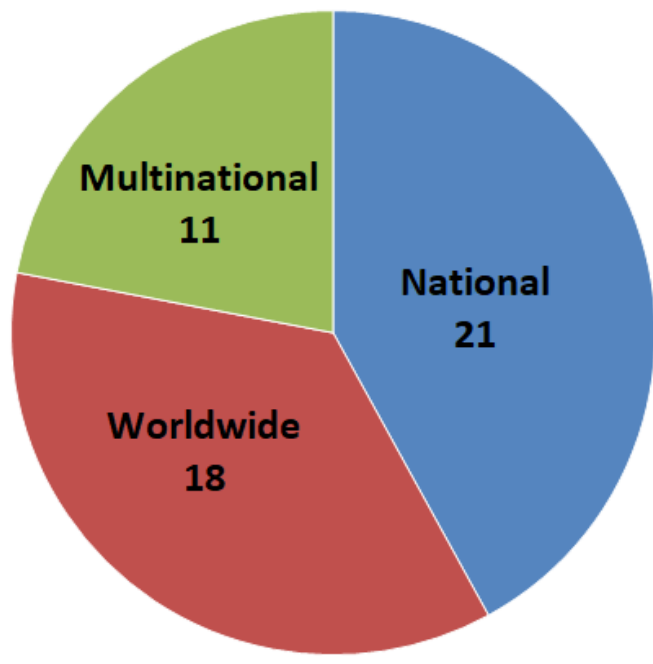

Figure 7. Innovations segmented by geographic diffusion

Looking at the sample of frugal healthcare innovations that are developed by grassroots entrepreneurs, a different picture emerges. Grassroots entrepreneurs developed almost all process or combined process and product innovations in our sample. In contrast to MNCs and research, they also have a stronger focus on curative innovations, followed by the group of enablers and preventative innovations and cover a wide area of medical specialties.

Type of innovator, characteristics of innovation, and geographic diffusion

Our expectation was that the geographic diffusion of MNC innovations would be higher than for other innovators. Indeed, the descriptive statistics show that almost $60 \%$ of grassroots innovations have a national reach only. Another 25\% of grassroots entrepreneurs' innovations are available in a maximum of five countries. In the group of research innovations, $50 \%$ have a national focus only. More than $30 \%$ of innovations in the group of research innovations are available in more than five countries. Finally, over 50\% of MNC innovations are distributed in more than five countries and only $23 \%$ are available in one country only.

We also examined how the characteristics of the frugal healthcare innovation correlate with geographic diffusion. In our sample, product innovations have a larger geographic diffusion than process innovations or combined product and process innovations. Out of 12 innovations that are process or combined process and product innovations, only one is available in more than five countries. On the other hand, two thirds of the larger group of product innovations are available in at least two countries, over $40 \%$ even in five or more countries.

In terms of WHO healthcare categories, we find that two thirds of all innovations that belong to the group of the so-called enablers are predominantly available in one country only. The picture is more balanced for curative and preventative healthcare innovations. The small group of three rehabilitative innovations all have a reach of five and more countries.

\section{Summary and Conclusion}

Despite the relevance of frugal innovations for global health, little research on this topic is available. The objective of this article was to shed more light on this topic and discover patterns of frugal innovations in healthcare. To this aim, we performed a comprehensive literature review and identified 50 frugal healthcare innovations. For these 50 innovations, we retrieved information for different innovation characteristics. We explored the entrepreneur's country of origin, first launch market, type of innovator, type of innovation, medical specialty, WHO healthcare categories, and geographic diffusion. Our analysis showed some expected and some unexpected results.

The majority of frugal healthcare innovation entrepreneurs in our sample have their origin in the industrialized countries of the world, predominantly in North America and Europe. Overall, the majority of innovations were expectedly first launched in emerging and developing economies compared to advanced economies, most of them in Africa and in Asia. The market where most healthcare innovations are first launched is India, followed by the United States where a lot of research innovations are first launched. Academia is overall the most active innovator in our sample with over $40 \%$ of innovations and is dominated by North American stakeholders. These were followed by the group of MNCs, which in our sample contains several companies rooted in Europe and grassroots entrepreneurs with around 25\% percent of innovations. Overall, we find that almost $85 \%$ percent of innovations from MNCs and research are from advanced economies. They thus play a prominent role in achieving the goals of better health and wellbeing worldwide. Three quarters of the innovations are product innovations. Half of the innovations are of preventative character. Another third of the frugal innovations are curative in their nature. Over $40 \%$ of innovations have a limited national diffusion only. Almost as many innovations are available in at least five countries. 


\title{
Patterns of Frugal Innovation in Healthcare
}

\author{
Hareem Arshad, Marija Radić, and Dubravko Radić
}

MNC innovations in our sample are predominantly product innovators with a preventative focus. From a medical specialty perspective, the innovations mostly fall into the categories of neonatology and general practice, which were also the most frequent categories in the total sample. Combined with the fact that MNCs primarily target preventative innovations, this seems to be an indicator that MNCs take a strategic approach and target the most pressing needs in developing countries. MNC innovations have expectedly the highest geographic diffusion. Over $50 \%$ of MNC innovations are distributed in more than five countries and only $23 \%$ percent are available in one country only. Product innovations enable scale-up effects and independence from local ecosystem-specific processes.

In terms of medical specialties, research innovations can be roughly equally attributed to neonatology, general practice, and orthopedics. We found that $50 \%$ of research innovations have a national focus only, and $30 \%$ are available in more than five countries.

Looking at the sample of frugal healthcare innovations that are developed by grassroots entrepreneurs, a different picture emerges. Grassroots entrepreneurs are predominantly from developing countries - especially India, the birthplace of the frugal innovation concept. Grassroots entrepreneurs solve local challenges: they develop almost all process or combined process and product innovations in our sample, which requires indepth knowledge about processes in local ecosystems. In contrast to MNCs and research, they also have a stronger focus on curative innovations, followed by enablers and preventative innovations and covering a wide area of medical specialties. According to our expectations, the geographic diffusion of grassroots entrepreneurs' innovations is lower than for MNC and research innovators. Almost $60 \%$ of grassroots innovations have a national reach only. Another $25 \%$ percent of grassroots entrepreneurs' innovations are available in a maximum of five countries. All these findings coincide with the view that grassroots entrepreneurs target a specific healthcare need in a country or region and try to develop a frugal product or process without necessarily taking an international perspective. Grassroots entrepreneurs may also not have the infrastructure or business expertise to scale up their solutions.

In order to generate a further impact on global health and wellbeing, the development of frugal innovations should be encouraged by companies, academia, inter- national healthcare organizations, and policy makers in both the advanced and developing parts of the world. MNCs have understood the value of local human resources and their frugal mindsets in developing products for the BOP markets and have gone down this road for several years now. Our analysis shows that grassroots entrepreneurs play a significant complementary role for healthcare systems in developing and emerging countries of the world, because they create solutions for punctual, local, and also processual challenges and are not necessarily driven by strategic scalability and profitability motives. This creativity could be further leveraged through initiatives of governments and international organizations, which bring together different types of innovators and disciplines in order to create knowledge spillovers, bring these ideas to other regions and countries, and support grassroots entrepreneurs to scale up their activities. This could create a positive impact in emerging and developing economies but also bring innovative solutions to industrialized countries that struggle with exploding healthcare costs.

Our study has several limitations. First, the small sample size prevented us from doing formal statistical tests. As stated above, the innovations included in the study may also not be representative of the entire frugal innovation landscape because we only examined articles written in English, meaning it may be biased towards innovations from industrialized countries. Innovations were also excluded if not enough information could be found, which increases the bias against innovations from emerging and developing countries that tend not to have an extensive English website or international partners. Finally, our search terms include only the keywords "frugal innovation" and "healthcare" thereby limiting the search and excluding frugal innovations that are not labelled as such or are labelled under related innovation terms such as jugaad innovation or low-cost innovation. A third limitation is the measurement of success of the innovations in our sample. Due to the unavailability of comparable data on, for example, revenues, profits, treated patients, or sold pieces, we approximated the success of an innovation through the variable geographic diffusion, which is a rather weak indicator. All these limitations provide opportunities for further research. Additional areas for research on frugal innovations lie in the fields of adequate business models or success factors for the diffusion of frugal innovations. 


\title{
Patterns of Frugal Innovation in Healthcare
}

\author{
Hareem Arshad, Marija Radić, and Dubravko Radić
}

\section{About the Authors}

Hareem Arshad is a $\mathrm{PhD}$ student at Leipzig University in Germany. She graduated in 2013 with a Master's degree in Business Administration from the Air University in Pakistan. She gained her first professional experience as a guest lecturer at Air University and has been affiliated with the Fraunhofer Center for International Management and Knowledge Economy IMW in Leipzig since 2016. Her research focuses on the areas of service innovation, diffusion of innovation, and frugal innovation in healthcare.

Marija Radić heads the Price and Service Management Group at the Fraunhofer Center for International Management and Knowledge Economy IMW in Leipzig, Germany, and is Deputy Head of the Department for Corporate Development in International Markets. She studied International Economics at the Universities of Tübingen in Germany and Chicago in the United States, and she earned her doctorate at the University of Dortmund in Germany. Prior to joining Fraunhofer IMW, Marija worked as a senior consultant at a renowned international management consultancy in Germany and the United States. As part of this activity, she advised customers from the fields of industry and technology, life sciences, and financial services on pricing, marketing, sales, and strategic issues on a national and international level. In her current role, her research focuses on marketing and strategy aspects of healthcare innovation.

Dubravko Radić holds the Chair of Service Management at Leipzig University, Germany, and is Deputy Head of Price and Service Management at the Fraunhofer Center for International Management and Knowledge Economy IMW. He completed his doctorate at the Department of Statistics and Econometrics at the University of Frankfurt, Germany. For his dissertation on innovation activities of German companies, he was awarded the Gerhard Fuerst Prize of the Federal Statistical Office. After researching at the Graduate School of Management at the University of California, Davis, and Harvard Business School, he completed his habilitation in 2009 on the topic of pricing policy in services at the Bergische Universität Wuppertal (Germany). His research interests include application of empirical methods to business issues, service management issues, and service pricing.

\section{References}

Agarwal, N., \& Brem, A. 2012. Frugal and Reverse Innovation Literature Overview and Case Study Insights from a German MNC in India and China. In Proceedings of the 18th International Conference on Engineering, Technology and Innovation (ICE 2012), Munich, Germany, June 18-20, 2012. https://dx.doi.org/10.1109/ICE.2012.6297683

Allen, L. N., \& Christie, G. P. 2016. The Emergence of Personalized Health Technology. Journal of Medical Internet Research, 18(5): e99.

http://doi.org/10.2196/jmir.5357

Anderson, J., \& Markides, C. 2007. Strategic Innovation at the Base of the Pyramid. MIT Sloan Management Review, 49(1): 83-88.

Audretsch, D., \& Thurik R. 2004. A Model of the Entrepreneurial Economy. International Journal of Entrepreneurship Education, 2(2): 143-166.

Basu, R. R., Banerjee, P. M., \& Sweeny, E. G. 2013. Frugal Innovation: Core Competencies to Address Global Sustainability. The Journal of Management for Global Sustainability, 1(2): 63-82. http://dx.doi.org/10.13185/JM2013.01204

Bhatti, Y., \& Ventresca, M. 2013. How Can 'Frugal Innovation' Be Conceptualized? Oxford: Said Business School Working Paper Series.

Brem, A., \& Wolfram, P. 2014. Research and Development from the Bottom Up - Introduction of Terminologies for New Product Development in Emerging Markets. Journal of Innovation and Entrepreneurship, 3(9): 1-22.

https://doi.org/10.1186/2192-5372-3-9

Clyde, P. 2005. Growing Pains: A Ross School Perspective on the Evolution of the Aravind Eyecare System. Ann Arbor, MI: University of Michigan.

http://www.aravind.org/content/aravindmediapdffiles/journalcas estudies/Growingpains.pdf

The Economist. 2010. First Break All the Rules: The Charms of Frugal Innovation. The Economist, April 15, 2010. Accessed April 11, 2018: https://www.economist.com/node/15879359

European Parliament and Council. 2005. Directive 2005/36/EC of the European Parliament and of the Council of 7 September 2005 on the Recognition of Professional Qualifications. Brussels: European Parliament and Council.

http://data.europa.eu/eli/dir/2005/36/2016-05-24

Hossain, M. 2016. Frugal Innovation: A Systematic Literature Review. Available at SSRN:

http://dx.doi.org/10.2139/ssrn.2768254

IMF. 2017. Country Composition of WEO Groups. International Monetary Fund (IMF), October 2017. Accessed January 7, 2018: https://www.imf.org/external/pubs/ft/weo/2017/02/weodata/gro ups.htm (Jan 7, 2018).

Kahle, H. N., Dubiel, A., Ernst, H., \& Prabhu, J. 2013. The Democratizing Effects of Frugal Innovation: Implications for Inclusive Growth and State-Building. Journal of Indian Business Research, 5(4): 220-234.

https://doi.org/10.1108/JIBR-01-2013-0008 


\section{Patterns of Frugal Innovation in Healthcare}

Hareem Arshad, Marija Radić, and Dubravko Radić

Khanna, T., Kasturi Rangan, V. \& Manocaran, M. 2005. Narayana Hrudayalaya Heart Hospital: Cardiac Care for the Poor. Harvard Business School Case 505-078. Boston, MA: Harvard Business School.

Landrum, N. E. 2007. Advancing the 'Base of the Pyramid' Debate. Strategic Management Review, 1(1): 1-12.

OECD. 2005. Oslo Manual: Guidelines for Collecting and Interpreting Innovation Data, (3rd ed.). Paris: Organisation for Economic Cooperation and Development (OECD). http://dx.doi.org/10.1787/19900414

OECD. 2010. SMEs, Entrepreneurship and Innovation. Paris: Organisation for Economic Cooperation and Development (OECD).

http://dx.doi.org/10.1787/20780990

Oppong, F. C. 2015. Innovation in Income-Poor Environments. British Journal of Surgery, 102(2): 102-107.

https://doi.org/10.1002/bjs.9712

Ostraszewska, Z., \& Tylec, A. 2015. Reverse Innovation - How It Works. International Journal of Business \& Management, 3(1): $57-74$.

https://doi.org/10.20472/BM.2015.3.1.004

Pansera, M., \& Sarkar, S. 2016. Crafting Sustainable Development Solutions: Frugal Innovations of Grassroots Entrepreneurs. Sustainability, 8(1): 51. http://dx.doi.org/10.3390/su8010051

Prahalad, C. K. 2004. The Fortune at the Bottom of the Pyramid: Eradicating Poverty through Profits. Philadelphia: Wharton Business Publishing.

Prahalad, C. K. 2012. Bottom of the Pyramid as a Source of Breakthrough Innovations. Journal of Product Innovation Management, 29(1): 6-12.

https://doi.org/10.1111/j.1540-5885.2011.00874.x

Prahalad, C. K., \& Lieberthal, K. 1998. The End of Corporate Imperialism. Harvard Business Review, 76, 68-79.

Prahalad, C. K., \& Hart S. L. 2002. The Fortune at the Bottom of the Pyramid. Strategy+Business, 26(1): 55-67.

Prahalad, C. K., \& Hammond, A. 2002. Serving the World's Poor, Profitably. Harvard Business Review, 80(9): 48-57.

PRISMA. 2018. Transparent Reporting Systematic Reviews and MetaAnalyses. PRISMA. Accessed March 23, 2018:

http://prisma-statement.org

Ramdorai, A., \& Herstatt C. 2015. Frugal Innovation in Healthcare. How Targeting Low-Income Markets Leads to Disruptive Innovation. Cham, Switzerland: Springer International Publishing.

Rosca, E., Arnold, M., \& Bendul, J. C. 2016. Business Models for Sustainable Innovation - An Empirical Analysis of Frugal Products and Services. Journal of Cleaner Production, 162: 133-145. http://dx.doi.org/10.1016/j.jclepro.2016.02.050
Sarangi, S., Patro, S., \& Kumar, R. S. 2014. Sustainable Distribution in Emerging Markets - African Perspective. Transnational Marketing Journal, 2(1): 39-60.

Schumacher, E. F. 1973. Small Is Beautiful - A Study of Economics as If People Mattered. London: Blond and Briggs.

Thurik, R. 2009. Entreprenomics: Entrepreneurship, Economic Growth, and Policy. In Z. Acs, D. Audretsch \& R. Strom (Eds.), Entrepreneurship, Growth, and Public Policy: 219-249. Cambridge: Cambridge University Press.

Tiwari, R., Fischer, L., \& Kalogerakis, K. 2016. Frugal Innovation in Scholarly and Social Discourse: An Assessment of Trends and Potential Societal Implications. Working Paper. Hamburg and Leipzig, Germany: Center for Frugal Innovation, Hamburg University of Technology, Fraunhofer Center for International Management and Knowledge Economy.

https://doi.org/10.15480/882.1288

Tiwari, R., \& Herstatt, C. 2012. Assessing India's Lead Market Potential for Cost-Effective Innovations. Journal of Indian Business Research, 4(2): 97-115.

https://doi.org/10.1108/17554191211228029

UN. 2015. Sustainable Development Goals: 17 Goals to Transform Our World. United Nations (UN), September 25, 2015. Accessed January 5, 2018:

http://www.un.org/sustainabledevelopment/sustainabledevelopment-goals/

Weyrauch, T., \& Herstatt, C. 2016. What Is Frugal Innovation? Three Defining Criteria. Journal of Frugal Innovation, 2(1): 1-17. https://doi.org/10.1186/s40669-016-0005-y

WHO. 2017. What is Universal Coverage? World Health Organization (WHO). Accessed January 9, 2018:

http://www.who.int/health_financing/universal_coverage_definiti on/en/

Zeschky, M. B., Winterhalter, S., \& Gassmann, O. 2014. From Cost to Frugal and Reverse Innovation: Mapping the Field and Implications for Global Competitiveness. Research-Technology Management, 57(4): 20-27.

https://doi.org/10.5437/08956308X5704235

Citation: Arshad, H., Radić, M., \& Radić, D. 2018.

Patterns of Frugal Innovation in Healthcare. Technology

Innovation Management Review, 8(4): 28-37.

http://doi.org/10.22215/timreview/1150

Keywords: frugal innovation, healthcare, global health, developing economies, emerging economies (cc) BY 


\title{
Overcoming Barriers to Frugal Innovation: Emerging Opportunities for Finnish SMEs in Brazilian Markets
}

\author{
Mirva Hyypiä and Rakhshanda Khan
}

\author{
" Industry, perseverance, and frugality make fortune yield. ") \\ Benjamin Franklin (1706-1790) \\ Polymath and a Founding Father of the United States
}

\begin{abstract}
Frugal innovation has become a popular concept, in academia but also in industry at large. Although there has been a great deal of discussion about the relevance of frugal innovation to the developed world, the notion's full acceptance within small and medium-sized enterprises (SMEs) still seems far in the distance. The opportunities and barriers seen with practical implementation of frugal innovation during the development processes have received little attention. This article considers these opportunities and barriers in the context of Finnish SMEs, providing insight specifically into the approaches these companies take in Brazilian markets. Qualitative data were drawn from a case study forming part of an extensive action research-based development project called SCALA, aimed at creating suitable and scalable mobile learning services for global markets. The concepts of frugal innovation and proceeding from user needs - essential parts of the development processes - are examined by observing three Finnish SMEs and their top managers, with particular focus on their interaction with Brazilian partners. Development sessions and meetings shed light on how the companies perceived and responded to testing their products/services with six individual schools in Brazil. Although frugal innovation is seen as essential for guaranteeing long-term competitiveness of Finnish SMEs - and access to rapidly growing, unsaturated emerging markets such as Brazil can be a step in the right direction - our study highlights numerous barriers and ways to overcome them in the real-world implementation of frugality in SMEs' development processes.
\end{abstract}

\section{Introduction}

Frugal innovation has become a popular concept, in academia and industry alike. Over the years, this phenomenon has been seen as relevant not only for emerging markets (Hart \& Christensen, 2002; Prahalad, 2010) but also for developed ones (Radjou \& Prabhu, 2015; Weyrauch \& Herstatt, 2016). Advanced economies with under-served customers are in dire need of low-cost products and services. Moreover, lacklustre growth, aging population bases, environmental constraints, growing demand for sustainability, and other factors create pressure for more frugality-oriented models of production and consumption in the developed world (Bound \& Thornton, 2012; Hossain et al., 2016). To serve poorer consumers in advanced economies, a frugality mindset associated with bottom-ofthe-pyramid strategies must be instilled in firms and inherent in their business models (Angot \& Ple, 2015). The necessity of such a mindset is becoming increasingly apparent: scholars and practitioners have now recognized its importance for businesses. This has pushed many to study the applicability of frugal innovation to advanced economies (Bound \& Thornton, 2012; Fraunhofer ISI \& Nesta, 2016; Tiwari et al., 2016).

Even though the results of these studies point to the importance of frugality-oriented products and services in advanced economies, the application of frugal innovation in most companies still remains far from reality. 


\section{Overcoming Barriers to Frugal Innovation: Emerging Opportunities for Finnish SMEs in Brazilian Markets Mirva Hyypiä and Rakhshanda Khan}

Multinational corporations display gradual strivings towards the acceptance of frugality in resource consumption or production, with examples being General Electric's culture of simplification, the Siemens SMART strategy, and Pearson PLC's frugal innovation strategy. However, there are many barriers to scaling up frugal solutions to larger markets. A recent study conducted for the European Commission (Fraunhofer ISI \& Nesta, 2016) pointed to such obstacles, which include "possible disconnection between producers and users, the way producers conceive and develop the production and delivery processes of their frugal solutions, and different implications that tend to occur like standardization in the production processes." The small and medium-sized enterprises (SMEs) in advanced economies are finding it even more challenging to incorporate frugal strategies into their business.

As the relevance of frugal innovation grows, numerous efforts to understand this concept are being made. Most of the publications addressing frugal innovation have been attempts to propose frameworks to enrich our understanding of the concept of frugal innovation. Scholars have conducted both qualitative and quantitative studies to systematize the literature on frugal innovation. This is done by contrasting it against other forms of innovation, such as jugaad innovation in India (Radjou \& Prabhu, 2014; Radjou et al., 2012), reverse innovation (Govindarajan \& Ramamurti, 2011), grassroots innovation (Smith et al., 2014), bottom-of-the-pyramid innovation (Prahalad \& Hart, 2002), and good-enough innovation or constraint-based innovation (Zeschky et al., 2014). Others have made efforts to address specific characteristics or provided definitions of frugal innovation (Brem \& Wolfram, 2014; Tiwari \& Herstatt, 2012; Weyrauch \& Herstatt, 2016). Many other scholars have attempted organized surveys of research on frugal innovation (Hossain, 2016; Pisoni et al., 2018).

Earlier studies provide fruitful ground for understanding frugal innovation, including concepts related to it; prerequisites for it; defining criteria, characteristics, and attributes; and categories that can aid in identifying its similarities and differences in relation to other pertinent concepts. Notwithstanding the valuable contributions already made, a need remains for a study that investigates the opportunities and barriers linked to frugal innovation in practice in the development processes of SMEs in advanced economies.

Even though frugal innovation has received a lot of academic attention as an important underpinning for the developed markets of the future, the approach by which it can be incorporated into firms' development processes needs further elucidation. Accordingly, we conducted a study, using data from work on the Scalable Mobile Learning Services for Global Markets (SCALA) project on conducting mobile-learning research and developing frugal-innovation knowledge and research for developing markets in Brazil.

For the purposes of this article, we adhere to Radjou and Prabhu's (2014) definition of frugal innovation: "Frugal innovation is the ability to do more with less by creating more business and social value while minimising the use of resources such as energy, capital and time". Additionally, the study emphasizes the bottomup development processes of Finnish SMEs towards meeting Brazilians' actual needs and designing adaptable solutions and services for them (Basu et al., 2013; Ostraszewska \& Tylec, 2015). We discuss the potential of frugal innovation in Finnish SMEs, and we explore how they can use bottom-up development processes to overcome barriers when approaching emerging markets. The purpose of the study is to investigate three Finnish SMEs aspiring to scale mobile and virtual learning solutions and services to Brazil.

The work is structured thus: in the next section, we discuss frugal innovation as an opportunity for Finland. We also look at the prospects for Finnish SMEs in emerging markets. Then, we provide an overview of mobile learning services for Brazilian markets and explain our methods and approach. In the results section, we discuss the potential needs and barriers facing mobile and virtual learning services in Brazil. Final discussion and conclusions describe possible limitations of this study and potential traps, along with opportunities for overcoming them.

\section{Frugal Innovation as an Opportunity for Finland}

Frugal innovation is much more than low-cost innovation, even though it is generally viewed as such. It involves reconsidering the nature of innovation: "Frugal innovation is not just about redesigning products; it involves rethinking entire production processes and business models" (Soni \& Krishnan, 2014). According to Prahalad and Mashelkar (2010), frugal innovation is about "doing more with less for more people". Frugal innovations are considered to be potentially disruptive and transformational, not only for emerging markets but also for developed markets (Immelt et al., 2009). 


\section{Overcoming Barriers to Frugal Innovation: Emerging Opportunities for Finnish SMEs in Brazilian Markets Mirva Hyypiä and Rakhshanda Khan}

Frugal innovation is strongly user-oriented; it is a creative approach to problem-solving that starts with user needs and works from the bottom up to develop contextually appropriate solutions (Fraunhofer ISI \& Nesta, 2016). It is understood as a "holistic rethinking of products, services, underlying processes and business models so that companies can squeeze costs and expand the customer base, business and profit" (Jagati, 2011).

Even though the practice of frugal innovation had its beginnings in emerging markets and is generally seen as a necessity of resource-constrained economies, it is absolutely relevant to Finland and indeed to advanced economies in general. Among many other factors influencing Finland, pressing problems such as environmental constraints, an aging population, and highly saturated markets make frugal innovation highly relevant and applicable nationally.

The demand for frugal innovation within Europe again, not only in Eastern Europe but also in developed economies - is likely to grow, in response to socioeconomic and demographic change and increasing resource constraints (Fraunhofer ISI \& Nesta, 2016). Therefore, it is clear that underprivileged consumers too must be served in Finland. Moreover, this demand in the Finnish context will only escalate on account of lacklustre economic growth. In addition, frugal innovation has potential for tackling public-policy challenges in Europe such as delivery of good public services and promotion of social and economic inclusion (Fraunhofer ISI \& Nesta, 2016). In a similar vein, frugal innovation, especially in terms of high-quality public services and ecological sustainability, seems highly relevant to Finnish society overall.

In addition, the role of technologies in frugal innovation seems significant. The "frugal potential" of many technologies has so far been under-explored (Fraunhofer ISI \& Nesta, 2016). According to rankings in a report compiled by the United Nations Development Programme (UNDP), Finland is the world's most technologically advanced country (Cordis, 2001). It is highly plausible that digital technologies could be utilized accordingly to deliver numerous frugal solutions to emerging markets; however, Finnish firms require deeper knowledge of frugal innovation and emerging markets in their bottom-up development processes, particularly if they are to supply frugality (i.e., the same or new for less) in their learning solutions and services (Basu et al., 2013; Hautamäki, 2016; Ostraszewska \& Tylec, 2015).

\section{Prospects for Finnish SMEs in Emerging Markets}

In Finland, even though advocates of frugal innovation, among them business experts, entrepreneurs, scholars, and consultants, have started to market frugal innovation to Finnish companies (especially SMEs) for its potential, it is still not recognized as something significant enough to be pursued. This is regrettable given that emerging markets offer huge opportunities for Finnish firms. To avail themselves of such opportunities effectively in these markets, firms need to embrace frugal innovation and inculcate a frugal mindset so as to stay competitive in these markets. With the purpose of providing consumption opportunities to non-affluent consumers, a price-sensitivity consideration has to be incorporated into the firm's business models (Prahalad \& Hart, 2002; Wooldridge, 2010). At Finnish SMEs, the key precondition for frugal innovation is instilling a frugal mindset for development of low cost innovation. Firms need to "change the mindset of the employees, by changing the culture of the organization" (Agnihotri, 2015). Finnish firms need to adopt a new mindset, thereby understanding that making a profit is still possible in the case of low prices - through scalability (Hautamäki, 2016). Moreover, within this context, Finnish SMEs can choose to adapt their strategies to the principle of basic functionality at low costs.

Winter and Govindarajan (2015) recommend that, in designing frugal innovations, firms should avoid five "traps" by applying five specific design principles. The first trap is matching market segments to existing products, which can be overcome by defining problems independently of preexisting solutions. The second trap is trying to reduce prices by eliminating features; this trap, in turn, can be avoided by creating an optimal solution, not a watered-down one. Another trap is to neglect to think through all technical requirements. It can be avoided by analyzing the technical landscape behind the consumer problem. The fourth trap, neglecting stakeholders, can be sidestepped by testing products with as many stakeholders as possible. The final trap is to forget that products designed for emerging markets could have global appeal. Firms can overcome it by using emerging-market constraints as tools to create global winners.

According to Hautamäki (2016), Finnish firms have to improve their capabilities if they are going to produce frugal solutions. First of all, they need better knowledge of frugal engineering and bottom-of-pyramid markets. Second, they need to have better access and connec- 


\section{Overcoming Barriers to Frugal Innovation: Emerging Opportunities for Finnish SMEs in Brazilian Markets Mirva Hyypiä and Rakhshanda Khan}

tions to emerging markets. Third, they must also develop partnerships with local agencies and enterprises in emerging markets for establishing solid marketing and distribution channels. Fourth, they need to establish true, deep collaboration on innovation and production, marrying Finnish competencies in engineering and in information and communication technologies with the vast production capacities and low costs of emerging markets. Lastly, a need exists to build vibrant global business ecosystems between Finland and emerging markets.

Frugal innovation is essential for securing long-term competitiveness of Finnish SMEs. For organizations armed with this tool, access to rapidly growing, unsaturated emerging markets such as those in Brazil can be a step in the right direction.

\section{Mobile Learning Services for Brazilian Markets}

Revenues for mobile learning products and services in Brazil reached \$338.3 million USD in 2014 (Adkins, 2015). The growth rate is a robust $25.7 \%$, and revenues are projected surge to over $\$ 1.0$ billion USD by 2019 . Brazil generates Latin America's largest revenues for mobile learning, by a wide margin; they are four times higher in Brazil than in Mexico, the region's secondlargest buying country (Adkins, 2015). In April 2015, Brazil had a population of just over 200 million people. Brazil accounts for one third of all mobile users in Latin America and is adding a million mobile-subscription users per month. As of May 2015, over 38\% of the population accessed the web via mobile devices, with 8.7 million of these people using only mobile devices to access the Internet (Adkins, 2015).

More than 52 million smartphones were sold in Brazil in 2014, and 95\% of all phones sold in Brazil are smartphones. By the end of 2014, 6.7 million 4G-enabled smartphones were in use there, marking a $416.5 \%$ increase from 2013 levels. Brazil's 4G users (31.7\% of the population) are concentrated in São Paulo. In addition, more than 9.9 million tablets were sold in Brazil in 2014 (Adkins, 2015).

In Brazil, consumer users dominate the mobile learning market. The nearly recessionary economy notwithstanding, consumers are still buying mobile learning apps and edugames, and they are subscribing eagerly to value-added service (VAS) products for mobile learning. Usually, struggling economies see consumer spending diminish dramatically, but conditions have not stopped Brazilians from buying mobile learning products, especially ones related to language learning and early childhood learning. These value-added services for mobile learning are reasonably priced, from $\$ 2.50$ to $\$ 6.00$ USD per month, and hence attract millions of consumers. It is estimated that the consumer segment of the market will account for above $60 \%$ of all mobile-learning revenues in Brazil in 2019 (Adkins, 2015).

Across Latin America, there were 38 mobile learning VAS products on the market in 2015, of which 13 were found in Brazil. Most of the mobile learning products are designed for consumers, though there are products on the market designed for schools. In addition, managing training and education services generally, not just institutional ones, requires supporting enormous user bases, and few suppliers can scale their service solutions to that extent. Therefore, revenues from these mobile learning products are somewhat limited, to those few companies that have the resources to scale their services to any quantity of users (Adkins, 2016).

\section{Methods}

\section{Background}

The empirical data used in the study come from a case study that formed part of a wider research and-development-based project, connected with SCALA, a project (programmed for September 2016 - April 2018) in which mobile-learning research is conducted and knowledge and research related to frugal innovation for developing markets in Brazil are developed. The research and development work of the SCALA project is funded by Business Finland (the national public funding agency), which is also actively supporting Finnish companies in accessing emerging markets through various services and programs.

Despite the challenging situation of the Brazilian economy, consumers there are keenly buying mobile learning products, which is not often the case in struggling economies. In addition, the interest in Finnish education and learning services is already high in Brazil.

Our research approach was experimental, learningand business-driven, and iterative, and our study involved three Finnish case companies, researchers, and Brazilian research partners.

The aim of the study was to test the existing online learning services of the Finnish companies and obtain 


\section{Overcoming Barriers to Frugal Innovation: Emerging Opportunities for Finnish SMEs in Brazilian Markets Mirva Hyypiä and Rakhshanda Khan}

authentic feedback from the users (students and teachers) in Brazil, thereby enabling the further development of the services in a simplified manner. Moreover, the companies were eager to create contacts in emerging markets through their collaboration with Finnish research partners and Brazilian education partners. The case companies were small and medium-sized organizations operating nationally and internationally in the online learning business. Two case companies were providing learning solutions for mathematics or language skills, and the third one offered a virtual learning environment, which began testing with Brazilian partners more comprehensively in early 2018.

For this research, a case-study-based research strategy was chosen because of its capabilities in explaining and describing complex social phenomena. The need for a case study arises out of the necessity to understand the opportunities and barriers related to frugal innovation. The case study is an ideal strategy when the researcher has little control over events and when the focus is on a contemporary phenomenon in a real-life context. Therefore, specifically, a case study is the method of choice when the phenomenon studied is not readily distinguishable from its context (Yin, 2009).

This case study was qualitative. Qualitative researchers tend to collect data in the field at the site where the par- ticipants experience the issue or problem under study. This up-close information gathered by actually talking to people directly and seeing them behave and act within their context is a core characteristic of qualitative research (Creswell, 2007). The data collection in case-study research is usually extensive, drawing on multiple sources of information (Creswell, 2007). The empirical data in our case came from development sessions, learning-solution testing, and pilot weeks with Brazilian students and teachers (Table 1). Additionally, face-to-face and online meetings with the SCALA project group in Finland and Brazil are part of the dataset, alongside background inquiries from the Finnish SMEs. The documentation used in this study consists of notes, emails, written background inquiries, observations, video recordings, photographs, and shared written and verbal feedback.

In this case study, the researchers were not solely observers; they took part in the jointly designed pilot weeks and testing as developers, users, or facilitators. Whatever the roles of the authors were in the course of the research, the first author is aware that a position internal to the study influences the way one interprets data (particularly related to the pilot weeks in Brazil). Mindful of such issues, the researchers analyzed the data in cooperation, and the case companies and other participants from the project group reviewed the res-

Table 1. Outline of the data gathering

\begin{tabular}{|c|c|c|c|c|}
\hline Timeframe & Testing Content & Data & Documentation & Participants \\
\hline March 2017 & $\begin{array}{l}\text { Online learning } \\
\text { solutions in Java, } \\
\text { math, and English }\end{array}$ & $\begin{array}{l}\text { - } 6 \text { schools } \\
\text { - } 6 \text { student groups }\end{array}$ & $\begin{array}{l}\text { - Notes, photographs, } \\
\text { and a questionnaire }\end{array}$ & $\begin{array}{l}\text { - } 180 \text { students } \\
\text { - } 9 \text { professors/teachers } \\
\text { - } 2 \text { researchers }\end{array}$ \\
\hline October 2017 & $\begin{array}{l}\text { - Mobile learning apps: } \\
4 \text { math apps \& } \\
4 \text { English apps }\end{array}$ & $\begin{array}{l}\text { - } 6 \text { schools } \\
\text { - } 8 \text { student groups }\end{array}$ & $\begin{array}{l}\text { Notes, photographs, } \\
\text { video recordings, } \\
\text { and a questionnaire }\end{array}$ & $\begin{array}{l}\text { - } 144 \text { students } \\
\text { - } 8 \text { professors/teachers } \\
\text { - } 2 \text { researchers }\end{array}$ \\
\hline November 2017 & $\begin{array}{l}\text { - Newly developed } 8 \\
\text { mobile learning apps } \\
\text { (math \& English) }\end{array}$ & - Workshop & $\begin{array}{l}\text { Notes, photographs, } \\
\text { and co-created } \\
\text { written materials }\end{array}$ & $\begin{array}{l}\text { - } 33 \text { students } \\
\text { - } 2 \text { company } \\
\text { representatives } \\
\text { - } 4 \text { teachers } \\
\text { - } 2 \text { researchers }\end{array}$ \\
\hline $\begin{array}{l}\text { September 2016- } \\
\text { March } 2018\end{array}$ & $\begin{array}{l}\text { - Virtual learning } \\
\text { environment }\end{array}$ & $\begin{array}{l}\text { - Project meetings } \\
\text { - Learning/testing } \\
\text { meetings (ongoing } \\
\text { until end of } \\
\text { March, 2018) }\end{array}$ & $\begin{array}{l}\text { Notes, videos, } \\
\text { presentations, and } \\
\text { co-created learning } \\
\text { content }\end{array}$ & $\begin{array}{l}\text { Varied approx. from } 6 \\
\text { to } 24, \text { CEOs, } \\
\text { professors, teachers, } \\
\text { researchers, or } \\
\text { students }\end{array}$ \\
\hline
\end{tabular}




\section{Overcoming Barriers to Frugal Innovation: Emerging Opportunities for Finnish SMEs in Brazilian Markets Mirva Hyypiä and Rakhshanda Khan}

ults collectively at the project meetings. The data-based inquiry was based on content analysis - for example, evaluating the common themes that arose, adversarial feedback, user experiences, and suggestions for improvements of the learning solutions tested.

\section{The data-gathering process}

Two week-long pilot implementations were carried out in the São Paulo region in 2017. In March, 207 students aged 12-46 and in October, 144 students aged 13-52, from basic education and adult vocational schools, participated in the testing, which covered Finnish online learning solutions (in the first pilot study; see Table 2) and mobile application prototypes (in the second; see Table 3). Each testing session lasted approximately $1-1.5$ hours.

In March, Java programming, mathematics, and English e-learning content formed the core of the pilot phase. The existing Finnish learning solutions were not adaptable as such to the Brazilian schools and education systems, and therefore in-depth testing sessions and comprehensive user experience from students and teachers were required to develop human centric, easyto-use adaptable designs for Brazilians (Basu et al., 2013). Because the learning solutions were not yet optimized for usage on a mobile device, students tested them primarily via different browsers on their smartphones (mainly with an Android system). Additionally, some student groups combined use on smartphones and personal computers. For younger students, teachers incorporated the testing into the course or led the testing via a laptop computer with screen content projected for the whole classroom.

One of the significant outputs of the pilot in March 2017 indicated that online learning services as such are not marketable in Brazil. Instead, mobile learning applications are desired and willingly used. Based on the given feedback and to meet the mobile-learning requirements of Brazilian students, for the second pilot week, eight distinct mobile application prototypes were co-created by Finnish students of business information technology and two case companies. Four applications concentrated on mathematical skills, and the other four were created for learning English. Executing the required changes in their learning solutions, within the timeframe of the project, was rather challenging for the case companies. Hence, the Finnish students were involved to allow the development of learning solutions to continue. The case companies instructed and supported the students' work. Furthermore, students were keen to co-create solutions for companies' real-life problems and simultaneously receive credits towards their studies.

In addition to the testing of mobile-learning applications, there were several meetings with Brazilian professors and personnel from several schools. The aim of these meetings was to establish separate piloting with the third Finnish case company, scheduled for implementation in early 2018 and expected to last six weeks. The virtual learning environment and the learning context of waste management will form the core of the piloting, with the virtual platform of the case company having been pre-tested with a broad spectrum of teachers from Finland and Brazil in 2017. Additionally, that virtual platform has been utilized in online meetings among the project partners.

\section{Results and Discussion}

The aim of this study is to emphasize the bottom-up development process of Finnish SMEs in meeting the actual needs of Brazilian users and designing adaptable solutions and services for them (Basu et al., 2013; Ostraszewska \& Tylec, 2015). The starting point for technology development typically is technology-centered and assumptions are made concerning the needs of the users. The existing Finnish learning solutions were not adaptable as such in Brazil, thus it was necessary to conduct in-depth testing sessions and to gather comprehensive user experiences from students and teachers.

The teachers had worked hard to familiarize themselves with the Finnish learning services, to understand the opportunities they represented in Brazilian teaching, and to prepare the classes to integrate the use of mobile learning services into their students' learning processes. The feedback from Brazilian students and teachers in the first pilot week (in March 2017) indicated a fundamental need for mobile learning applications that comprise offline solutions alongside online platforms. The Android system was highlighted especially strongly during the development process, because Android smartphones are widely used in Brazil.

All the teachers supported the sessions and guided the researchers from Finland in negotiating the language differences between Portuguese and English during both pilot weeks. Very important information was gathered in October also, related, for example, to the editors used by the mathematics applications and to applying pedagogical approaches that should enhance the 


\section{Overcoming Barriers to Frugal Innovation: Emerging Opportunities for Finnish \\ SMEs in Brazilian Markets Mirva Hyypiä and Rakhshanda Khan}

Table 2. The first pilot study in Brazil in March 2017, which focused on online learning solutions

\begin{tabular}{|c|c|c|c|}
\hline School & Ages & Participants & Subject \\
\hline Brisabella & $12-13$ & 36 & English \\
\hline $\begin{array}{l}\text { Escola Estadual Professora Brisabella de } \\
\text { Almeida Nobre }\end{array}$ & $15-16$ & 26 & Math \\
\hline \multirow{2}{*}{$\begin{array}{l}\text { FSA } \\
\text { Colégio da Fundação Santo André }\end{array}$} & $18-46$ & 29 & Math \\
\hline & $19-27$ & 46 & English \\
\hline \multirow{3}{*}{$\begin{array}{l}\text { Alcina } \\
\text { EME Prof Alcina Dantas Feijão }\end{array}$} & $13-14$ & 16 & Math \\
\hline & $18-26$ & 19 & Java \\
\hline & $18-26$ & 8 & English \\
\hline $\begin{array}{l}\text { USCS } \\
\text { Municipal University of São Caetano do Sul }\end{array}$ & $20-34$ & 27 & Java \\
\hline Total & & 207 & \\
\hline
\end{tabular}

Table 3. The second pilot study in Brazil in October 2017, which focused on mobile learning applications

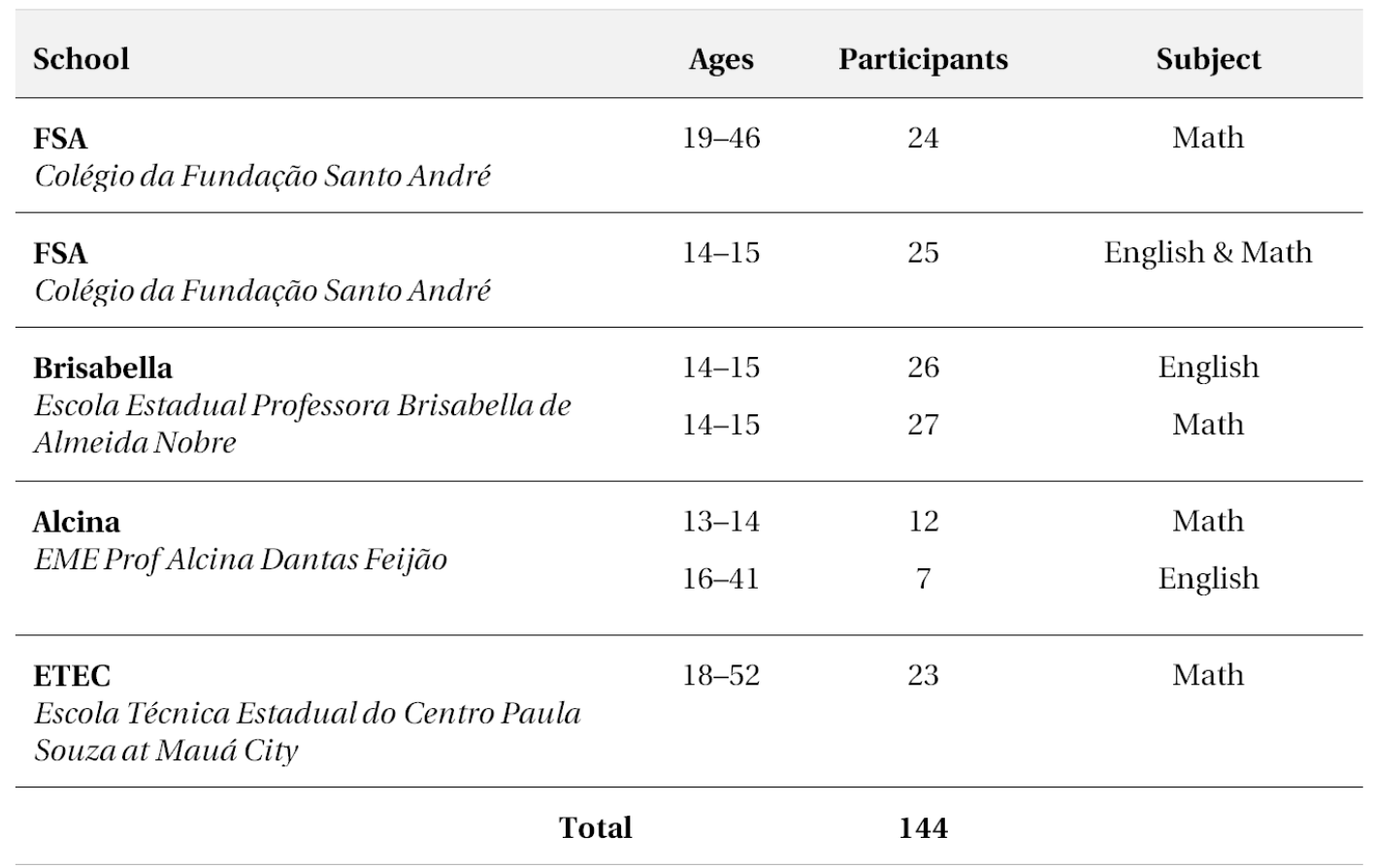




\section{Overcoming Barriers to Frugal Innovation: Emerging Opportunities for Finnish SMEs in Brazilian Markets Mirva Hyypiä and Rakhshanda Khan}

learning experience of a student using mobile applications in general. The most successful application from the students' standpoint was a language application with which the user is able to practice pronunciation of English. Overall, the students indicated a desire for more gamified and audio-based applications and instruction in the Brazilian education system.

Access to the Internet is sometimes problematic in Brazil. Additionally, based on the feedback and user experience in the second pilot in October, Brazilians often keep applications open, and these applications are quite diverse. For example, having sufficient memory capacity available to accommodate social media services and multiple mobile learning applications on a single smartphone can be rather challenging. The development work of the Finnish companies and students on mobile learning applications should not only focus on having the feature work in an offline mode but also to reconsider the content and amount of the adaptable application(s). Consequently, in November 2017, the feedback and video-recorded user experiences from the pilot week in October were shared with the Finnish students who had co-created the prototypes with the SMEs. The students were eager to see how well their applications had been accepted and how they had fared in testing at the Brazilian schools. The students improved and developed their application prototypes further in line with the feedback given. For instance, the four math applications were combined into a unified application solution. The completed mobile learning applications were launched in a digital distribution service in December 2017. At present, Finnish SMEs are making the decisions as to whether they will use the cost-effectively developed applications in their future business and which learning products should be chosen for Brazilian markets. As one of the CEO stated after the workshop in November: "the smart and skillful students have been doing their work very well as well as cost-efficiently, now it is up to us how we will use the developed apps or should we co-create a different type of learning solutions or applications completely. However, I feel that the project is going to be finished a bit too early since not all our products can be changed rapidly or tested separately with newly established contacts and users."

Access to the fast-growth, unsaturated Brazilian market is significant for securing the long-term competitiveness of Finnish SMEs. However, as they expand their business and design frugal solutions for emerging markets, there are always wrinkles that need to be taken into consideration. The study highlighted some traps related to mobile learning solutions and possible opportunities for dealing with these traps.

First of all, the technical requirements for mobile learning solutions in Brazilian markets need to be analyzed carefully. Finland's education system and learning solutions are highly valued in countries around the world, with Brazil being no exception. However, most online learning systems require continuous Internet access, which is not available in Brazil as readily as it is in Finland, and the Finnish SMEs were not prepared for this significant difference in the beginning of the project and before the user feedback. The knowledge of somewhat limited Internet access was shared before the pilots in Brazil, but the influence on performing different tasks by users was not acknowledged comprehensively. In addition, the infrastructure of Brazilian school buildings is not designed for mobile-learning devices. For example, the possibility of recharging their batteries is not always guaranteed; there is a shortage of sockets in the classrooms. Furthermore, the virtual learning environment is not optimized for smartphone use (it is currently better suited to laptops or, in some cases, to tablets, even though some learning material can be downloaded and updated offline). Therefore, there is a need for mobile learning applications with offline solutions alongside online platforms. This has to be taken into consideration by the Finnish SMEs that offer mobile solutions in Brazilian markets.

Second, the study provided insight into the actual needs related to mobile learning solutions in Brazilian markets. No learning solutions already offered by Finnish SMEs were suitable in Brazil. Instead of matching Brazilian markets to existing learning solutions, one has to understand the real needs of Brazilian users. For example, there were design and implementation errors in the learning solutions. Most importantly, it was noted that a Portuguese language option is needed in the initial learning solutions and the manuals. The pedagogical skills and education systems are also rather different between Finland and Brazil. For example, in the Nordic region, problem-based learning methods or selfdirected group work is commonly used in various disciplines and at many levels of education. The same is not true of Brazil. Such differences have to be acknowledged by the Finnish SMEs, especially when the virtual learning environment is to be used in formal education. Further, focusing on development of mobile learning applications that will suit Brazilian markets is strongly recommended. For example, offline solutions suiting specific markets could be developed, tasks could be translated and the pedagogical approaches localized, 


\section{Overcoming Barriers to Frugal Innovation: Emerging Opportunities for Finnish SMEs in Brazilian Markets Mirva Hyypiä and Rakhshanda Khan}

and audiovisual materials could be viewed by means of Portuguese-language subtitles.

Third, Finnish SMEs are small and may lack the resources to cater to user requirements in large emerging markets. Had the case companies not collaborated with the Finnish and Brazilian education and research partners, it would not have been possible to approach the schools, obtain the actual user feedback, or observe the diversity of the Brazilian schools. In addition, unexpected circumstances might have had a bigger impact than expected. For example, the holiday seasons differ significantly between Finland and Brazil, which escalates unexpected obstacles into development processes (both countries having several national holidays and long summer vacations over the course of a year), and therefore, it would have been rather challenging for the case companies to test their services and solutions and then make suitable changes within the timeframe of the project. In our study, the case companies were small and did not possess the resources to concentrate primarily on the mobile learning applications at all times. Overcoming that hurdle entailed engaging Finnish students to enable the product development to continue. It is clear that Finnish SMEs' solutions must mesh with the resource crunch and be planned accordingly.

Last, understanding the stakeholders, especially when they belong to different cultures, is of tremendous importance. An essential factor that emerged early in the SCALA project is that Brazilians tend to be very open and sociable. It is important to consider some aspects of this when one negotiates with them. For instance, in business and otherwise, people significantly prefer faceto-face meetings initially. That creates a bond and helps in becoming familiar with business partners. Likewise, as several teachers at the Brazilian university said, "The real problem is not about products or services plenty of applications and online services are available. It is more about the service solutions. The companies should prefer to provide integrated and personalized solutions for us here in Brazil. In particular, developing applications with certain Brazilian schools and acknowledging their specific curricula would be more beneficial to Finnish SMEs."

\section{Conclusion}

We investigated the opportunities and barriers connected with Finnish mobile learning solutions and services in Brazilian markets. This work highlighted the need for frugal innovation in practice during the bottom-up development processes employed by SMEs. It also recog- nized that, whatever the competition in Brazilian markets might be, those Finnish SMEs that provide comprehensive solutions based on actual user needs instead of merely offering products and services, and that focus on integrating them with Brazilian partners' operations, can be successful. It was revealed that frugal innovation processes need to be incorporated into the development processes of Finnish SMEs from the very outset. The possibilities for scalability to Brazilian markets could be considered from the bottom-up perspective: one could proceed from the experiences and future demands of users (students) and synthesize that valuable feedback with input from decision makers on school management, municipal, and government levels. Thereby, undesirable methods, inappropriate devices, and irrelevant high-tech investments for various separate levels of education could be diminished or possibly avoided completely.

Most Finnish SMEs lack resources compared to multinational companies for catering to user requirements in emerging markets. One of the best management practices in resource-constrained conditions could be engaging students in the development processes wherever possible, for example, in this particular case, combining local knowledge and skills from Brazilian and Finnish students. This could provide the desired help to SMEs towards solving the challenges of resource scarcity. Compared to SMEs, for example, bigger companies have better access to emerging markets. They have monetary resources alongside manpower. Most importantly, they have existing technical equipment as well, for instance, they have their own servers, which our case companies lacked. Although one of the SMEs was interested in investing in a server in Brazil, the Brazilian partners highly recommended establishing partnerships and sharing hubs with local partners instead.

Furthermore, all the CEOs were very pleased to have the opportunity to run intensive pilots in Brazil and to gain insightful and diverse feedback from the users for their own solutions and services. This would not have been possible for the SMEs to accomplish had they approached the Brazilian markets on their own accord. This study also drew attention to the need to create value for all stakeholders, including Finnish SMEs and emerging Brazilian markets, and it focused on the possibility of creating business ecosystems in collaboration with local Brazilian actors. This study contributes to knowledge of frugal innovation and develops the body of research especially in relation to Brazilian markets. Instead of emphasizing the top of the pyramid and the 


\section{Overcoming Barriers to Frugal Innovation: Emerging Opportunities for Finnish SMEs in Brazilian Markets Mirva Hyypiä and Rakhshanda Khan}

various levels in the hierarchy of education, focusing on millions of users with reasonably priced mobile learning solutions offer a competitive advantage for Finnish SMEs that specialize in mobile and virtual learning solutions and that wish to access emerging markets. Brazilian markets offer great potential for frugally developed mobile learning solutions, with many consumers buying mobile learning applications and edugames, and with many being avid subscribers to mobile learning value-added services.

The novelty of our study is related to the bottom-up development approach focusing on actual user needs in Brazilian learning context before entering the markets, because the usual approach is for (Finnish) companies to contact top-level school management or government. This research may be useful for Finnish SMEs who could benefit from this knowledge. Most often, Finnish SMEs innovate for developed markets; if they become aware of the benefits of adopting a frugal approach to innovation, they could perhaps find new markets for their products.

The study has a few obvious limitations, some of which are inherent to work of this nature. The samples sizes were small, so the findings are best treated as exploratory. Furthermore, the study was conducted with a specific set of Finnish SMEs and Brazilian schools; hence, these do not explicitly represent the business environment for mobile learning services and their providers in either country. That said, the upcoming piloting for the virtual learning environment will supplement this research. In addition, collaboration among Finnish and Brazilian students using the same learning service simultaneously will deepen understanding of the significance of the user experience for the implementation of frugality in the development processes of SMEs, particularly as they approach emerging markets.

By linking frugal innovation and digital technologies, we demonstrate to SMEs how frugal potential of technologies can be utilized. Finnish SMEs currently uninterested in emerging markets may in future deliver frugal digital technologies to emerging markets and develop their own knowledge and understanding of frugal engineering.

\section{About the Authors}

Mirva Hyypiä, D.Sc. (Tech.), is a Senior Researcher of Industrial Management at Lappeenranta University of Technology, Finland, where she has worked since 2006. Her current research focuses on various aspects of leadership, innovation management, frugal innovation, innovation systems, userdriven innovation, service design, multi-sensory environment, gamification, and co-creation of digitalization. She has published several articles in international and national scientific journals.

Rakhshanda Khan is a Postdoctoral Researcher at Lappeenranta University of Technology, Finland. Her doctoral dissertation in Business and Management (2017) focused on the contribution of socially driven businesses and innovations to social sustainability. Her expertise lies in sustainable, socially driven businesses, inclusive business models, and sustainable innovations, with a special focus on frugal innovation. She has published in several refereed journals including Applied Energy, Sustainability, the International Journal of Innovation and Sustainable Development, and the International Journal of Information Systems and Social Change.

\section{References}

Adkins, S. S. 2015. The 2014-2019 Brazil Mobile Learning Market. Monroe, WA: Ambient Insight.

http://www.ambientinsight.com/Resources/Documents/Ambient Insight-2014-2019-Brazil-Mobile-Learning-Market-Abstract.pdf

Adkins, S. S. 2016. The 2016-2021 Worldwide Self-Paced eLearning Market: Global eLearning Market in Steep Decline. Monroe, WA: Ambient Insight.

http://www.ambientinsight.com/Resources/Documents/Ambient Insight_2015-2020_US_Self-paced-eLearning_Market_Abstract.pdf

Agnihotri, A. 2015. Low-Cost Innovation in Emerging Markets. Journal of Strategic Marketing, 23(5): 399-411. https://doi.org/10.1080/0965254X.2014.970215

Angot, J., \& Ple, L. 2015. Serving Poor People in Rich Countries: The Bottom-of-the-Pyramid Business Model Solution. Journal of Business Strategy, 36(2): 3-5. https://doi.org/10.1108/JBS-11-2013-0111

Basu, R. R., Banerjee, P. M., \& Sweeny, E. G. 2013. Frugal Innovation: Core Competencies to Address Global Sustainability. The Journal of Management for Global Sustainability, 1(2): 63-82. http://dx.doi.org/10.13185/JM2013.01204

Bound, K., \& Thornton, I. W. 2012. Our Frugal Future: Lessons from India's Innovation System. London: Nesta. 


\section{Overcoming Barriers to Frugal Innovation: Emerging Opportunities for Finnish SMEs in Brazilian Markets Mirva Hyypiä and Rakhshanda Khan}

Brem, A., \& Wolfram, P. 2014. Research and Development from the Bottom Up - Introduction of Terminologies for New Product Development in Emerging Markets. Journal of Innovation and Entrepreneurship, 3(9): 1-22. https://doi.org/10.1186/2192-5372-3-9

Cordis. 2001. Finland, the World's Most Technologically Advanced Country - UN report. European Commission Community Research and Development Information Service (Cordis), August 17, 2001. Accessed December 8, 2017:

http://cordis.europa.eu/news/rcn/17266_en.html

Creswell, J. W. 2007. Qualitative Inquiry \& Research Design: Choosing among Five Approaches (2nd ed.). Thousand Oaks, CA: SAGE Publications.

Fraunhofer ISI \& Nesta. 2016. A Conceptual Analysis of Foundations, Trends and Relevant Potentials in the Field of Frugal Innovation (for Europe). Interim Report Prepared for the European Commission Directorate General for Research and Innovation. Brussels: European Commission.

Govindarajan, V., \& Ramamurti, R. 2011. Reverse Innovation, Emerging Markets, and Global Strategy. Global Strategy Journal, 1(3-4): 191-205. https://doi.org/10.1002/gsj.23

Hart, S. L., \& Christensen, C. M. 2002. The Great Leap: Driving Innovation from the Base of the Pyramid. MIT Sloan Management Review, 44(1): 51-56.

Hautamäki, A. 2016. Frugal Innovation - A New Approach to Sustainable Innovation in Emerging Markets. Sustainable Innovation, April 27, 2016. Accessed November 2, 2017: https://sustainableinnovation.fi/2016/04/27/frugal-innovation-anew-approach-to-sustainable-innovation-in-emerging-markets/

Hossain, M. 2016. Frugal Innovation: A Systematic Literature Review. Available at SSRN:

http://dx.doi.org/10.2139/ssrn.2768254

Hossain, M., Simula, H., \& Halme, M. 2016. Can Frugal Go Global? Diffusion Patterns of Frugal Innovations. Technology in Society, 46: 132-139.

https://doi.org/10.1016/j.techsoc.2016.04.005

Immelt, J., Govindarajan, V., \& Trimble, C. 2009. How GE Is Disrupting Itself. Harvard Business Review, 87(10): 56-65.

Jagati, O. P. 2011. Business Strategy through Frugal Innovation. Chartered Secretary, 41(11) 1533-1535.

Ostraszewska, Z., \& Tylec, A. 2015. Reverse Innovation - How It Works. International Journal of Business \& Management, 3(1): 57-74.

https://doi.org/10.20472/BM.2015.3.1.004

Pisoni, A., Michelini, L., \& Martignoni, G. 2018. Frugal Approach to Innovation: State of the Art and Future Perspectives. Journal of Cleaner Production, 171(10): 107-126. https://doi.org/10.1016/j.jclepro.2017.09.248

Prahalad, C. K. 2010. The Fortune at the Bottom of the Pyramid: Eradicating Poverty through Profits (2nd ed.). Upper Saddle River, NJ: Pearson Education.

Prahalad, C. K., \& Hart, S. L. 2002. The Fortune at the Bottom of the Pyramid. Strategy+ Business, 26: 1-14.
Prahalad, C. K., \& Mashelkar, R. A. 2010. Innovation's Holy Grail. Harvard Business Review, 88(7/8): 132-141.

Radjou, N., \& Prabhu, J. 2014. Frugal Innovation: How to Do More with Less. London: Profile Books Ltd.

Radjou, N., \& Prabhu, J. 2015. The Frugal Way to Grow. Frugal Innovation Hub, February 11, 2015. Accessed November 26, 2017: https://frugalinnovationhub.com/en/resources/2015/11/02/thefrugal-way-to-grow.html

Radjou, N., Prabhu, J.,\& Ahuja, S. 2012. Jugaad Innovation: Think Frugal, Be Flexible, Generate Breakthrough Growth. San Francisco, CA: Jossey-Bass.

Smith, A., Fressoli, M., \& Thomas, H. 2014. Grassroots Innovation Movements: Challenges and Contributions. Journal of Cleaner Production, 63: 114-124. https://doi.org/10.1016/j.jclepro.2012.12.025

Soni, P., \& Krishnan, R. T. 2014. Frugal Innovation: Aligning Theory, Practice, and Public Policy. Journal of Indian Business Research, 6(1): 29-47. https://doi.org/10.1108/JIBR-03-2013-0025

Tiwari, R., Fischer, L., \& Kalogerakis, K. 2016. Frugal Innovation in Scholarly and Social Discourse: An Assessment of Trends and Potential Societal Implications. Joint working paper of Fraunhofer MOEZ Leipzig and Hamburg University of Technology in the BMBF-ITA project. Leipzig and Hamburg, Germany.

Tiwari, R., \& Herstatt, C. 2012. India - A Lead Market for Frugal Innovations? Extending the Lead Market Theory to Emerging Economies. Working Paper No. 67. Hamburg, Germany: Institute for Technology and Innovation Management, Hamburg University of Technology.

Weyrauch, T., \& Herstatt, C. 2016. What Is Frugal Innovation? Three Defining Criteria. Journal of Frugal Innovation, 2(1): 1-17. https://doi.org/10.1186/s40669-016-0005-y

Winter, A., \& Govindarajan, V. 2015. Engineering Reverse Innovations. Harvard Business Review, 93(7-8): 80-89.

Wooldridge, A. 2010. The World Turned Upside Down. The Economist, April 15, 2010. Accessed November 20, 2017:

http://www.economist.com/node/15879369

Yin, R. 2009. Case Study Research: Design and Methods (4th ed.). Thousand Oaks, CA: SAGE Publications, Inc.

Zeschky, M. B., Winterhalter, S., \& Gassmann, O. 2014. From Cost to Frugal and Reverse Innovation: Mapping the Field and Implications for Global Competitiveness. Research-Technology Management, 57(4): 20-27. https://doi.org/10.5437/08956308X5704235

Citation: Hyypiä, M., \& Khan, R. 2018. Overcoming Barriers to Frugal Innovation: Emerging Opportunities (cc) BY for Finnish SMEs in Brazilian Markets. Technology Innovation Management Review, 8(4): 38-48. http://doi.org/10.22215/timreview/1151

Keywords: frugal innovation, barriers, opportunities, Finnish SMEs, Brazilian markets 


\title{
Science Is Indispensable to Frugal Innovations Balkrishna C. Rao
}

\author{
"The science of today is the technology of tomorrow." \\ Edward Teller (1908-2003) \\ Theoretical physicist
}

\begin{abstract}
In recent years, frugal innovations have become widely popular due to their no-frills nature that entails lower costs. However, most of the frugal innovations, at least at the grassroots level, are makeshift contraptions, made from indigenous ingenuity, that achieve their goals under constraints on various resources but may suffer from limited lifespans due to premature failure. Consequently, it is imperative that sound scientific principles not be overlooked or haphazardly applied in realizing these innovations, irrespective of their grassroots or sophisticated nature. This article therefore argues for the need to use science, sometimes at the cutting edge, to realize grassroots and advanced frugal innovations that are not prone to failure under various working conditions. In so doing, this work advocates the use of classical and new design methodologies that are rooted in science to save resources and, hence lower costs, while aiming for robust functionality of frugal products. In particular, a frugal design approach using a modern version of the safety factor called the "factor of frugality" has been propounded to effectively create any type of frugal innovation from scratch. By combining the ingenuity of the resourceful creators of frugal innovations with a scientific approach that aims to make the resulting products "fail proof", such innovations may better contribute value to business and benefits to society.
\end{abstract}

\section{Introduction}

The notion of frugal innovation, with its conceptual origins arising from observations of grassroots-level innovation (Basu, 2007; Raturi, 2010), mainly in India and China, has captured the attention of researchers and practitioners in developed countries (The Economist, 2010). Frugality has been associated with engineering and innovations and has been touted as a significant tool for creating low-cost products and services in an era beset by crises including planetary ones such as climate change and resource scarcity (Rao, 2013). Frugal products are also catering to the needs of both the poor and lower income segments, whose ranks are swelling in developed and developing nations alike due to man-made crises such as the bursting of the dotcom bubble and the global financial calamity of 2007-2008.

Although the concept of "frugal innovation" took root in the inventiveness of very talented grassroots creators of emerging economies, numerous products and services in sectors ranging from education and health- care to applications in space have been realized with an eye for lowering costs through a "no frills" structure (Rao, 2013). Examples include the production of lowcost products such as the Tata Nano (nano.tatamotors.com) car and Tata Swach (tataswach.com) filters for potable water by the Indian conglomerate Tata Sons. Another example is the no frills refrigerator called chotuKool (www.chotukool.com) by yet another Indian business, Godrej \& Boyce. Other than products showcased by Indian business titans, other countries are also jumping onto the frugal bandwagon as is evidenced by handheld electrocardiograms and portable ultrasound scanners developed by General Electric of the United States and also the Square Kilometre Array in South Africa (Nordling, 2012), built from nonoperational communications antennas retrofitted into a radio telescope for peering into space. Frugality has also been observed in other recent high-tech products, such as the robotic hand from Sandia Labs (Greenemeier, 2012); a salt telescope in Africa (Nordling, 2013); the small Spike missile developed for the US Navy (The Economist, 2012), and a low-cost technology for particle colliders in high-energy physics applications (Downer \& Zgadzaj, 2014; Rao, 


\title{
Science Is Indispensable to Frugal Innovations
}

\author{
Balkrishna C. Rao
}

2017a). In services, the appearance of no-frills flights by low-cost airlines (The Economist, 2014) and complex heart surgeries offered at lower prices by Narayana Hrudayalaya in Bangalore, India (Khanna et al., 2005) are prominent examples.

Moreover, as observed in the examples covered above, frugal innovations encompass both grassroots and sophisticated types, with the latter being termed as advanced frugal innovations (Rao, 2017a). In other words, an advanced frugal innovation is systematically created through rigorous application of scientific methods, whereas its grassroots brethren are typically makeshift contraptions that are realized through very talented innovators possessing significant ingenuity. Also, an advanced frugal innovation is developed against an imposed constraint on resources whereas the grassroots type are developed by the poor against natural constraints. But, cases of advanced frugal innovation are not rare exceptions. Other than the 25 examples of frugal innovation recently examined by this author (Rao , 2017a), the majority of examples qualify as advanced frugal innovations due to the degree of sophistication in science and technology needed for their systematic realization (see, for example: Rao, 2013).

The advanced frugal innovations developed to date are a testimony to the knowledge and also ingenuity of the creators (i.e., engineers, scientists, and other workers) in their endeavours for cutting costs while attending to the stringent needs of science, engineering, and other relevant knowledge areas. Although frugality lends itself to sustainable solutions for tackling the crises of our times, the act of indulging in these innovations has to be tempered with detailed knowledge. In other words, frugal innovations have to be firmly supported on the sound principles of science and engineering. Such an association would not only enhance the potential of these innovations in critical sectors such as healthcare and aviation but would also encourage the private sector and other entities to increase the market share for commercial products built on the concept of frugality.

Therefore, this effort will focus on deepening the association between frugal innovations and science and hence make the frugal concept more than a makeshift arrangement. Weaving science around these innovations would make them amenable to the myriads of approaches available in engineering literature for the systematic realization of these innovations into quality products. The term "science" as used in this effort comprises both basic and applied science or engineering. In particular, some relevant existing engineering methodologies will be examined that will consequently lead to the need for a "factor of frugality" in making frugal innovations of superior quality. A scientific framework based on the factor of frugality approach will also be presented for the systematic realization of these products whose functioning is not hampered by frugality. Moreover, for frugal innovations of the grassroots type, any attempt at strengthening their foundations through science - using tools such as the factor of frugality - would enhance their usefulness at the base of the pyramid wherein exists a significant stakeholder for sustainable development.

\section{Performance of Frugal Innovations}

The premise underlying the concept of frugal innovation is the achievement of lower costs against natural constraints for the grassroots type and resource-savings through artificial constraints for the advanced type. In either case, a no-frills structure is achieved through various aspects aiding in the real-time realization of these innovations. These aspects cover design, materials, and manufacturing, and supply-chain logistics, to name a few. However, the design, materials, and manufacturing aspects of these innovations are by far the most significant due to their direct bearing on the quality performance of a frugal product in the real world. In other words, engineering leads to the realization of frugal products and any compromise in the rigours of its tools (i.e., design, materials, and manufacturing) would hamper the effective functioning of the product concerned. Such a sacrifice in rigour while designing and building a product for achieving a no-frills structure is a real possibility for grassroots innovations due to their makeshift nature. Moreover, the zero scores achieved in recent crash tests of some of the relatively cheaper cars for the masses (Global NCAP, 2014) and the glitches in both the salt telescope in Africa (Nordling, 2013) and the radio telescopes of the Square Kilometre Array project (Nordling, 2012) imply that there may be less rigorous engineering for advanced frugal innovations when working under a bootstrapped budget. Furthermore, multiple design iterations might be warranted even after adopting a rigorous design process to iron out all the weak spots of a frugal product as is evidenced by the reported malfunctioning in the first generation Tata Nano car (The Economic Times, 2010; The Economist, 2011), which has been rectified in the latest version. In other words, the Tata Nano has gone through at least two iterations of design to arrive at the latest model, and this attests to the complexity of rigorously designing this and other advanced frugal 


\title{
Science Is Indispensable to Frugal Innovations
}

\author{
Balkrishna C. Rao
}

products, which makes the ironing out of weak spots difficult in the first instance. The successful development of the Nano through these design iterations was ultimately made possible through the rigorous application of scientific principles by an ingenious workforce possessing advanced skills. Indeed, these examples of advanced frugal innovations again attest to the ingenuity and the knowledge-based skills of the workforce involved, some of whom are continuously improving the quality of their products. Although less rigour in engineering practices could be tolerated in grassroots innovations such as earthen refrigerators (Raturi, 2010) and bamboo microscopes (Basu, 2007), stringent engineering practices should be the norm for advanced frugal innovations used in sectors such as the healthcare and aerospace industries, where human lives are at stake. Thus, engineering rigour should be made compulsory or the norm for any frugal innovation achieved through the ingenuity of innovators, whether the products are of the grassroots, advanced, or any other type.

It should be noted that the theme of frugality has been applied to both products and services. However, even though this effort focuses on the improvement of frugal products, the same theme of rigorous procedures for achieving good quality is also applicable for improving the quality of frugal services in areas such as healthcare, where the need for speed to achieve economies of scale in surgeries is of concern (Nagral, 2014).

\section{Scientific Framework for Frugal Innovations}

The weaknesses imposed on these innovations, by their very aim of achieving frugality, could be minimized or even avoided by applying suitable engineering design tools rooted in scientific principles. Therefore, the design and engineering of any frugal innovation, whether grassroots or advanced, must be subjected to scientific rigour to harness their true potential for sustainable development. The scientific framework based on engineering design measures that are advocated in this study applies to both the grassroots and advanced frugal innovations. Therefore, both the collider for particle physics (Downer \& Zgadzaj, 2014, Rao, 2017a) and the earthen refrigerator or MittiCool Fridge (Rao, 2013) need the ingenuity of their creators in using such a engineering framework to realize these game-changing innovations with the collider also needing advances in other relevant knowledge areas, such as particle physics, for its completion.

The approach outlined in this study brings out the necessity of using sound engineering principles for im- proving the quality, and hence usefulness, of frugal innovations. As mentioned before, the design and manufacturing of a frugal product from scratch is assumed to be the primary approach for achieving frugality with the utilization of other features, such as supply chain and quality-control tests, being secondary or ancillary. Consequently, this effort emphasizes the usage of the classical factor of safety and hence its extension the factor of frugality due to the ubiquity and also the interrelationship between design measures and the factor of safety. Accordingly, some of the relevant design principles based on the factor of safety have been expounded to undergird the factor of frugality approach to design and engineering.

\section{Factor of safety approach}

The frugality of an innovative design will usually push the traditional factor of safety or safety factor (FOS) (Shigley \& Mischke, 1989) towards a numeric value of one. Since a unit value of the FOS corresponds to the failure-prone load being equal to the working load, many frugal innovations could possibly be experiencing maximum loads with a propensity to fail due to poor design. In other words, frugal innovations may routinely be pushed to their limits under normal working conditions. The predominant reason being that nofrills designs of frugal innovations are typically realized with minimal amounts of raw materials that in turn lower their factor of safety. Other reasons for an unsafe design include uncertainties in the models and data needed for the design, which in the case of grassroots innovations might not be accessible in the first place due to the absence of a suitable knowledge base.

Accordingly, a preliminary scientific framework for realizing frugal innovations of both the grassroots and advanced types with robust functionality is depicted in Figure 1. The framework depicts the classical approach to design that has traditionally been followed for creating engineering structures and products (Shigley \& Mischke, 1989; Urugal, 2015). The various elements of the framework depicted in Figure 1 represent a knowledge base that is widely used by designers and engineers around the world. A rigorous design procedure reducing uncertainties through accurate models for design, engineering, and scientific phenomena; precise selection of materials and manufacturing processes limiting waste; and accurate prediction of scenarios for overloading, to name a few, would also lead to FOS values in the vicinity of one but with a reduced susceptibility to failure. The conceptual stage would also involve multiple iterations of the rigorous design process, where needed, to iron out as many bottlenecks as possible in 


\section{Science Is Indispensable to Frugal Innovations}

\section{Balkrishna C. Rao}

the modelling, material behaviour, sustainable manufacturing, overloading, and other aspects of design during this initial stage because design modifications would be difficult to implement during fabrication. The various principles, shown in Figure 1, facilitating a rigorous design procedure accompanying a lower factor of safety, are described in the lines that follow. These principles form the bedrock of a rigorous frugal-design and will be adhered to in the factor of frugality approach, described later, for the systematic realization of robust frugal products:

\section{Accurate design and engineering models: After con-} ceptualization, the mathematical models used to capture the complex features of the functioning of a product are important to its design and subsequent engineering. These models have to encompass the important features of a product while being tractable for accurate solutions. The term "accurate" signifies the error with respect to the exact solution or real behaviour that can be tolerated. While working with frugal designs, it is imperative that tight tolerances are strictly implemented for error due to the low FOS values inherent in the design of these innovations. In other words, model predictions ideally have to match real values so as to avoid failure whose chances are high due to lower safety factors. But realistic conditions introduce a risk of error that has to be maintained at such low values that the chance of failure becomes insignificant. Since the progress in both technology and knowledge base, such as science, engineering, or any other relevant area, will dictate the limit on accuracy, it is imperative to seek accurate models through research \& development (R\&D) programs dedicated to frugal products. These $R \& D$ activities should also strive to obtain exact values or real-time behaviour through meticulous experimentation or real-time tests so as to reduce their margins of uncertainty for effective comparison with model predictions.

\section{Accurate characterization of material behaviour:} The lower values of FOS also necessitate accurate characterization of the behaviour of materials going into a frugal product. The various properties critical to the design of a frugal product have to be procured through well-controlled experimental tests generally yielding data with least uncertainty and also good repeatability. This is because frugal products are typically designed without excess material padding and hence require accurate estimation of material properties to lead to a product that is lean and also robust and effective in its performance. Therefore, im- proved accuracy in outputs of both mathematical models and material characterization would aid in minimizing design uncertainties, which is critical considering the inherently higher stresses experienced by frugal products. Moreover, these accurate models in engineering and materials should also be utilized to widen the range of size, shape, and type of parts for standardization so as to lower costs for fabrication and assembly.

3. Sustainable manufacturing: The need for economy in the usage of materials for building a frugal product beckons the use of manufacturing technologies that minimize generation of waste. In this regard, sustainable manufacturing processes, with their emphasis on lower emissions and also lower waste, should be utilized to fabricate products out of frugal material resources. An instance of technology for sustainable manufacturing would be the use of near-net shapemanufacturing processes, such as additive manufacturing or 3D printing, for building frugal products with the attendant meagre waste.

4. Low probability events: The low FOS design of a frugal product should envisage and also account for scenarios of rare events where the product might be subjected to both marginal overloading and severe loading conditions.

\section{Factor of frugality approach}

The new approach to frugal design was developed by coupling the existing FOS-based design (described earlier) with the new-found utilization of additional material saving schemes that are extraneous to the FOS approach. The vulnerability of frugal innovations notwithstanding, their lower FOS designs typically lead to streamlined products. Accordingly, rigorous design procedures accompanying low FOS designs - see Figure 1 - should be coupled with additional material-saving schemes for achieving the highest savings in material resources going into a frugal product. Accordingly, as seen in Figure 2, in a frugal design approach developed recently by Rao (2017b), the factor of frugality (F of FFOS) utilizes rigorous design procedures and additional material-saving schemes to conserve the maximum amounts of material resources going into a design thereby making it a frugal product. The symbolic representation shows both the classical FOS and the new factor of frugality $(\mathrm{F})$, which is also dependent on the FOS value. In other words, the classical FOS is subsumed into the modern $\mathrm{F}$ value. The rigour of classical design with a low FOS ensures robust functionality of the frugal product under normal working and some 


\section{Science Is Indispensable to Frugal Innovations}

\section{Balkrishna C. Rao}

\section{Scientific Framework for Factor of Safety}

(FOS approach applies to grassroots \& advanced frugal innovations)

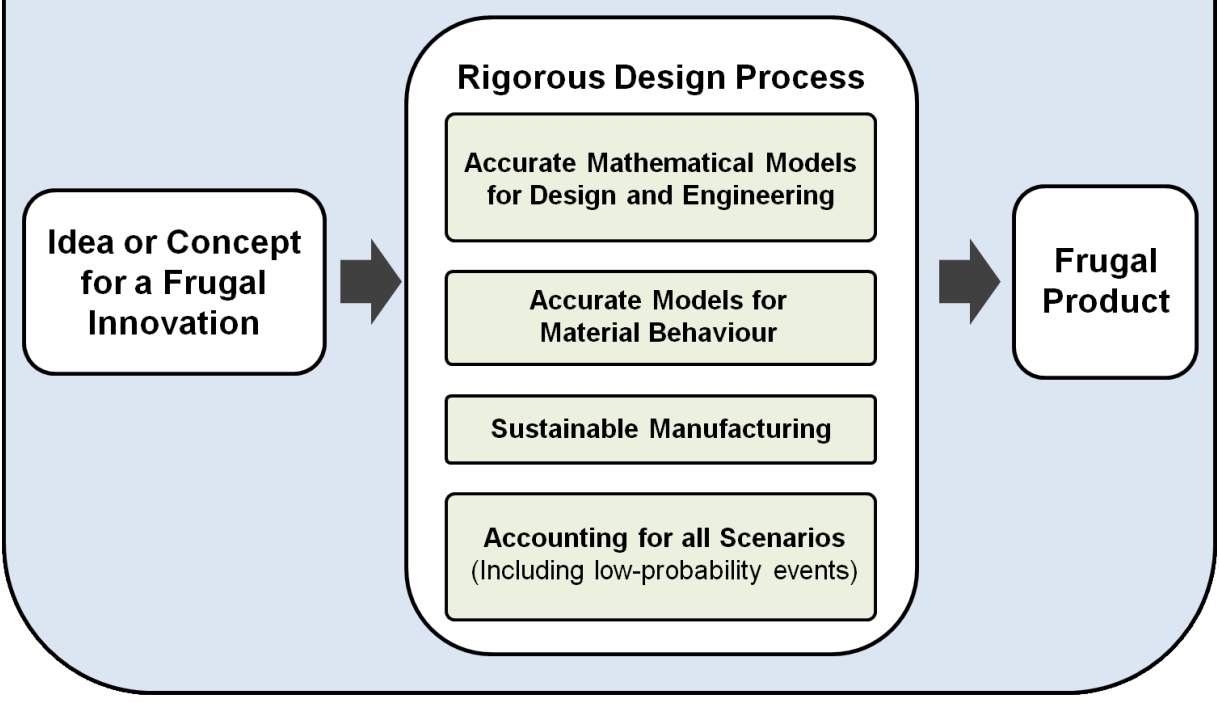

Figure 1. Scientific framework for factor of safety (FOS) approach

\section{Scientific Framework for Frugal Innovations}

(Applies to any frugal innovation: grassroots, advanced, and others)

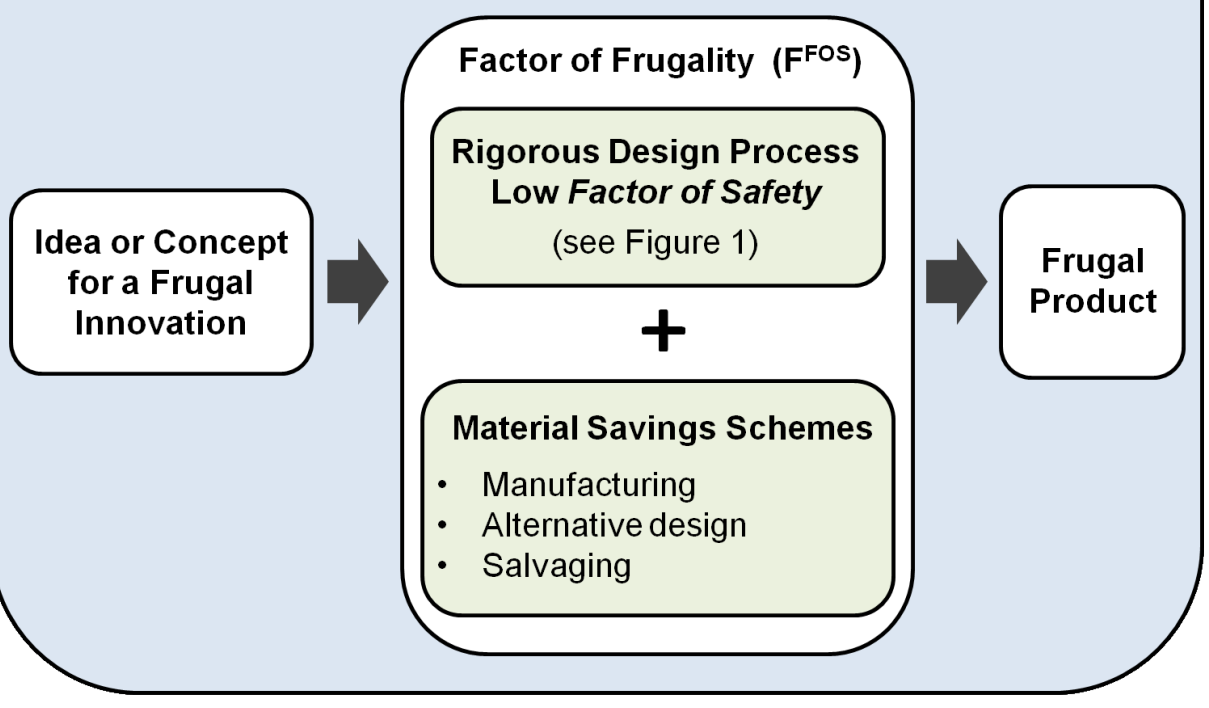

Figure 2. Scientific framework for the proposed frugal design approach 


\section{Science Is Indispensable to Frugal Innovations}

\section{Balkrishna C. Rao}

overloading conditions with the attendant evasion of material padding. Additional material is saved for such a low FOS design by adopting extraneous schemes related to design, manufacturing and salvaging, to name a few.

\section{Discussion}

The advent and subsequent progress of frugal innovations from this century onwards is a force for good in the fight against global crises. In particular, climate change and resource scarcity, to name a few of the planetary crises, warrant judicious utilization of earth's resources. Also, crises such as the one affecting global finance in 2007-2008 leave, in their wake, swelling ranks of unemployed in addition to those suffering from poverty. Consequently, widespread use of frugal products and frugal services, where possible, would aid in both uplifting the living standards of the society at large including the poor (Rao, 2014) and sustainable development.

Although many of the frugal products and frugal services developed to date could be utilized against the above backdrop, rigorous design seems to have been employed for only advanced frugal innovations used in sectors ranging from healthcare and transportation to defence. It should be noted that this work assumes the adoption of sound engineering principles in realizing advanced frugal products such as GE's Mac 400, the Square Kilometre Array, the Tata Nano and others due to their sophisticated technology. In addition, technology titans such as GE and Tata also possess a highly skilled workforce, including scientists and engineers, who use their ingenuity for the scientific creation of these innovations. This is in contrast to grassroots innovations, which are typically fabricated by applying makeshift techniques. In any case, the need for a rigorous scientific approach, as presented here, applies to any frugal innovation, irrespective of whether it is a grassroots or advanced type, or anything in between.

The successful adoption of frugal innovations on a wider scale requires the realization of frugal products and frugal services, whose quality is not compromised for attaining lower costs. Although advanced frugal innovations have been created through rigorous application of science, a dedicated methodology for designing frugal products is needed from here onwards to systematically utilize science for creating frugal innovations from ground zero. In this regard, the factor of frugality developed recently by Rao (2017b) could be utilized to systematically build frugal products of any type from the design stage through to their successful realization by using suitable fabrication techniques. The factor of frugality is computed in two steps. First, a baseline design through the framework of Figure 1 is carried out for a low FOS. Second, additional material-saving schemes steeped in sustainability are employed whose savings are quantified. The FOS and the numbers from the second step are summed to give the factor of frugality (F of FFOS).

A FOS of, say, 1.5 is selected in the first step of utilizing the factor of frugality provided a rigorous design procedure is carried out for the concerned frugal innovation. The value of 1.5 is not arbitrary and has been taken from the aircraft industry where it is imperative to shell weight through rigorous design for eventually attaining efficient flight (Shanley, 1962; Norton, 2006). Besides, the value of 1.5 being just above the failure conditions would result in savings of raw materials as opposed to larger values. All the same, frugality comes with the caveat that even though lower costs can be achieved by changes to supply chain or sales and marketing, it is design-related parameters such as FFOS that can lead to the realization of frugal innovations for sustainable development with emphasis on human life. Therefore, rigorous design principles should be combined with the ingenuity of Jugaad to create myriads of good quality frugal products and also frugal services.

Although rigorous procedures accompanying a low FOS design of the first step would result in a streamlined product, additional savings for this low FOS product is possible through other schemes. These additional schemes comprising the second step of application of the factor of frugality are rooted in sustainability. Such schemes utilize various features of the design process such as manufacturing and salvaging from end-of-life systems to further economize material consumption for the low FOS design. An end-of-life system refers to any product that is nearing the end of its useful life, and such products may have valuable components that can be repurposed. For example, the fabrication of the low FOS design should employ suitable manufacturing technologies to reduce wastage of stock removed while also scouting for end-of-life systems that might already have such a manufactured part.

Overall, successful application of the factor of frugality approach results in a streamlined product with maximum material savings and hence generally maximal positive impact on the environment. The outlays involved in applying rigorous design procedures would inflate the costs of the frugal product in the short term with 


\section{Science Is Indispensable to Frugal Innovations}

\section{Balkrishna C. Rao}

sales over the longer term aiding to go beyond the break-even point and eventually making a profit. Therefore, the decision to go frugal is a serious one that needs to be addressed during the conceptual or design stage so as to minimize the uncertainties in both the quality and margins of a frugal product. In other words, businesses and other entities have to take the rigour in design and engineering of these products as a must with room only for forecasting various scenarios of returns. However, costs could be lowered to some extent by the adoption of concepts such as open innovation systems, whose "open" environment allows unfettered flow of knowledge and also resources among the various stakeholders of an innovation ecosystem (Oganisjana, 2015).

Last but not least, companies, governmental bodies, academia, and other entities working with frugal innovations should actively develop research and development (R\&D) programs to delve deeper into the scientific framework presented in this article for possible modifications and hence improving the functionality of frugal products in the foreseeable future. These $R \& D$ units should actively pursue the application of science, both pure and applied (engineering), to these innovations, whose contribution as low-cost alternatives for achieving better standards of living would be an indispensable tool for sustainable development. In particular, $R \& D$ activities on these innovations should develop on the scientific principles set in the framework presented in this effort by focusing on advanced studies in materials science, manufacturing processes, and design aspects, to name a few. These $R \& D$ programs are all the more important when human lives are at stake. Moreover, R\&D entities pursuing frugal innovations should also team up with the poor in society to aid in the diffusion of these good quality products and also learn newer ways, if any, of utilizing frugality for the benefit of society (Rao, 2014). The makeshift nature of many of these innovations has to be nourished for their ingenuity and tempered with science to create robust frugal innovations for wide-ranging sustainable development.

\section{Conclusions}

This article highlights the importance of strengthening the foundations of frugal innovations through science and engineering. The dependence on sound scientific principles is warranted due to the makeshift nature of Jugaad, inherent in many of these innovations, which could make frugal products prone to failure working under normal or nominal conditions. Therefore, a scientific framework for the systematic realization of all types of frugal innovations has been presented in this article wherein classical tools of engineering design are brought to bear upon these innovations at the conceptual stage of the design process. This framework employing the recently developed factor of frugality is applicable to all types of frugal innovations irrespective of their degrees of sophistication in technology. Accordingly, the factor of frugality approach entails using traditional measures of design such as the factor of safety under tightly controlled conditions coupled with other schemes for saving extra materials to make frugal products robust. The weaving of pure and applied science around these innovations, created through the ingenuity of their resourceful creators, necessitates a strong $R \& D$ program, for delving deeper into the advanced aspects of these innovations, which would result in the systematic fabrication of frugal products that are sound in quality.

\section{About the Author}

Balkrishna C. Rao is an Associate Professor in the Department of Engineering Design at the Indian Institute of Technology Madras (IITM) in India. As a member of the Sustainable Manufacturing Group at IITM, he conducts research pertaining to sustainable manufacturing, additive manufacturing, and frugal design. Other than the work in manufacturing for automotive and aerospace sectors, his work in frugal innovations has led to the creation of a new type called Advanced Frugal Innovation (AFI) to account for the increasing sophistication seen in these products. He has also developed a frugal approach to design wherein advanced and grassroots frugal products can be built from scratch. Such a frugal design tool can greatly aid sustainable development in designing streamlined products for various sectors while also improving functionality. Among his other contributions, he has also developed a concept for tallying the innovative output of a country through Gross Domestic Innovation (GDI). Professor Rao earned his $\mathrm{PhD}$ in Mechanical Engineering with emphasis on manufacturing from Purdue University in the United States. 


\section{Science Is Indispensable to Frugal Innovations}

\section{Balkrishna C. Rao}

\section{References}

Basu, P. 2007. Science on a Shoestring: Microscopes Made from Bamboo Bring Biology into Focus. Nature Medicine, 13(10): 1128-1129.

http://doi.org/10.1038/nm1007-1128a

Downer, M., \& Zgadzaj, R. 2014. Surf's Up at SLAC. Nature, 515(7525): 40. http://doi.org/10.1038/515040a

The Economic Times. 2010. Tata Motors Investigating Nano Fire Incident. The Economic Times, March 25, 2010. Accessed April 11, 2018:

https://economictimes.indiatimes.com/automobiles/tata-motorsinvestigating-nano-fire-incident/articleshow/5723591.cms

The Economist. 2010 First Break All the Rules: The Charms of Frugal Innovation. The Economist, April 15, 2010. Accessed April 11, 2018: https://www.economist.com/node/15879359

The Economist. 2012. Rockets Galore: Cheap Smart Weapons. The Economist, September 29, 2012. Accessed April 11, 2018: https://www.economist.com/node/21563702

The Economist. 2014. Low-Cost Airlines: Making Laker's Dream Come True. The Economist, November 27, 2014. Accessed April 11, 2018:

https://www.economist.com/news/business/21635001-low-costairlines-have-revolutionised-short-haul-flying-now-after-severalfailed-attempts

The Economist. 2011. Tata's Nano: Stuck in Low Gear. The Economist, August 20, 2011. Accessed April 11, 2018:

https://www.economist.com/node/21526374

Global NCAP. 2014. UN Crash Test Standards Would Make Cars Safer In India Says Global NCAP. Global New Car Assessment Programme (Global NCAP), November 3, 2014. Accessed April 11, 2018:

http://www.globalncap.org/un-crash-test-standards-would-makecars-safer-in-india-says-global-ncap/

Greenemeier, L. 2012. Four-Fingered Robot Can Replace Flashlight Batteries. Scientific American, August 19, 2012. Accessed April 11, 2018:

https://blogs.scientificamerican.com/observations/four-fingeredrobot-can-replace-flashlight-batteries-video/

Khanna, T., Kasturi Rangan, V., \& Manocaran, M. 2005. Narayana Hrudayalaya Heart Hospital: Cardiac Care for the Poor. Harvard Business School Case N9-505-078. Boston, MA: Harvard Business School.

Nordling, L. 2012. Recycled Dishes Form Telescope Network. Nature, 488(7413): 571 .

http://doi.org/10.1038/488571a
Nordling, L. 2013. Can the Southern African Large Telescope Live Up to Its Potential? Nature, 502(7473): 608-610.

http://doi.org/10.1038/502608a

Nagral, S. 2014. The Chhattisgarh Tragedy and Indian Surgeons' Love for Speed. Rediff.com, November 28, 2014. Accessed April 11, 2018: http://www.rediff.com/news/column/the-chhattisgarh-tragedyand-indian-surgeons-love-for-speed/20141128.htm

Norton, R. L. 2006. Machine Design: An Integrated Approach. New Jersey: Pearson Prentice Hall.

Oganisjana, K. 2015. Promotion of University Students' Collaborative Skills in Open Innovation Environment. Journal of Open Innovation: Technology, Market and Complexity, 1(1): 18. https://doi.org/10.1186/s40852-015-0021-9

Rao, B. C. 2013. How Disruptive Is Frugal? Technology in Society, 35(1): 65-73. https://doi.org/10.1016/j.techsoc.2013.03.003

Rao, B. C. 2014. Alleviating Poverty in the Twenty-First Century Through Frugal Innovations. Challenge, 57(3): 40-59. https://doi.org/10.2753/0577-5132570302

Rao, B. C. 2017a. Advances in Science and Technology Through Frugality. IEEE Engineering Management Review, 45(1): 32-38. https://doi.org/10.1109/EMR.2017.2667219

Rao, B. C. 2017b. Revisiting Classical Design in Engineering from a Perspective of Frugality. Heliyon, 3(5): e00299. https://doi.org/10.1016/j.heliyon.2017.e00299

Raturi, P. 2010. Potter Power: Son of the Soil. Entrepreneur, December 2010: 108-109.

Shanley, F. R. 1962. Historical Note on the 1.5 Factor of Safety for Aircraft Structures. Journal of the Aerospace Sciences, 29(2): 243-244. https://doi.org/10.2514/8.9385

Shigley, J. E., \& Mischke, C. R. 1989 Mechanical Engineering Design. New York: McGraw Hill, Inc.

Urugal, A. C. 2015. Mechanical Design of Machine Components. New York: CRC Press.

Citation: Rao, B. C. 2018. Science Is Indispensable to Frugal Innovation. Technology Innovation Management (cc) BY Review, 8(4): 49-56.

http://doi.org/10.22215/timreview/1152

Keywords: factor of safety, factor of frugality, sustainable development, frugal innovation, research 


\section{Author Guidelines}

These guidelines should assist in the process of translating your expertise into a focused article that adds to the knowledge resources available through the Technology Innovation Management Review. Prior to writing an article, we recommend that you contact the Editor to discuss your article topic, the author guidelines, upcoming editorial themes, and the submission process: timreview.ca/contact

\section{Topic}

Start by asking yourself:

- Does my research or experience provide any new insights or perspectives?

- Do I often find myself having to explain this topic when I meet people as they are unaware of its relevance?

- Do I believe that I could have saved myself time, money, and frustration if someone had explained to me the issues surrounding this topic?

- Am I constantly correcting misconceptions regarding this topic?

- Am I considered to be an expert in this field? For example, do I present my research or experience at conferences?

If your answer is "yes" to any of these questions, your topic is likely of interest to readers of the TIM Review.

When writing your article, keep the following points in mind:

- Emphasize the practical application of your insights or research.

- Thoroughly examine the topic; don't leave the reader wishing for more.

- Know your central theme and stick to it.

- Demonstrate your depth of understanding for the topic, and that you have considered its benefits, possible outcomes, and applicability.

- Write in a formal, analytical style. Third-person voice is recommended; first-person voice may also be acceptable depending on the perspective of your article.

\section{Format}

1. Use an article template: .doc .odt

2. Indicate if your submission has been previously published elsewhere. This is to ensure that we don't infringe upon another publisher's copyright policy.

3. Do not send articles shorter than 2000 words or longer than 5000 words.

4. Begin with a thought-provoking quotation that matches the spirit of the article. Research the source of your quotation in order to provide proper attribution.

5. Include a 2-3 paragraph abstract that provides the key messages you will be presenting in the article.

6. Provide a 2-3 paragraph conclusion that summarizes the article's main points and leaves the reader with the most important messages.

7. Include a 75-150 word biography.

8. List the references at the end of the article.

9. If there are any texts that would be of particular interest to readers, include their full title and URL in a "Recommended Reading" section.

10. Include 5 keywords for the article's metadata to assist search engines in finding your article.

11. Include any figures at the appropriate locations in the article, but also send separate graphic files at maximum resolution available for each figure. 


\section{Issue Sponsor}

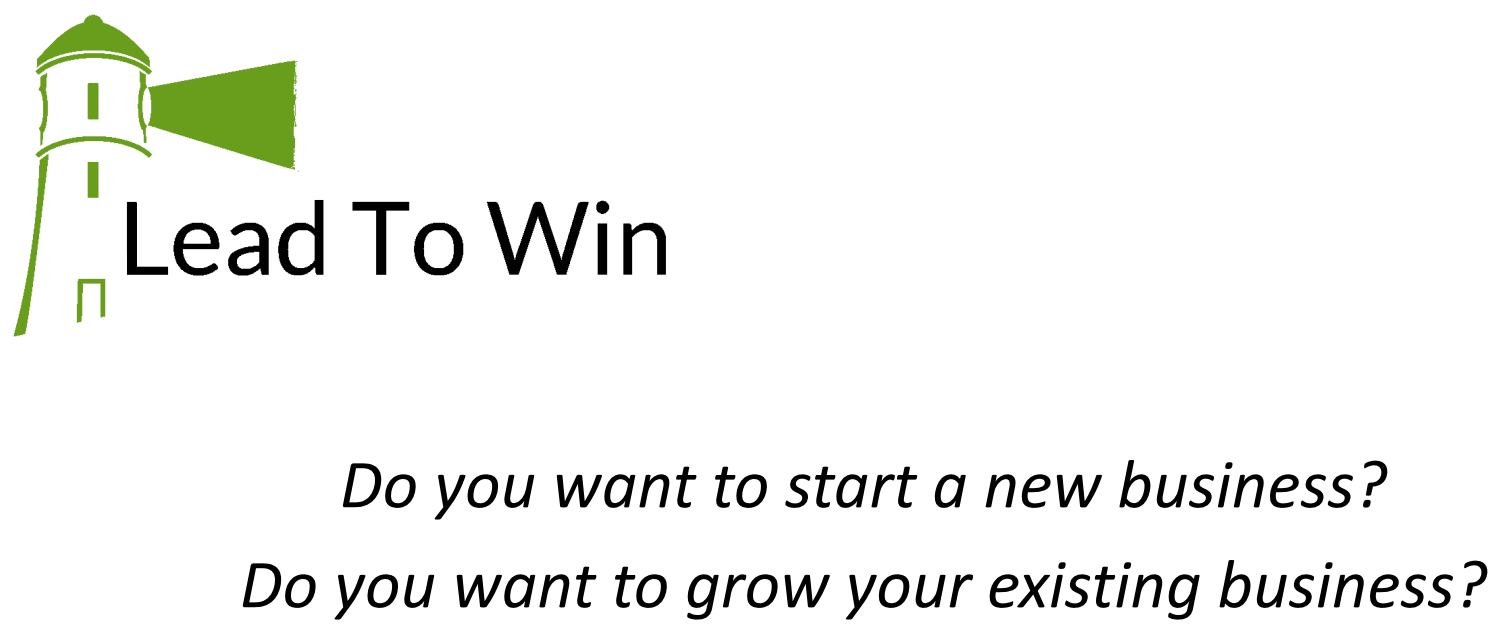

Lead To Win is a free business-development program to help establish and grow businesses in Canada's Capital Region.

Benefits to company founders:

- Knowledge to establish and grow a successful businesses

- Confidence, encouragement, and motivation to succeed

- Stronger business opportunity quickly

- Foundation to sell to first customers, raise funds, and attract talent

- Access to large and diverse business network

\section{Apply Now}

* Twitter

f Facebook

in Linkedin

E Eventbrite

9 Slideshare

- YouTube

-๑ Flickr 


\section{Academic Affiliations and Funding Acknowledgements}

Canadà
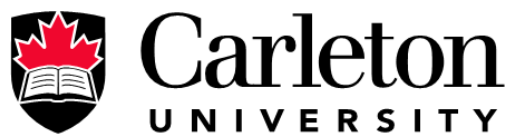

U N I V E R S I T Y

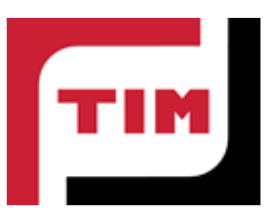

The Federal Economic Development Agency for Southern Ontario (FedDev Ontario; feddevontario.gc.ca) is part of the Innovation, Science and Economic Development portfolio and one of six regional development agencies, each of which helps to address key economic challenges by providing regionallytailored programs, services, knowledge and expertise.

- The TIM Review receives partial funding from FedDev Ontario's Investing in Regional Diversification initiative.

Technology Innovation Management (TIM; timprogram.ca) is an international master's level program at Carleton University in Ottawa, Canada. It leads to a Master of Applied Science (M.A.Sc.) degree, a Master of Engineering (M.Eng.) degree, or a Master of Entrepreneurship (M.Ent.) degree. The objective of this program is to train aspiring entrepreneurs on creating wealth at the early stages of company or opportunity lifecycles.

- The TIM Review is published in association with and receives partial funding from the TIM program. 